
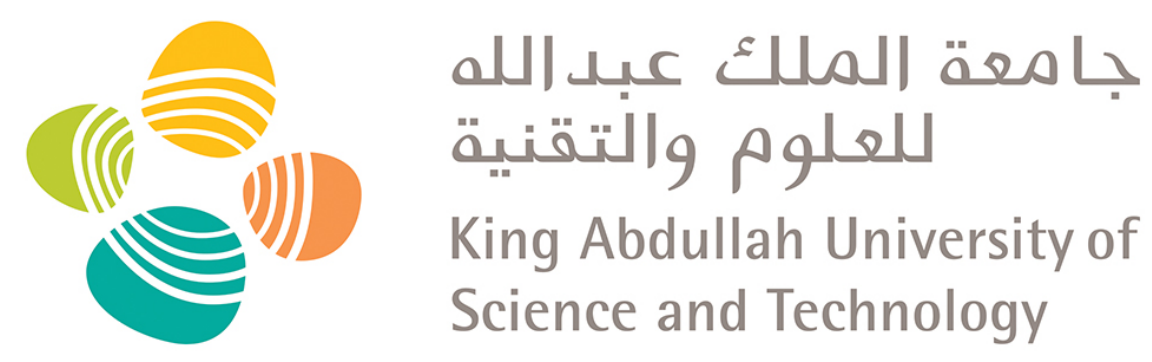

King Abdullah University of

Science and Technology

\title{
Laminar flame speed, Markstein length, and cellular instability for spherically propagating methane/ethylene-air premixed flames
}

\begin{tabular}{|c|c|}
\hline Item Type & Article \\
\hline Authors & $\begin{array}{l}\text { Kim, Hee J.; Van, Kyuho; Lee, Dae K.; Yoo, Chun S.; Park, Jeong; } \\
\text { Chung, Suk Ho }\end{array}$ \\
\hline Citation & $\begin{array}{l}\text { Kim, H. J., Van, K., Lee, D. K., Yoo, C. S., Park, J., \& Chung, S. } \\
\text { H. (2020). Laminar flame speed, Markstein length, and cellular } \\
\text { instability for spherically propagating methane/ethylene- } \\
\text { air premixed flames. Combustion and Flame, } 214,464-474 . \\
\text { doi:10.1016/j.combustflame.2020.01.011 }\end{array}$ \\
\hline Eprint version & Post-print \\
\hline DOI & 10.1016/j.combustflame.2020.01.011 \\
\hline Publisher & Elsevier BV \\
\hline Journal & Combustion and Flame \\
\hline Rights & $\begin{array}{l}\text { NOTICE: this is the author's version of a work that was accepted } \\
\text { for publication in Combustion and Flame. Changes resulting } \\
\text { from the publishing process, such as peer review, editing, } \\
\text { corrections, structural formatting, and other quality control } \\
\text { mechanisms may not be reflected in this document. Changes } \\
\text { may have been made to this work since it was submitted for } \\
\text { publication. A definitive version was subsequently published in } \\
\text { Combustion and Flame, [[Volume], [lssue], (2020-02-04)] DOI: } \\
10.1016 / j \text {.combustflame.2020.01.011 . @ 2020. This manuscript } \\
\text { version is made available under the CC-BY-NC-ND } 4.0 \text { license } \\
\text { http://creativecommons.org/licenses/by-nc-nd/4.0/ }\end{array}$ \\
\hline
\end{tabular}




\begin{tabular}{|l|l|}
\hline Download date & 23/04/2020 07:22:06 \\
\hline Link to Item & http://hdl.handle.net/10754/661491 \\
\hline
\end{tabular}




\section{Laminar flame speed, Markstein length, and cellular instability for spherically propagating methane/ethylene-air premixed flames}

\footnotetext{
Hee June Kim ${ }^{1}$, Kyuho Van ${ }^{1}$, Dae Keun Lee ${ }^{2}$, Chun Sang Yoo ${ }^{3 *}$, Jeong Park ${ }^{1 *}$, Suk Ho Chung ${ }^{4}$

${ }^{1}$ Dept. of Mechanical Engineering, Pukyong National University, Busan, Korea

${ }^{2}$ Advanced Combustion Lab, Korea Institute of Energy Research, Daejeon, Korea

${ }^{3}$ Dept. of Mechanical Engineering, Ulsan National Institute of Science and Technology (UNIST), Ulsan, Korea

${ }^{4}$ Clean Combustion Research Center (CCRC), King Abdullah University of Science and Technology (KAUST), Thuwal, Saudi Arabia
}

\section{* Corresponding authors}

E-mail: jeongpark@pknu.ac.kr, csyoo@unist.ac.kr 


\title{
Laminar flame speed, Markstein length, and cellular instability for spherically propagating methane/ethylene-air premixed flames
}

\author{
Hee June Kim ${ }^{1}$, Kyuho Van $^{1}$, Dae Keun Lee ${ }^{2}$, Chun Sang Yoo ${ }^{3 *}$, Jeong Park ${ }^{1 *}$, Suk Ho Chung ${ }^{3}$ \\ ${ }^{1}$ Dept. of Mechanical Engineering, Pukyong National University, Busan, Korea \\ ${ }^{2}$ Advanced Combustion Lab, Korea Institute of Energy Research, Daejeon, Korea \\ ${ }^{3}$ Dept. of Mechanical Engineering, Ulsan National Institute of Science and Technology (UNIST), \\ Ulsan, Korea \\ ${ }^{4}$ Clean Combustion Research Center (CCRC), King Abdullah University of Science and Technology \\ (KAUST), Thuwal, Saudi Arabia
}

\begin{abstract}
An experimental study on laminar flame speed, Markstein length, and the onset of cellular instability was conducted by varying the equivalence ratio and ethylene/methane mixing ratio in spherically propagating premixed flames at ambient temperature and elevated pressures up to $0.8 \mathrm{MPa}$. Unstretched laminar burning velocities were first validated for methane-air flames by optimizing the range of the flame radius in testing linear and non-linear extrapolation models, and subsequently comparing the results with those simulated using four kinetic mechanisms. Based on the results, unstretched laminar burning velocities were determined for premixed flames of methane/ethylene mixture fuels. The predictability of theoretical Markstein lengths was appreciated by adopting a composite solution of the heat-release-weighted Lewis number and the temperature-dependent Zel'dovich number. Measured Markstein lengths were compared with those predicted based on a composite model for laminar flame speeds against flame radius. Depending on the fuels (methane or methane/ethylene mixture), pressure, and equivalence ratio, the predictability of the model varied. For methane-air flames, cellular instabilities were not observed within the observation window at pressures up to $0.6 \mathrm{MPa}$. Cell formation, caused by hydrodynamic instability, was enhanced by an increase in the ethylene ratio and chamber pressure. Theoretical critical flame radii for the onset of
\end{abstract}


cellular instability predicted by the composite model were consistent with the measured ones for both lean and rich mixtures.

Keywords: Cellular instability, critical flame radius, laminar flame speed, Markstein length, methane/ethylene 


\section{Introduction}

Natural gas, with methane as a major constituent, supplies $22 \%$ of the energy used worldwide, and contributes nearly a quarter of the electricity generated [1]. The growth in the natural gas supply is linked, in part, to its environmental benefits relative to other hydrocarbon fuels, particularly for air quality as well as climate change. Various industrial burners and gas turbine combustors have been designed and developed to meet many requirements, including high efficiency over a wide range of operating conditions and low NOx and smoke emissions. Particularly, stringent regulations limit NOx emission for stationary sources (e.g., industrial burners, power plants, and boilers) and mobile sources (e.g., engines and gas turbines). Applying lean-burn technology with natural gas to such combustion systems may fulfill low NOx and $\mathrm{CO}_{2}$ emission requirements. However, lean-burn natural gas systems have been limited by flame stability [2-4]. Several proposals have been put forward to address the stability issue, such as blending hydrogen (or $\mathrm{H}_{2} / \mathrm{CO}$ syngas) with methane, resulting in an extension of lean flammable limit, and thereby a reduction of NO emission [5-7].

Ethylene, as one of the major components in practical fuels [8-10], has much better improved burning velocity and ignition temperature characteristics than methane [8-10]. In this regard, ethylene flames have been studied to understand the fundamental combustion characteristics, e.g., ignition temperature and laminar burning velocity [8] and chemical structures [9]. Although ethylene could play a role similar to hydrogen when mixed with methane, in terms of laminar burning velocity and ignition temperature, research on this has been rather limited; some studies have explored laminar burning velocities of the mixture fuels of methane and ethylene [8] and the effects of additional diluents $\left(\mathrm{CO}_{2}\right.$ and $\mathrm{He}$ ) and chamber pressure (up to $0.3 \mathrm{MPa}$ ) on unstretched laminar burning velocity and Markstein length in outwardly propagating spherical flames with the blended fuel of $50 \% \mathrm{CH}_{4}$ and $50 \% \mathrm{C}_{2} \mathrm{H}_{4}$ in volume [11].

The present study focused on three important characteristics of premixed flame: laminar burning velocity, Markstein length, and cellular instability, by varying mixture composition, equivalence ratio, and ambient pressure (up to $0.8 \mathrm{MPa}$ ) in outwardly propagating spherical premixed flames for blended fuels of $\mathrm{CH}_{4}$ and $\mathrm{C}_{2} \mathrm{H}_{4}$ with an ethylene mixing ratio (in volume) ranging from 0 to 0.3 . An 
experimental determination of unstretched laminar burning velocity $S_{\mathrm{u}}^{\mathrm{o}}$ depends strongly on the choice of extrapolation method from the measured stretched flame speed [12-23]. The present study first examined extrapolation methods for methane-air premixed flames by comparing measured data with existing data [12-23] and conducting numerical simulations with four kinetic mechanisms of GRI v3.0 [24], USC Mech II [25], Sung Mech [26], and Aramco 2.0 [27]. An optimized method was applied to the present methane/ethylene mixture flames.

Laminar burning velocity is a key parameter in understanding flame characteristics in practical spark-ignition engines and gas turbine combustors. Because practical flames are either curved and/or propagate through a strained flow field, the Markstein length [28-36], which quantifies the response of flame speed to stretch rate, also plays an important role in characterizing flame behavior. Even in the absence of initial turbulence, spherical flames could form a cellular structure due to diffusivethermal and hydrodynamic instabilities [37-46], resulting in flame acceleration with an increase in flame surface area. In this regard, Markstein length and cellular instability have been studied extensively. These have been investigated for several blended fuels such as methane-hydrogen, and syngas and bio-syngas mixtures as well as diluted fuels [11, 47-50]. However, those for the blended fuels of methane and ethylene have not been investigated in detail, and are therefore the focus of the present study. Here, theoretical and measured Markstein lengths are compared and discussed, and cellular instabilities are evaluated by comparing theoretical and measured critical flame radii for cell formation.

\section{Experiment}

Details of a similar experimental setup and method are described in our previous work. Here, as schematically shown in Fig. 1 [11], a larger stainless steel cylindrical constant-volume combustion chamber (CVCC) was used (inner diameter: $300 \mathrm{~mm}$; length: $390 \mathrm{~mm}$ ). Two quartz windows (diameter: $150 \mathrm{~mm}$ ) were installed for visualization. Methane (purity 99.99\%) and ethylene (99.99\%) were used for the fuel, and zero air (99.95\%) was used as the oxidizer. Fuel and air were metered from partial pressures using a pressure gauge (LabDMM AEP, -1 to 40 bar, $\pm 0.5 \%$ FSO). Outwardly propagating 
spherical flames were visualized using a Schlieren setup with a 300-W xenon light source and a pair of concave mirrors (diameter: $150 \mathrm{~mm}$ ), taken by a high-speed camera (Phantom v-7.2) at 10,000 frames per second (fps). The position of the flame front was determined by converting to a monochromatic image to accommodate the IMADJUST function in Matlab software for image enhancement [11]. The image was subsequently binarized (with a center intensity of 127 as a threshold from the monochromatic intensity range of $0-255)$, from which the flame front position was identified. This arbitrary choice of the threshold value did not affect the determination of the laminar burning velocity. The initial pressure range covered up to $P_{0}=0.8 \mathrm{MPa}$.

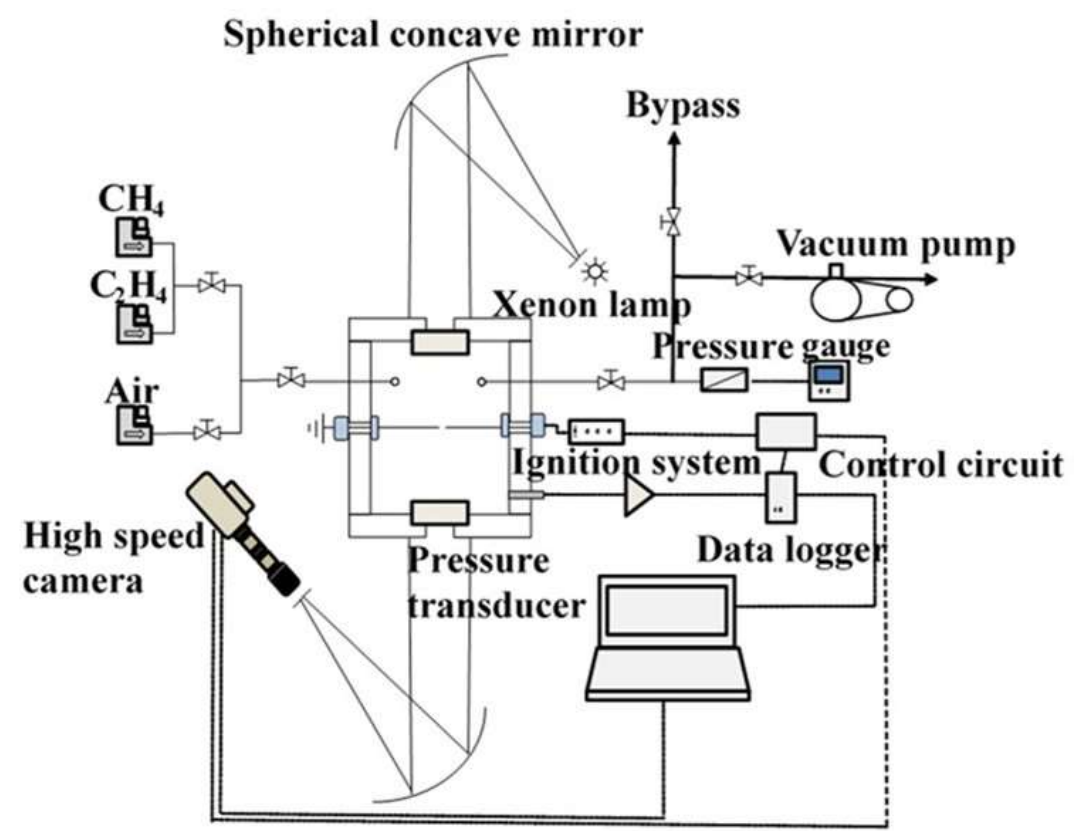

Fig. 1. Schematic diagram of the experimental setup.

\section{Results and discussion}

\subsection{Determination of unstretched laminar burning velocity}

The time history of the flame front radius, $R_{\mathrm{f}}(t)$, for an outwardly propagating spherical flame can be obtained using the Schlieren method. With the assumption of a static burnt gas inside the spherical flame, the stretched burnt flame speed, $S_{\mathrm{b}}$, becomes $S_{\mathrm{b}}=d R_{\mathrm{f}} / d t$. When the spherical flame is assumed to be infinitesimally thin, weakly stretched, quasi-steady, and zero-gravity in an unconfined environment, the unstretched laminar burning velocity, $S_{\mathrm{b}}^{\mathrm{o}}$, with respect to the burnt mixture can be obtained via the following linear extrapolation model (LM) [11-23]: 


$$
S_{\mathrm{b}}=S_{\mathrm{b}}^{\mathrm{o}}-L_{\mathrm{b}} K
$$

where $L_{\mathrm{b}}$ denotes the Markstein length with respect to the burnt gas, which can be determined experimentally from the slope of $S_{\mathrm{b}}$ with flame stretch, $K=2 S_{\mathrm{b}} / R_{\mathrm{f}}$, and $S_{\mathrm{b}}^{\mathrm{o}}$ through the extrapolation to $K=0$. Then, the unstretched laminar burning velocity, $S_{\mathrm{u}}^{\mathrm{o}}$, with respect to the unburned mixture can be determined from the mass conservation of $S_{\mathrm{u}}^{\mathrm{o}}=\left(\rho_{\mathrm{b}} / \rho_{\mathrm{u}}\right) S_{\mathrm{b}}^{\mathrm{o}}$, where $\rho_{\mathrm{b}}$ and $\rho_{\mathrm{u}}$ are the densities of the burnt and unburned mixtures, respectively.

Because errors with the LM could arise, especially when the equivalence ratio deviates appreciably from unity [12], the following two nonlinear models (NM I and NM II) are proposed:

$$
\begin{gathered}
S_{\mathrm{b}}=S_{\mathrm{b}}^{\mathrm{o}}-\frac{2 S_{\mathrm{b}}^{\mathrm{o}} L_{\mathrm{b}}}{R_{\mathrm{f}}} \quad \text { or } \quad S_{\mathrm{b}}=S_{\mathrm{b}}^{\mathrm{o}}-L_{\mathrm{b}} K\left(\frac{S_{\mathrm{b}}^{\mathrm{o}}}{S_{\mathrm{b}}}\right) \quad(\mathrm{NM} \mathrm{I}), \\
\ln S_{\mathrm{b}}=\ln S_{\mathrm{b}}^{\mathrm{o}}-S_{\mathrm{b}}^{\mathrm{o}} L_{\mathrm{b}} \times \frac{2}{R_{\mathrm{f}} S_{\mathrm{b}}} \quad(\mathrm{NM} \mathrm{II}) .
\end{gathered}
$$

NM I was proposed by Markstein [31] and analyzed by Frankel and Sivashinsky [32] in propagating spherical flames, where $S_{\mathrm{b}}$ varies nonlinearly with $K$. Note that $S_{\mathrm{b}}$ is linear with the flame curvature $2 / R_{\mathrm{f}}$, through which $L_{\mathrm{b}}$ and $S_{\mathrm{b}}^{\mathrm{o}}$ can be determined from a linear extrapolation. NM II has been derived for quasi-steady and adiabatic flame conditions using an asymptotic method [33,34], and its validity in predicting $S_{\mathrm{b}}^{\mathrm{o}}$ has been tested previously [35]. Here, $\ln S_{\mathrm{b}}$ varies linearly with $2 / R_{\mathrm{f}} S_{\mathrm{b}}$; thus, $L_{\mathrm{b}}$ and $S_{\mathrm{b}}^{\mathrm{o}}$ can be determined by a linear extrapolation from the plot of $\ln S_{\mathrm{b}}$ against $2 / R_{\mathrm{f}} S_{\mathrm{b}}$. Note that the LM and NM I can be derived readily from NM II in the limit of a large flame radius, with accuracies of the order of $O\left(1 / R_{\mathrm{f}}^{2}\right)$ representing the error [51,52].

Choice of an appropriate extrapolation model depends on the size of the combustion chamber and the range of flame radius to be used in the extrapolation. When the smaller CCVC (as compared with the present one) was used previously [11], NM II provided the best performance in determining laminar burning velocities from simulated results using GRI v-3.0 for methane-air premixed flame under normal temperature and pressure (NTP) conditions. For further confirmation with the present 
chamber size, we extensively re-evaluated the results for methane-air premixed flames at NTP by comparing measured data with existing data [12-23], along with simulation data with four kinetic mechanisms of GRI v-3.0 [24], USC Mech II [25], Sung Mech [26], and Aramco 2.0 [27]. By excluding the effects of spark-ignition transient, chamber confinement, and cellular instability, the flame radius monitored was taken over the range of $13.0 \leq R_{\mathrm{f}} \leq 31.0 \mathrm{~mm}$ (see the detailed discussion concerning Figs. S1-S5 and Table S1 in the Supplementary Material (SM)). At various equivalence ratios $\phi$ for $P_{0}=0.1$ and $0.6 \mathrm{MPa}$, the results revealed that NM II was appropriate in the present study and that Aramco Mech 2.0 best fit the measured laminar burning velocities.

For further confirmation, measured laminar burning velocities with equivalence ratio for $\mathrm{CH}_{4}-\mathrm{air}$ premixed flames were compared with numerical simulations with Aramco Mech 2.0 (Fig. S6) at several ambient pressures. The measured data were in good agreement with numerical simulations. Given the validity of the present methodology for methane fuels, fuel mixtures of methane and ethylene were investigated as described in the following.

\subsection{Laminar flame speeds for $\mathrm{CH}_{4} / \mathrm{C}_{2} \mathrm{H}_{4}$-air premixed flames}

Instantaneous Schlieren images of $\mathrm{CH}_{4}$-air (first and second columns for $\Omega_{\mathrm{C}_{2} \mathrm{H}_{4}}=0$ ) and $\mathrm{CH}_{4} / \mathrm{C}_{2} \mathrm{H}_{4}$-air (third and fourth columns for $\Omega_{\mathrm{C}_{2} \mathrm{H}_{4}}=0.3$ ) premixed flames are compared in Fig. 2 at $\phi=0.7$ and 1.2 for several initial chamber pressures. Here, the ethylene mixing ratio $\left(\Omega_{\mathrm{C}_{2} \mathrm{H}_{4}}\right)$ is defined as $\Omega_{\mathrm{C}_{2} \mathrm{H}_{4}}=X_{\mathrm{C}_{2} \mathrm{H}_{4}} /\left(X_{\mathrm{CH}_{4}}+X_{\mathrm{C}_{2} \mathrm{H}_{4}}\right)$ where $X_{i}$ is the mole fraction of species $i$. The images were obtained when the radius of the uppermost flame edge was about $45 \mathrm{~mm}$ from the ignition point. The $\mathrm{CH}_{4}$-air cases generally had smooth flame surfaces, except for some large-scale cracks (typically observed in spherically propagating flames [41, 43-46]) up to $P_{0}=0.6 \mathrm{MPa}$ for both $\phi=0.7$ and 1.2. For the $\mathrm{CH}_{4} / \mathrm{C}_{2} \mathrm{H}_{4}$-air flames, the surfaces were smooth overall, with the exception of $P_{0}=0.6 \mathrm{MPa}$ and $\phi=1.2$, in which fine cellular structures were observed. These finding will be discussed in the sections that follow. 


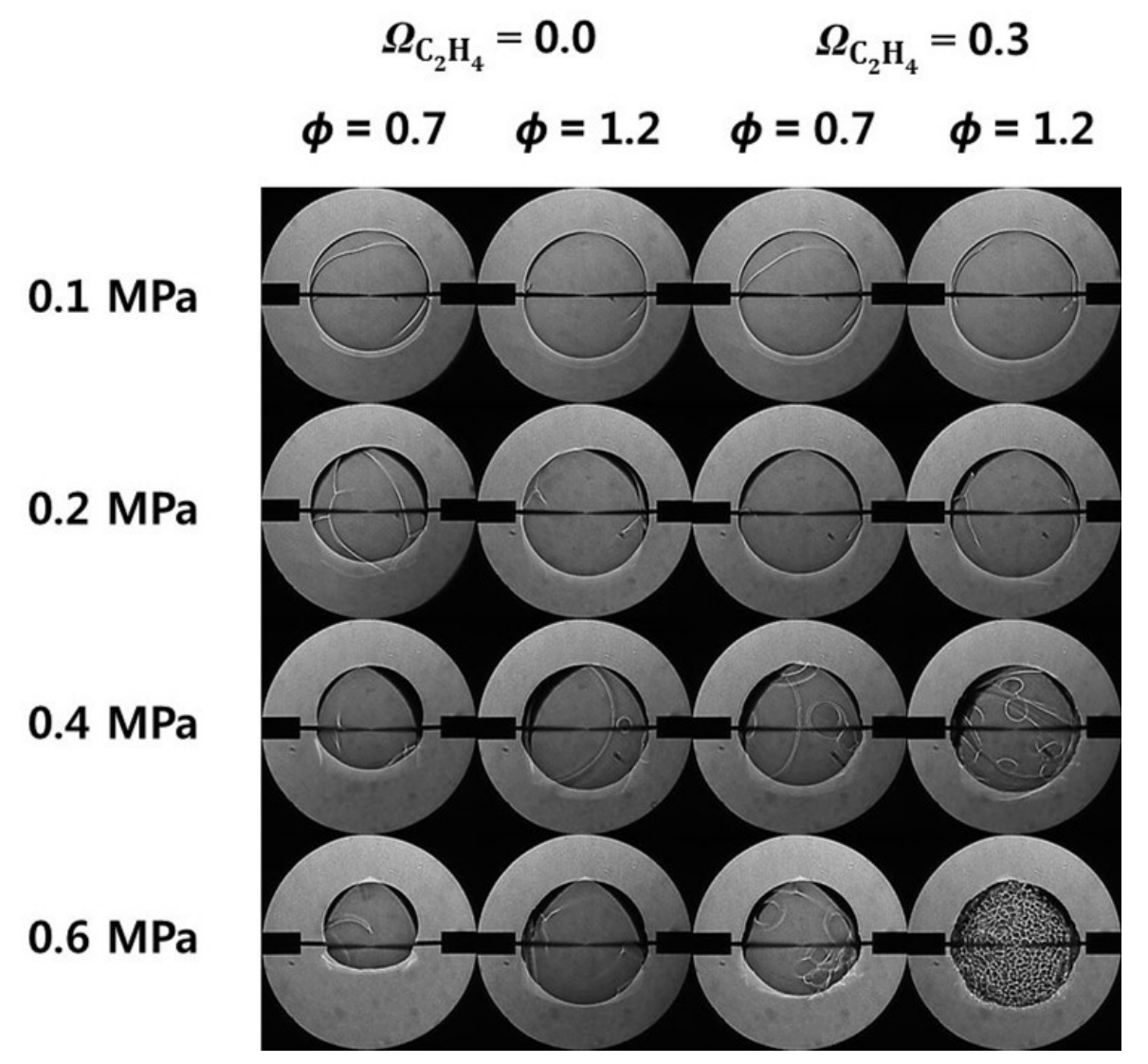

Fig. 2. Instantaneous Schlieren images of $\mathrm{CH}_{4}$-air $\left(\Omega_{\mathrm{C}_{2} \mathrm{H}_{4}}=0\right)$ and $\mathrm{CH}_{4} / \mathrm{C}_{2} \mathrm{H}_{4}-$ air $\left(\Omega_{\mathrm{C}_{2} \mathrm{H}_{4}}=0.3\right)$ premixed flames with $\phi=0.7$ and 1.2 at various initial chamber pressures.

Buoyancy effects in measuring unstretched laminar burning velocities are considered to be weak in cases with $S_{\mathrm{u}}^{\mathrm{o}}>15 \mathrm{~cm} / \mathrm{s}$ [16-27], compared with other error sources [12]. However, as the pressure becomes large, such a flame can be influenced appreciably by buoyancy, because $S_{\mathrm{u}}^{\mathrm{o}}$ decreases with pressure. This is exemplified by the cases of $\phi=0.7$ at $P_{0}=0.4$ and $0.6 \mathrm{MPa}$ for $\Omega_{\mathrm{C}_{2} \mathrm{H}_{4}}=0$ in Fig. 2. Although sphericity is reasonably maintained, the center of the flame moves upward appreciably.

Figure 3a presents typical time histories of flame radii in the horizontal $\left(R_{\mathrm{f}, \mathrm{H}}\right)$ and vertical $\left(R_{\mathrm{f}, \mathrm{V}}\right)$ directions for $\phi=0.7$ and $P_{0}=0.4 \mathrm{MPa}$ when $\Omega_{\mathrm{C}_{2} \mathrm{H}_{4}}=0$; compared with the horizontal radius, the vertical flame radius accelerates over time, as marked with solid lines for $R_{\mathrm{f}}=1.3-3.1 \mathrm{~cm}$. Assuming that buoyancy-induced flow acts mainly in the vertical direction, the horizontal displacement velocity can be approximated as the burnt flame speed. In such a case, the magnitude of buoyancy-induced vertical velocity can be approximated as the difference between the vertical and horizontal burnt displacement speeds $\left(S_{\mathrm{d}, \mathrm{V}}-S_{\mathrm{d}, \mathrm{H}}\right)$. 

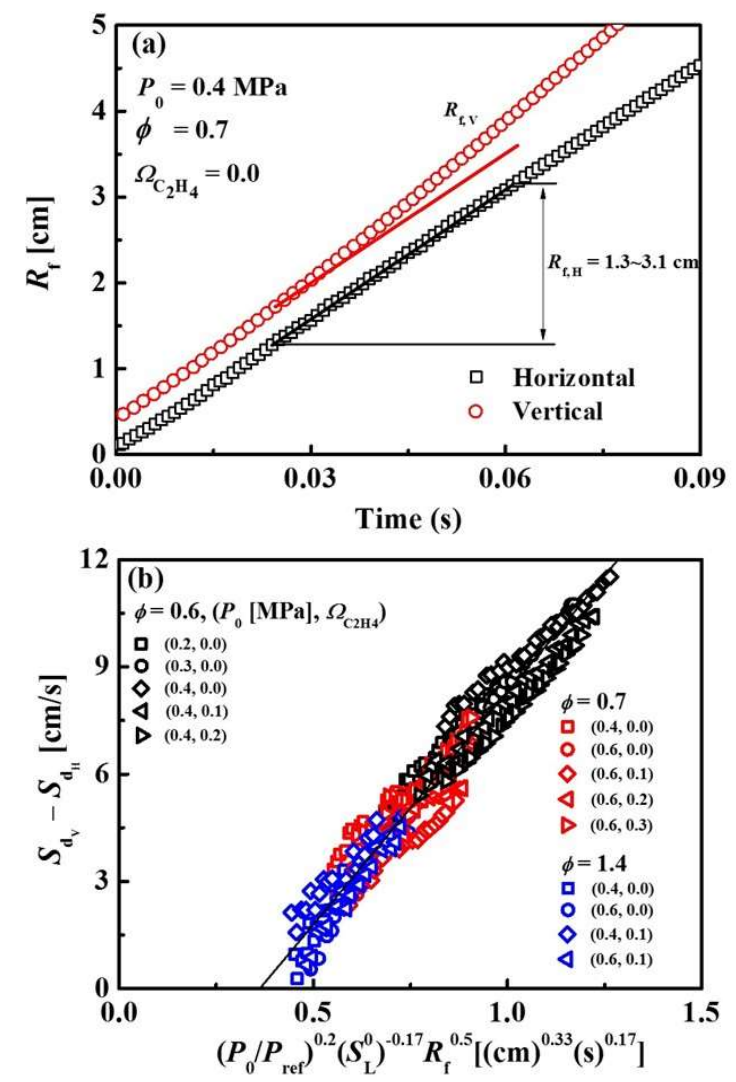

Fig. 3. Influence of buoyancy on flame speed with respect to burnt gas: (a) typical time histories of horizontal and vertical flame radii at $\phi=0.7$ and $P_{0}=0.4 \mathrm{MPa}$ for $\Omega_{\mathrm{C}_{2} \mathrm{H}_{4}}=0$ and (b) parameter dependence of the buoyancy-induced velocity component.

For future data reduction on laminar burning velocity from outwardly propagating spherical flames, we correlated the buoyancy-induced vertical velocity based on our experimental data for $\phi=0.6,0.7$, and 1.4 at various initial pressures and ethylene mixing ratios. The horizontal burnt flame speed was obtained from the rate of change of the flame front with time over the range of $13.0 \leq R_{\mathrm{f}, \mathrm{H}} \leq 31.0$ mm, excluding the effects of spark-ignition, and thereby ignition transient and chamber confinement effects. The vertical burnt flame speed was also obtained using a similar approach. Buoyancy effects can also be enhanced for a small laminar burning velocity (longer residence time for the buoyancy effect to develop), a large initial chamber pressure, and a large flame radius. The buoyancy-induced velocity component $\left(S_{\mathrm{d}, \mathrm{V}}-S_{\mathrm{d}, \mathrm{H}}\right)$, is correlated with the parameters of $P_{0}, S_{\mathrm{L}}^{0}$, and $R_{\mathrm{f}}$. The best fit corresponded to $\left(S_{\mathrm{d}, \mathrm{V}}-S_{\mathrm{d}, \mathrm{H}}\right)[\mathrm{cm} / \mathrm{s}]=13.0 \times\left(P_{0} / P_{\mathrm{ref}}\right)^{0.17}\left(S_{\mathrm{L}}^{0}\right)^{-0.17} R_{\mathrm{f}}^{0.5}-4.7$ with a correlation coefficient of $\mathrm{R}=0.98$, where $P_{\text {ref }}$ is the atmospheric pressure $(0.1 \mathrm{MPa})$ and $S_{\mathrm{L}}^{0}$ and $R_{\mathrm{f}}$ are given units of $[\mathrm{cm} / \mathrm{s}]$ and $[\mathrm{cm}]$, respectively. The results presented in Fig. 3b show a satisfactory correlation. More 
precise buoyancy-induced velocity may be obtained through the local flow velocity at the center, and this will be a future work.

For further confirmation of the three extrapolation models in $\mathrm{CH}_{4} / \mathrm{C}_{2} \mathrm{H}_{4}$-air premixed flames, the burnt flame speed versus flame stretch was again tested at various equivalence ratios for $\Omega_{\mathrm{C}_{2} \mathrm{H}_{4}}=0.3$ (see Fig. S7 at $P_{0}=0.1 \mathrm{MPa}$ and Fig. S8 at $P_{0}=0.6 \mathrm{MPa}$ in the $\mathrm{SM}$ ). NM II best traced to measured burnt flame speeds, as shown in Figs. S7 and S8. The results of uncertainty were also summarized in Table S2 for $\mathrm{CH}_{4} / \mathrm{C}_{2} \mathrm{H}_{4}$-air premixed flames $\left(\Omega_{\mathrm{C}_{2} \mathrm{H}_{4}}=0.3\right)$ with $P_{0}=0.1,0.4$, and $0.6 \mathrm{MPa}$, when the four kinetic mechanisms [24-27] were adopted again. The results showed that using Aramco 2.0 resulted in the smallest errors among them. Again, NM II and Aramco 2.0 were adopted again in $\mathrm{CH}_{4} / \mathrm{C}_{2} \mathrm{H}_{4}$-air premixed flames.

Figure 4 presents laminar burning velocities as a function of equivalence ratio for the $\mathrm{CH}_{4} / \mathrm{C}_{2} \mathrm{H}_{4}-$ air premixed flames at several initial pressures and ethylene mixing ratios, along with simulation data using PREMIX code [51] by adopting Aramco Mech 2.0. The error bars denote the maximum and minimum values taken from six experiments for each condition. Note that the monitored range of flame radius was $13.0 \leq R_{\mathrm{f}} \leq 31.0 \mathrm{~mm}$ in the present experiment. As shall be shown later, even at $\phi=1.2$ for $P_{0}=0.6 \mathrm{MPa}$ (Fig. 2), the experimental critical radius for the onset of cellular instability is larger than $31 \mathrm{~mm}$ (maximum flame radius monitored). Thus, unstretched laminar burning velocity could be measured. The laminar burning velocity increased (decreased) with the increase of $\Omega_{\mathrm{C}_{2} \mathrm{H}_{4}}\left(P_{0}\right)$. The results also revealed that the numerical simulation results at various initial pressures and ethylene mixing ratios for $\mathrm{CH}_{4} / \mathrm{C}_{2} \mathrm{H}_{4}$-air premixed flames were in good agreement with the present experimental ones, despite the appreciable deviation in the equivalence ratio from unity when determining $S_{\mathrm{u}}^{\mathrm{o}}$ from the horizontal radius. In the following, Aramco Mech 2.0 will be used in evaluating the theoretical Markstein length and critical flame radius for cellular instability. 


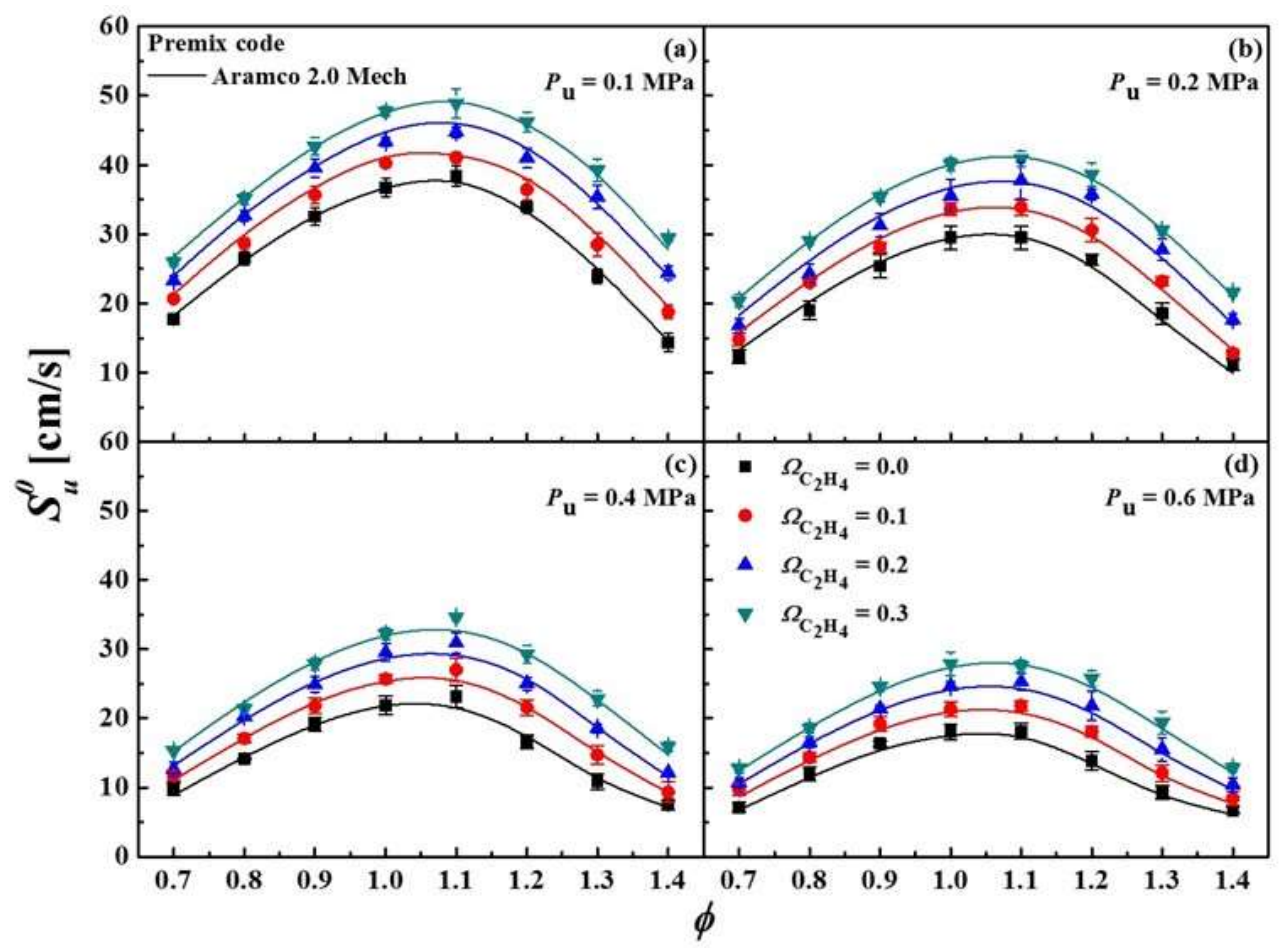

Fig. 4. Experimental and predicted unstretched laminar burning velocities against equivalence ratio in $\mathrm{CH}_{4} / \mathrm{C}_{2} \mathrm{H}_{4}$-air premixed flames at various $\Omega_{\mathrm{C}_{2} \mathrm{H}_{4}}$ for $P_{0}=0.1$ (a), 0.2 (b), 0.4 (c), and 0.6 (d) MPa. Solid lines represent simulated data using PREMIX code [49] with Aramco Mech 2.0 [27].

\subsection{Markstein length in $\mathrm{CH}_{4} / \mathrm{C}_{2} \mathrm{H}_{4}$-air premixed flames}

A Markstein length characterizes the effect of flame stretch on laminar flame speed. Two theoretical models $[52,55]$ for evaluating Markstein length with respect to burnt gas were applied to $\mathrm{CO}_{2}$ - and He-diluted $\mathrm{CH}_{4} / \mathrm{C}_{2} \mathrm{H}_{4}$-air premixed flames with $\Omega_{\mathrm{C}_{2} \mathrm{H}_{4}}=0.5$ [11] up to $P_{0}=0.3 \mathrm{MPa}$. The results revealed that the model of Bechtold and Matalon [55] better predicted the measured Markstein length.

However, these models are applicable for infinitely thin, weakly stretched flames. When considering the finite flame thickness, one must account for the variation of the flow field in the preheat zone such that the corresponding Markstein number along the flame thickness could vary by $O(1)$ despite the small flame thickness. For comparison with experimental and/or numerical simulation data, the composite model valid within and outside the flame zone was derived by an asymptotic method [56]. Since the details of the composite solution can be found in [56], a brief explanation is made here.

At any location within a flame zone in outwardly-propagating spherical flame, the theoretical Markstein length [56] can be obtained as: 


$$
L^{*}=\left\{\alpha-\int_{1}^{\theta^{*}} \frac{\lambda(x)}{x} d x-\frac{\sigma-1}{\sigma} \int_{\theta^{*}}^{\sigma} \frac{\lambda(x)}{x-1} d x\right\}
$$

where

$$
\alpha=\frac{\sigma}{\sigma-1} \int_{1}^{\sigma} \frac{\lambda(x)}{x} d x+\frac{\beta\left(\mathrm{Le}_{\mathrm{eff}}-1\right)}{2(\sigma-1)} \int_{1}^{\sigma} \ln \left(\frac{\sigma-1}{x-1}\right) \frac{\lambda(x)}{x} d x
$$

Here $\sigma=\rho_{\mathrm{u}} / \rho_{\mathrm{b}}$ is the thermal expansion ratio, $\beta=E\left(T_{\mathrm{b}}-T_{\mathrm{u}}\right) / R T_{\mathrm{b}}^{2}$ is the Zel'dovich number, $\theta^{*}=$ $T^{*} / T_{\mathrm{u}}$ is the dimensionless temperature at the location of iso-surface taken as the flame front, $\mathrm{Le}_{\mathrm{eff}}$ is the effective Lewis number of the mixture, and $\lambda$ is the thermal conductivity of the mixture scaled with respect to its value in the unburned gas, respectively.

The errors for unstretched laminar burning velocity and Markstein length were previously shown to be within $10 \%$ and $200 \%$, respectively [52]. This explains the relatively consistent laminar burning velocities measured by various groups (see Figs. S5 and S7, and [52]), whereas large discrepancies in the Markstein lengths were evident, even at normal pressure (see Fig. S6 and [52]). Evaluating theoretical Markstein lengths via a comparison with measured values has generally been conducted at normal pressure $[13,14,17,18,20,52,55,56]$. Special care must be taken at elevated pressures when using the theoretical model.

The Zel'dovich number $\beta_{\mathrm{T}}$, with a temperature-dependent activation energy $\left(E a_{\mathrm{T}}=\right.$ $-2 R^{\mathrm{o}} \pi\left[\partial \ln \left(\rho_{\mathrm{u}} S_{\mathrm{u}}^{\mathrm{o}}\right) /\left(\partial\left(1 / T_{\mathrm{ad}}\right)\right]\right)[43-46]$ and a heat-release-weighted fuel Lewis number $\left(\mathrm{Le}_{\mathrm{F}, \mathrm{q}}=\right.$ $\left.1+\left(q_{\mathrm{CH}_{4}}\left(\mathrm{Le}_{\mathrm{CH}_{4}}-1\right)+q_{\mathrm{C}_{2} \mathrm{H}_{4}}\left(\mathrm{Le}_{\mathrm{C}_{2} \mathrm{H}_{4}}-1\right)\right) / q\right)[43-46]$, was used for the calculation of the theoretical Markstein length, because predictions using these have proven to be more accurate [11]. Here, $q$ is the total heat release $\left(q=q_{\mathrm{CH}_{4}}+q_{\mathrm{C}_{2} \mathrm{H}_{4}}\right)$, where $q_{i}$ is the non-dimensional heat release associated with the consumption of species $i\left(q_{i}=Q Y_{i} / C_{p} T_{\mathrm{u}}\right), Q$ is the heat of reaction, and $Y_{i}$ is the mass fraction of species $i$. When a single-component fuel is used, the two fuel Lewis numbers become the same. Note that both theoretical models are derived based on a deficient reactant concept. Thus, using such fuel Lewis numbers (as an effective Lewis number) may yield a good prediction of Markstein length under lean mixture conditions. Although the capability of predicting Markstein length can be restricted near stoichiometric or rich conditions, such a problem can be mitigated using 
the effective Lewis number $\operatorname{Le}_{q}=1+\left(\mathrm{Le}_{\mathrm{E}}-1\right)+A_{1}\left(\mathrm{Le}_{\mathrm{D}}-1\right) /\left(1+A_{1}\right)$, through $\mathrm{Le}_{\mathrm{E}, \mathrm{q}}$ [38]. Here, $\mathrm{Le}_{\mathrm{E}}$ and $\mathrm{Le}_{\mathrm{D}}$ are the Lewis numbers of abundant and deficient reactants, respectively. The parameter $A_{1}$ is a measure of mixture strength, defined as $A_{1}=1+\beta(\Phi-1) . \Phi$ is the ratio of the masses of abundant-to-deficient reactants in the fresh mixture relative to their stoichiometric ratio, i.e., $\Phi=1 / \phi$ for $\phi \leq 1$ and $\Phi=\phi$ for $\phi>1$. Heat-release-rate- and volume-weighted effective Lewis numbers $\left(\mathrm{Le}_{\mathrm{q}}, \mathrm{Le}_{\mathrm{V}}\right)$, constant and temperature-dependent Zel'dovich numbers $\left(\beta_{\text {const }}, \beta_{\mathrm{T}}\right)$, thermal expansion ratio $(\sigma)$ used in predicting Markstein lengths in $\mathrm{CH}_{4}$-air and $\mathrm{CH}_{4} / \mathrm{C}_{2} \mathrm{H}_{4}$-air premixed flames at various equivalence ratios are presented in Table S3 in the SM.

The theoretical Markstein lengths were first compared with the measured ones for $\mathrm{CH}_{4}$-air premixed flames at normal and elevated pressures (see Figs. S9-S12 in SM). The results show that the theoretical Markstein lengths are in good agreement with the present measured data when the isotemperature is $600 \mathrm{~K}$, the non-dimensional thermal conductivity is taken as $\lambda(x)=x$, and the flame thickness is defined by $\delta_{\mathrm{f}}^{0}=\left(T_{\mathrm{b}}-T_{\mathrm{u}}\right) /(\partial T / \partial x)_{\max }$. Based on them, measured and predicted Markstein numbers against equivalence ratio were compared in terms of ambient pressure for $\mathrm{CH}_{4}-$ air premixed flames with $\lambda(x)=x$ for $\delta_{\mathrm{f}}^{0}=\left(\lambda / c_{\mathrm{p}}\right) /\left(\rho_{\mathrm{u}} S_{\mathrm{u}}^{\mathrm{o}}\right)$ and $\left(T_{\mathrm{b}}-T_{\mathrm{u}}\right) /(\partial T / \partial x)_{\max }$ (see Fig. S13 in the SM). When $\delta_{\mathrm{f}}^{0}=\left(T_{\mathrm{b}}-T_{\mathrm{u}}\right) /(\partial T / \partial x)_{\max }$ is used, the theoretical Markstein numbers better traces the measured data. The measured Markstein number decreases appreciably (slightly) when the ambient pressure varies from 0.1 to $0.2(0.2$ to 0.6$) \mathrm{MPa}$, while the theoretical Markstein numbers are not influenced by ambient pressure. This implies that the theoretical Markstein number does not reflect the effect of reducing flame thickness. Further discussion on the effect of using the different definitions in flame thickness will be made later. The effect of using different effective Lewis numbers on Markstein length was tested in terms of ambient pressures for $\mathrm{CH}_{4}$-air premixed flame (see Fig. S13 in the SM). The results show that the effects are minor at normal and elevated pressures.

Further investigation on the capability of predicting Markstein length was made in $\mathrm{CH}_{4} / \mathrm{C}_{2} \mathrm{H}_{4}$-air premixed flames, by again varying the iso-temperature of flame front and using the different definition of flame thickness for $\lambda(x)=x$. Although not shown, we tested the effect of non-dimensional thermal 
conductivity defined differently with $\lambda(x)=1, x^{1 / 2}$, and $x$. When $\lambda(x)=x$ is used, the theoretical Markstein lengths better trace the measured ones. Thus, the effect of using the definitions of different flame thickness and elevated ambient pressures on Markstein length is investigated for $\mathrm{CH}_{4} / \mathrm{C}_{2} \mathrm{H}_{4}$-air premixed flames with $\delta_{\mathrm{f}}^{0}=\left(\lambda / c_{\mathrm{p}}\right) /\left(\rho_{\mathrm{u}} S_{\mathrm{u}}^{\mathrm{o}}\right)$ in Fig. 5 and with $\delta_{\mathrm{f}}^{0}=\left(T_{\mathrm{b}}-T_{\mathrm{u}}\right) /(\partial T / \partial x)_{\max }$ in Fig. 6 . The theoretical Markstein lengths with $\delta_{\mathrm{f}}^{0}=\left(T_{\mathrm{b}}-T_{\mathrm{u}}\right) /(\partial T / \partial x)_{\max }$ are in better agreement with the measured data, compared with those with $\delta_{\mathrm{f}}^{0}=\left(\lambda / c_{\mathrm{p}}\right) /\left(\rho_{\mathrm{u}} S_{\mathrm{u}}^{\mathrm{o}}\right)$. As shown in Fig. 6, when the isotemperature is taken to $600 \mathrm{~K}$ for $P_{0}=0.1 \mathrm{MPa}$, the theoretical Markstein lengths slightly underpredict the measured data for $\Omega_{\mathrm{C}_{2} \mathrm{H}_{4}}=0.1$, while for $\Omega_{\mathrm{C}_{2} \mathrm{H}_{4}}=0.3$, the theoretical Markstein lengths slightly over-predict (under-predict) the measured data for lean (rich) mixtures. With the increase of ambient pressure, the choice of iso-temperature surface in theoretical Markstein length becomes less sensitive while both theoretical and measured Markstein lengths decrease.

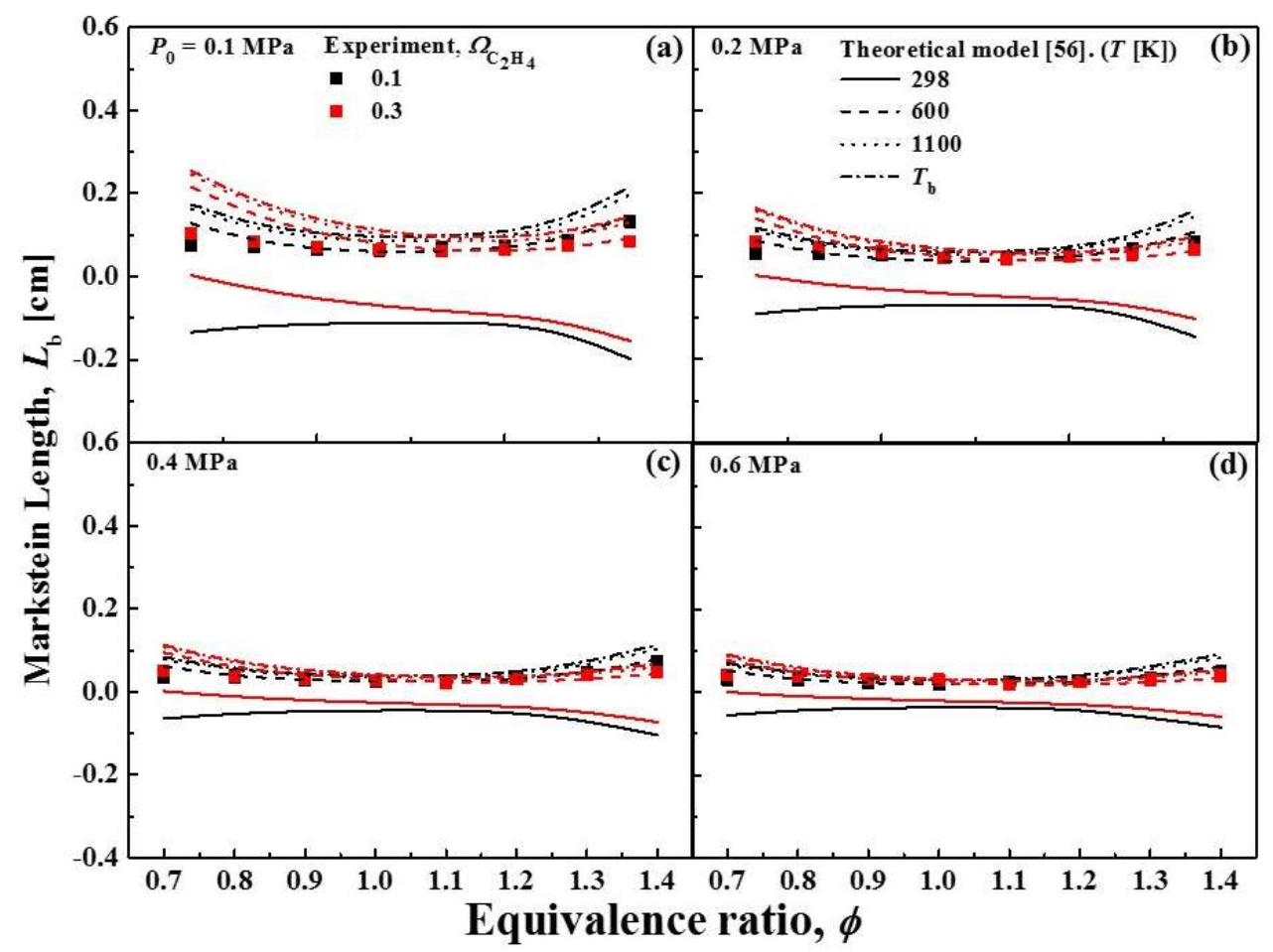

Fig. 5. Measured (symbol) and predicted (lines) Markstein lengths against the equivalence ratio in $\mathrm{CH}_{4} / \mathrm{C}_{2} \mathrm{H}_{4}$-air premixed flames with $\delta_{\mathrm{f}}^{0}=\left(\lambda / c_{\mathrm{p}}\right) /\left(\rho_{\mathrm{u}} S_{\mathrm{u}}^{\mathrm{o}}\right)$ at elevated pressures. For theoretical Markstein lengths, the temperature-dependent Zel'dovich number and the heat-release-weighted Lewis number are used. 


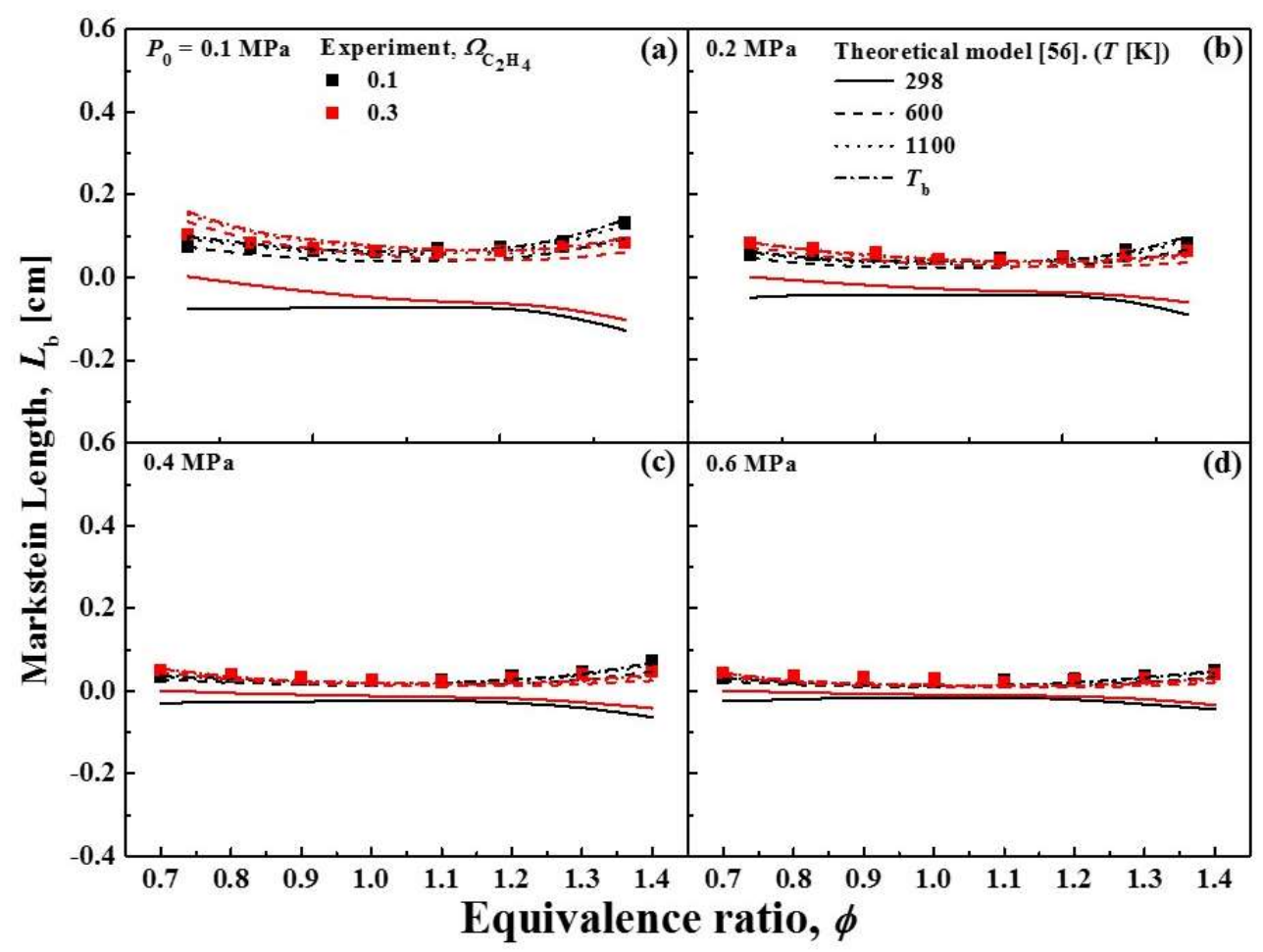

Fig. 6. Measured (symbol) and predicted (lines) Markstein lengths against the equivalence ratio in $\mathrm{CH}_{4} / \mathrm{C}_{2} \mathrm{H}_{4}$-air premixed flames with $\delta_{\mathrm{f}}^{0}=\left(T_{\mathrm{b}}-T_{\mathrm{u}}\right) /(\partial T / \partial x)_{\max }$ at elevated pressures. For theoretical Markstein lengths, the temperature-dependent Zel'dovich number and the heat-releaseweighted Lewis number are used.

Based on them, we reproduced Markstein numbers from Markstein lengths in Fig. 6 and plotted them in Fig. 7. The theoretical (measured) Markstein numbers vary little (appreciably) with ambient pressure. This can be attributed to the flame thickness calculated numerically to obtain the measured Markstein lengths. Several points are worth mentioning here. The theoretical Markstein lengths adopt a global reaction scheme that may not accurately reflect the effects of pressure. Experimentally, the flame displacement speed is defined with respect to the Schlieren boundary. Markstein length can change from negative to positive values when an iso-temperature surface is taken from an unburned temperature to an adiabatic one (see Figs. 5-6 and Figs. S9-S13 in the SM) [56]. An empirical relation of the cold flame front radius $\left(r_{\mathrm{u}}\right)$ to the Schlieren boundary radius $\left(r_{\mathrm{sch}}\right.$, assumed to be the $600 \mathrm{~K}$ isotherm) was proposed as $r_{\mathrm{u}}=r_{\mathrm{sch}}+1.95 \delta_{\mathrm{f}}^{0} \sigma^{0.5}$ [36]. However, the application of this empirical relation at elevated pressure is not clear. As shown in Fig. 7, when theoretical and measured Markstein numbers are compared, the flame thickness is needed to obtain experimentally in identifying measured Markstein number. These issues will be explored in future work. 


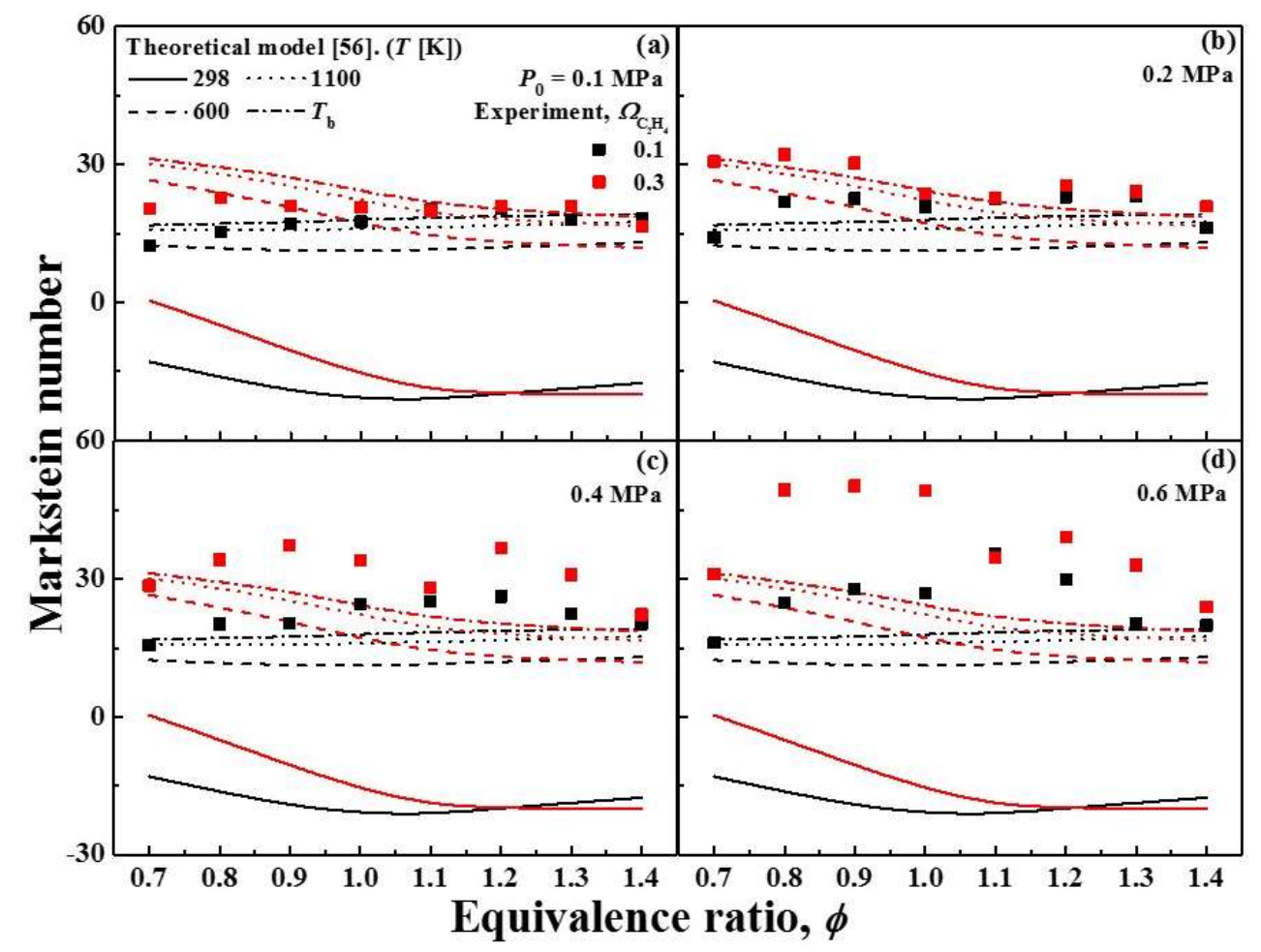

Fig. 7. Measured (symbol) and predicted (lines) Markstein numbers against the equivalence ratio in $\mathrm{CH}_{4} / \mathrm{C}_{2} \mathrm{H}_{4}$-air premixed flames with $\delta_{\mathrm{f}}^{0}=\left(T_{\mathrm{b}}-T_{\mathrm{u}}\right) /(\partial T / \partial x)_{\max }$ at elevated pressures. For theoretical Markstein lengths, the temperature-dependent Zel'dovich number and the heat-releaseweighted Lewis number are used.

\subsection{Onset of cellular instability}

Cellular instability in premixed flames is generated by hydrodynamic and/or diffusive-thermal instabilities [37-46], leading to local flame acceleration. This can be roughly evaluated based on the effective Lewis number for diffusive-thermal instability and flame thickness and the thermal expansion ratio for hydrodynamic instability. Sequential images of outwardly propagating spherical premixed flames with $\mathrm{CH}_{4} / \mathrm{C}_{2} \mathrm{H}_{4}$-air mixtures are shown in Fig. 8 at various $\Omega_{\mathrm{C}_{2} \mathrm{H}_{4}}$ for representative lean $(\phi=$ $0.8)$ and rich $(\phi=1.2)$ cases for $P_{\mathrm{u}}=0.6(\mathrm{a}, \mathrm{b})$ and $0.8(\mathrm{c}, \mathrm{d}) \mathrm{MPa}$. The images were obtained at the moment when the uppermost flame edge reached a specified distance (marked as $R_{\mathrm{f}}$ on the left side) from the center. The heat-release-weighted effective Lewis number, $\mathrm{Le}_{\mathrm{q}}$, the thermal expansion ratio $\sigma$, and the flame thickness $\delta_{\mathrm{f}}^{0}=\left(\lambda / c_{\mathrm{p}}\right) /\left(\rho_{\mathrm{u}} S_{\mathrm{u}}^{\mathrm{o}}\right)$ are specified for each image. 
(a) $0.6 \mathrm{MPa}, \phi=0.8$

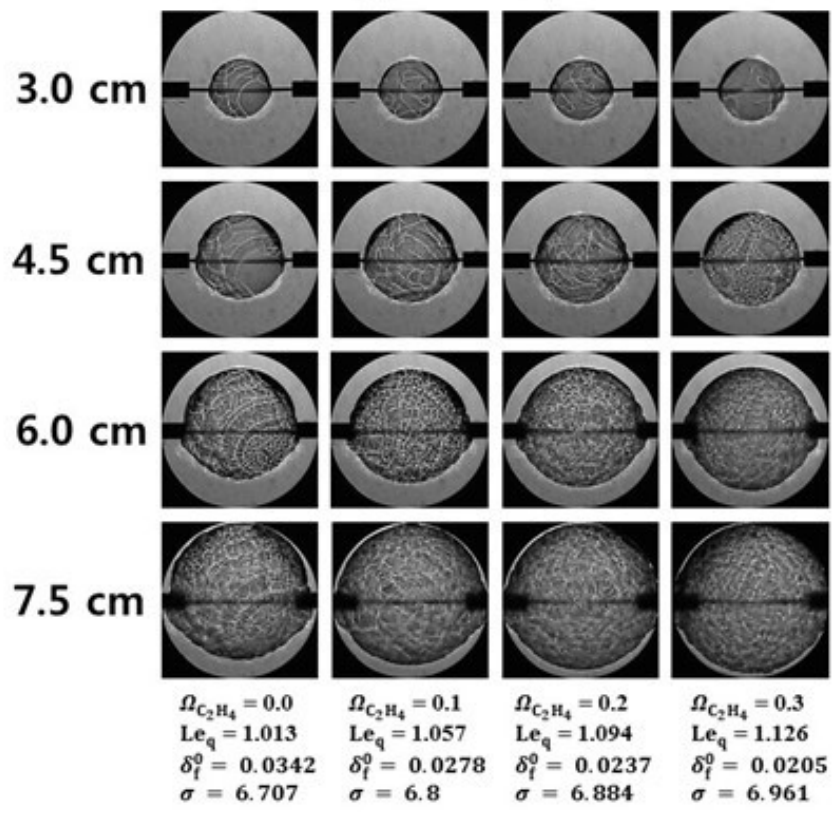

(a) $0.8 \mathrm{MPa}, \phi=0.8$

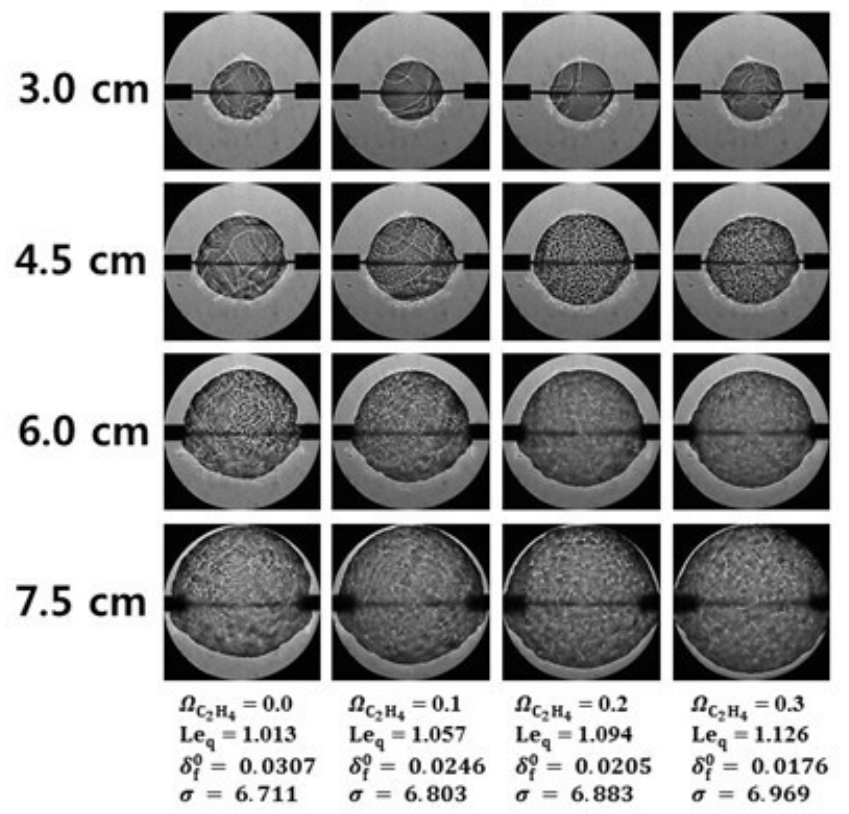

(b) $0.6 \mathrm{MPa}, \phi=1.2$
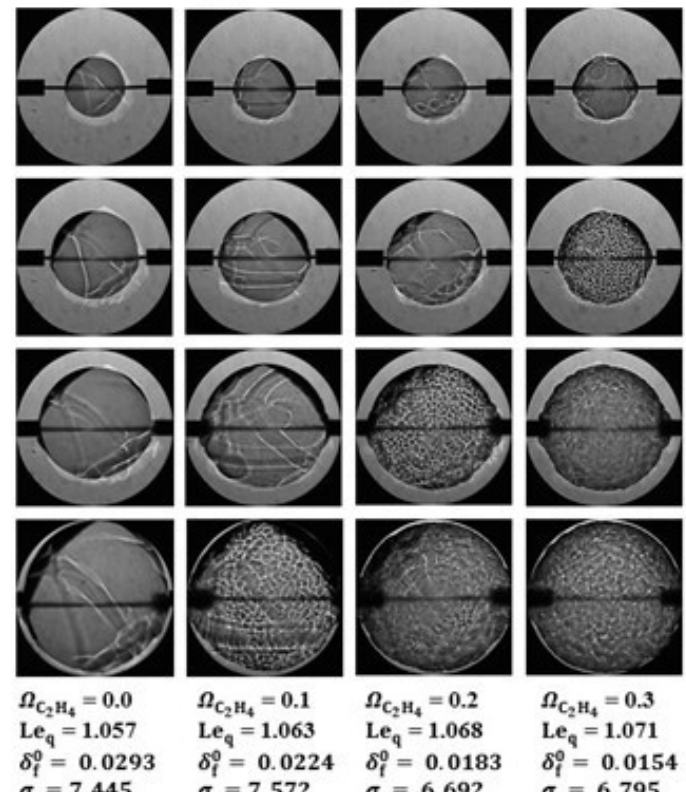

$\Omega_{\mathrm{C}_{\mathrm{H}} \mathrm{H}_{4}}=0.1 \quad \Omega_{\mathrm{C}_{\mathrm{N}}}=0.2$ $L_{Q}=1.063 \quad L e_{q}=1.068$ $\delta_{i}^{0}=0.0224 \quad \delta_{f}^{0}=0.0183$ $\sigma .572 \quad \sigma=6.692$

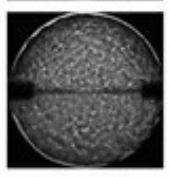

$\Omega_{\mathrm{C}_{2} \mathrm{H}_{4}}=0.3$

$\mathrm{Le}_{\mathrm{Q}}=1.071$

$\delta_{i}^{Q}=0.0154$

(b) $0.8 \mathrm{MPa}, \phi=1.2$
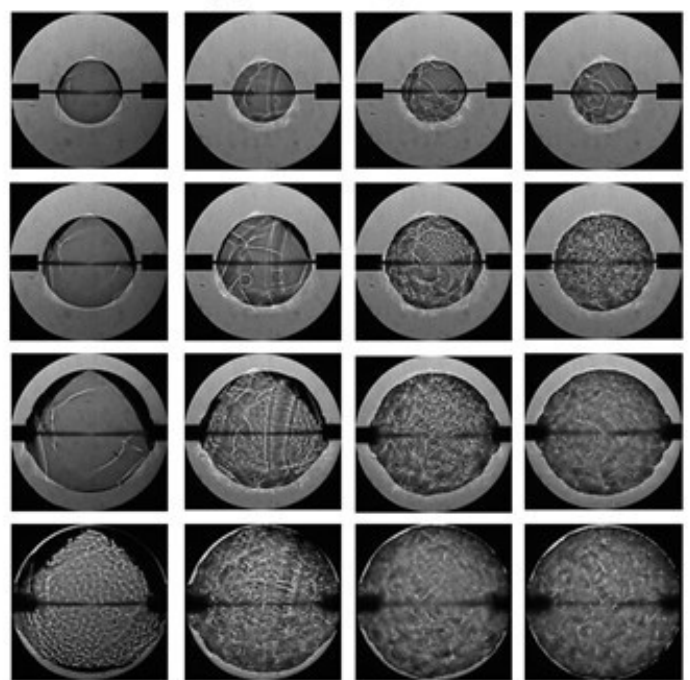

$\Omega_{\mathrm{C}_{2} \mathrm{H}_{4}}=0.0$

$\mathrm{Le}_{\mathrm{q}}=1.057$

$\delta_{f}^{0}=0.0261$

$\sigma=7.450$
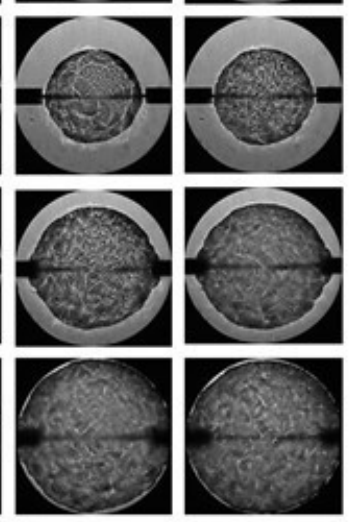

$\Omega_{\mathrm{C}_{2} \mathrm{H}_{4}}=0.2$

$\begin{array}{ll}\mathrm{Le}_{\mathrm{Q}} \mathrm{H}_{4}=1.063 & \mathrm{Le}_{\mathrm{Q}}=1.068 \\ \delta_{q}^{\circ}=0.0198 & \delta_{q}^{\circ}=\mathbf{0 . 0 1 6}\end{array}$

$\begin{array}{ll}\sigma=7.577 & \sigma=7.689\end{array}$

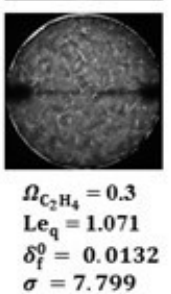

Fig. 8. Effect of ethylene ratio on cellular instability in $\mathrm{CH}_{4} / \mathrm{C}_{2} \mathrm{H}_{4}$-air premixed flames at $\phi=0.8$ and 1.2 for $P_{0}=0.6(\mathrm{a}, \mathrm{b})$ and $0.8 \mathrm{MPa}(\mathrm{c}, \mathrm{d})$.

The flame surfaces at $P_{0}<0.6 \mathrm{MPa}$ for $\phi=0.8$ and 1.2 were smooth during the propagation (although not shown), with the exception of some large cracks due to disturbance from the ignitor.

However, fine cells formed over the flame surface at both $\phi=0.8$ and 1.2 for $P_{0} \geq 0.6 \mathrm{MPa}$, as shown in Fig. 8. As $\Omega_{\mathrm{C}_{2} \mathrm{H}_{4}}$ increased for $P_{0}=0.6$ and $0.8 \mathrm{MPa}$, the effective Lewis number increased (but remained close to unity) for both $\phi=0.8$ and 1.2 , such that the contribution of cellular instability due to the imbalance between mass and thermal diffusivities was mitigated. $\sigma\left(\delta_{\mathrm{f}}^{0}\right)$ increased (decreased) 
such that hydrodynamic instability was enhanced. Thus the instabilities observed in the present experiment can mainly be attributed to hydrodynamic instability. Increasing the ambient pressure at a fixed $\Omega_{\mathrm{C}_{2} \mathrm{H}_{4}}$ and $\phi$, decreases (increases) flame thickness (thermal expansion ratio), thereby enhancing hydrodynamic instabilities.

Further analysis of cellular instability was conducted by investigating the critical flame radius at the onset of cellular instability. The theoretical analysis applied here was developed by Matalon's group [37-39], considering both hydrodynamic and diffusive-thermal instabilities by adopting temperaturedependent transport coefficients. Here, only a brief explanation is provided.

A disturbed flame front can be described by $r=R_{\mathrm{f}}(t)\left[1+Z(t) S_{k}(\theta, \phi)\right]$, where $Z(t)$ is the amplitude of the disturbance and $S_{k}$ is the spherical surface harmonics having an integer $k$. As a flame is expanded, the growth rate $(G R)$ is given by

$$
G R=\frac{1}{Z} \frac{d Z}{d t}=\frac{\dot{R}_{\mathrm{f}}}{R_{\mathrm{f}}}\left\{\omega_{\mathrm{DL}}-\frac{\delta_{\mathrm{f}}^{0}}{R_{\mathrm{f}}}\left[B_{1}+\beta\left(\mathrm{Le}_{\mathrm{eff}}-1\right) B_{2}+\operatorname{Pr} B_{3}\right]\right\}
$$

where $\omega_{D L}=\left(-\sigma+\sqrt{\sigma^{3}+\sigma^{2}-\sigma}\right) /(\sigma+1)$ represents the destabilizing effect via thermal expansion, because the thermal expansion ratio $(\sigma)$ is larger than unity in exothermic reactions. Here, $B_{1}, B_{2}$, and $B_{3}$ (refer to the definitions in [37-39]) depend only on $\sigma$ and $k$, and they are all positive with the exception of the small values of $k$. The terms multiplying $\delta_{\mathrm{f}}^{0} / R_{\mathrm{f}}$ denote, respectively, the influences of thermal, molecular, and viscous diffusions [37-39], and Pr represents the Prandtl number. When the effective Lewis number is less than a critical value $\left(\operatorname{Le}_{\mathrm{q}}^{*}<1\right)$, the amplitude grows over time for all wave numbers. In such a case, the instability, which can be developed from a small flame radius, can be judged as diffusive-thermal in nature. Based on these criteria, the cellular instabilities shown in Fig. 8 were not caused by diffusive-thermal ones.

Figure 9 shows the growth rate as a function of wavelength $\left(\gamma=2 \pi R_{\mathrm{f}} / n\right.$, where $n$ is the wave number) for $\phi=0.8$ and $P_{0}=0.6 \mathrm{MPa}$ in case of $\Omega_{\mathrm{C}_{2} \mathrm{H}_{4}}=0.0$. Here, $\mathrm{Pr}$ is not sensitive to temperature, pressure, or $\Omega_{\mathrm{C}_{2} \mathrm{H}_{4}}$; e.g., for $\phi=0.8$ and $P_{0}=0.8 \mathrm{MPa}, \operatorname{Pr}=0.716$ at $298 \mathrm{~K}$ and 0.709 
at $1200 \mathrm{~K}$ in the case of $\Omega_{\mathrm{C}_{2} \mathrm{H}_{4}}=0.3$ and 0.715 for $298 \mathrm{~K}$ in the case of $\Omega_{\mathrm{C}_{2} \mathrm{H}_{4}}=0$. Thus, Pr was reasonably fixed to 0.71 . The flame thicknesses were calculated at $298 \mathrm{~K}$. The results indicate that when $R_{\mathrm{f}}$ is less than $6.9 \mathrm{~cm}$ for the $\mathrm{CH}_{4}$-air premixed flame, the growth rate of the disturbance is always negative, meaning that instability is suppressed. When the flame radius exceeds $6.9 \mathrm{~cm}$, there exists a range of wave lengths where the growth rate becomes positive and the flame becomes unstable due to hydrodynamic effects, e.g., $1.8<\gamma<12.5 \mathrm{~mm}$ for $R_{\mathrm{f}}=15 \mathrm{~cm}$. The flames with shorter (longer) wavelengths can be stabilized by diffusion (flame stretch) [39].

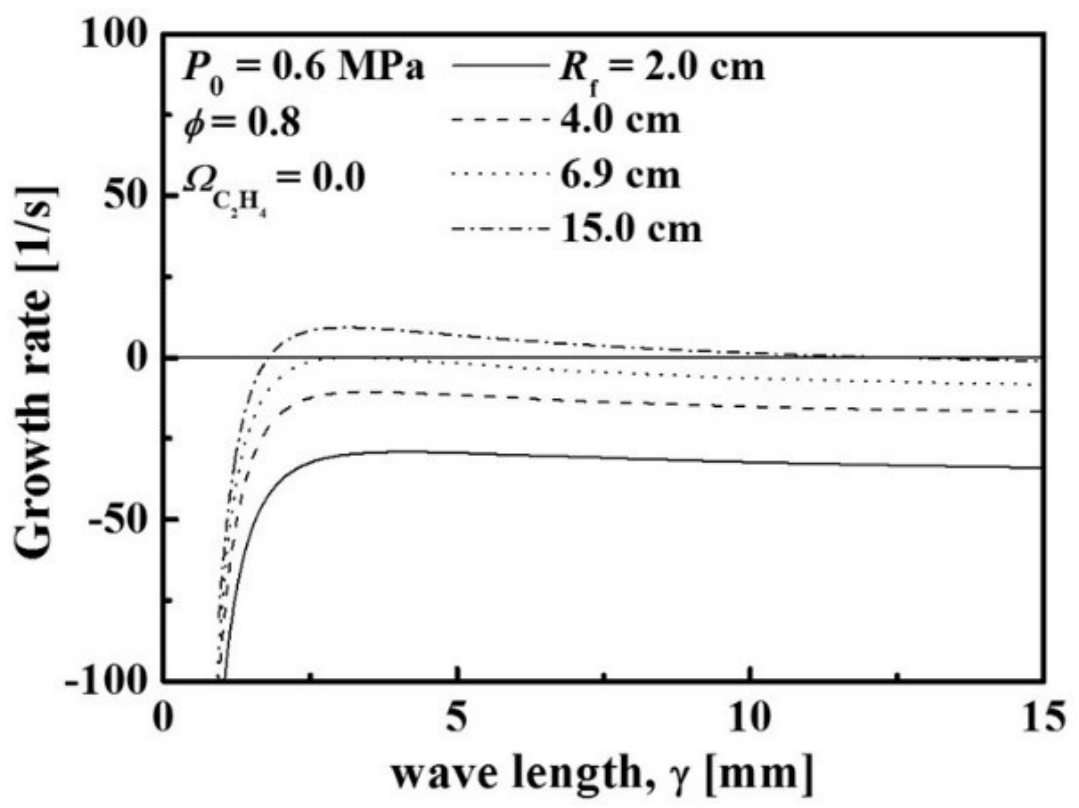

Fig. 9. Growth rate versus wavelength at $\phi=0.8$ for $P_{0}=0.6 \mathrm{MPa}$ and $\Omega_{\mathrm{C}_{2} \mathrm{H}_{4}}=0$.

Further details on the range of cell sizes observed during self-wrinkling can be deduced from Eq. (5), in the form of a marginal stability curve, which is obtained by taking the right-hand side to be zero. Figure 10 presents the results: C-shaped curves were obtained with $\tilde{\lambda}=$ constant $=1$ and $\tilde{\lambda} \sim\left(T / T_{\mathrm{u}}\right)^{1 / 2}[38]$ in terms of the wave number $n$ and Peclet number $(\mathrm{Pe})$ defined as $\mathrm{Pe}=R_{\mathrm{f}} / \delta_{\mathrm{f}}^{0}$. Here, $\tilde{\lambda}$ is the thermal conductivity scaled by its value for the unburned gas side. Thus, Fig. 10 plots results for $\tilde{\lambda}=1.0$ and 6.0 (corresponding to the thermal expansion ratio for $P_{0}=0.6 \mathrm{MPa}$ and $\phi=$ 0.8 , respectively). The region enclosed by each peninsula of Fig. 10 identifies the range of $n_{\min }<$ $n<n_{\text {max }}$ for a flame radius or Peclet number. Long-wavelength disturbances (large corrugations on 
the flame surface), corresponding to $n<n_{\max }$, are stabilized by flame stretch. Short-wavelength disturbances $\left(n>n_{\max }\right)$ are stabilized by diffusion effects, which tend to smooth out temperature and concentration differences $[38,39]$. A critical Peclet number, $\mathrm{Pe}_{\mathrm{c}}=R_{\mathrm{cr}} \delta_{\mathrm{f}}^{0}$, can be determined from the turning point of the instability peninsular. The upper branch of the peninsula asymptotes to a line, $\mathrm{Pe} / n=C$, where the constant $C$ depends on the effective Lewis number $[38,39]$. The details of determining the constant $C$ have been reported [38]. Thus, the smallest cell size $\gamma_{\min }=2 \pi R_{\mathrm{f}} /$ $n \sim 2 \pi C \delta_{\mathrm{f}}^{0}$ scales on the diffusion length, which is dependent on mixture composition. Note that the neutral stability curve can be obtained by setting the right side of Eq. (9) to zero. The lower branch of the peninsula asymptotes to the line $n_{\min }^{*}$ obtained by examining the limit $\mathrm{Pe} \rightarrow \infty$, namely by setting $\omega_{\mathrm{DL}}=0$. Because the stabilizing mechanism is purely hydrodynamics, the $n_{\min }^{*}$ depends only on $\sigma$, and the $n_{\mathrm{min}}^{*}$ asymptotes to 6.6 for all cases in Fig. 10. This value determines the largest theoretical cell size, $\gamma_{\max }=2 \pi R_{\mathrm{f}} / n_{\min }^{*}$, which increases linearly with flame radius. Due to the difficulty in experimentally defining cell size, we focused on the critical flame radius for hydrodynamic instability.

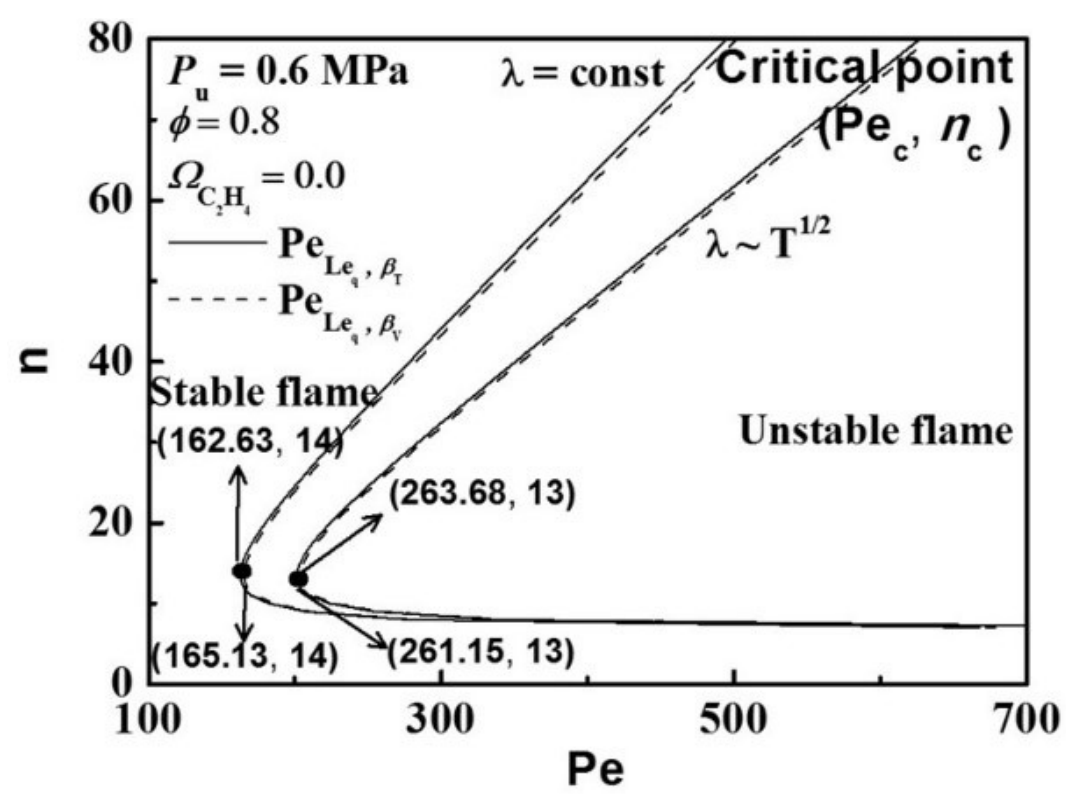

Fig. 10. Peninsular of cellular instability with a functional dependence of wave number upon the Peclet number for $\phi=0.8$ and $P_{0}=0.6 \mathrm{MPa}$ in case of $\Omega_{\mathrm{C}_{2} \mathrm{H}_{4}}=0$.

As mentioned previously (Fig. 8), the cellular instabilities are not attributed to diffusive-thermal instability but hydrodynamic instability. In such a case, the second terms inside the bracket in Eq. (9) 
are positive. The growth rate thus depends on burnt flame speed and flame thickness as well as the first term, $\omega_{\mathrm{DL}}$. Increasing the ambient pressure at a fixed $\Omega_{\mathrm{C}_{2} \mathrm{H}_{4}}$ and $\phi$ decreases (increases) flame thickness (thermal expansion ratio), thereby enhancing hydrodynamic instabilities despite reduction of flame speed. Increasing $\Omega_{\mathrm{C}_{2} \mathrm{H}_{4}}$ at a fixed $P_{0}$ and $\phi$ reduces (increases) flame thickness (flame speed) (see Fig. 4 and Figs. S15-16 in the SM).

As shown in Fig. 11, the theoretical critical flame radii determined from $\mathrm{Pe}_{\mathrm{c}}$ were compared with measured ones against $\Omega_{\mathrm{C}_{2} \mathrm{H}_{4}}$ at $\phi=0.8$ and 1.2 for $P_{0}=0.6$ and $0.8 \mathrm{MPa}$. Here, the experimental critical flame radius is defined as the value at the moment when the burnt laminar propagation speed increases appreciably, and fine cells are simultaneously formed uniformly over a flame surface (see Fig. S9 in the SM) [41]. The error bars were taken as the maximum and minimum values from four experiments. Note that observing cell formation and measuring critical flame radius were limited experimentally within the view of 150-mm-diameter quartz window. The functional relationship of flame radius on chamber pressure [57] can be expressed as

$$
\left(R_{\mathrm{f}} / R\right)^{3}=1-\frac{P_{\max }-P}{P_{\max }-P_{0}}\left(\frac{P_{0}}{P}\right)^{\gamma},
$$

where $R, P$, and $\gamma$ denote the chamber radius, the chamber pressure at flame radius $R_{\mathrm{f}}$, and the specific heat ratio, respectively. With the approximation of $\gamma=1.4$ (air) and $P_{\max }=8 P_{0}$, the pressure rises at $R_{\mathrm{f}}=30$ and $70 \mathrm{~mm}$ (within the range of observed onset of instability) for $P_{0}=0.8 \mathrm{MPa}$ are $0.5 \%$ and $7.1 \%$, respectively. Thus, the effect of chamber pressure rise is not appreciable in analyzing the onset of cellular instability. Also note that for the range of flame radius monitored, $13.0 \leq R_{\mathrm{f}} \leq 31.0 \mathrm{~mm}$, the pressure rise effects on laminar flame speed and Markstein length are expected to be minimal. Note that the influence of chamber pressure rise can be larger in measuring the critical flame radius for the onset of cellular instability when the flame radius increases further.

For $P_{0}<0.6 \mathrm{MPa}$, the critical flame radius could not be obtained experimentally in the window view. In the case of $\phi=1.2$, cellular instability was not observed in the window view at $\Omega_{\mathrm{C}_{2} \mathrm{H}_{4}}<0.2$ for $P_{0}=0.6$ and $0.8 \mathrm{MPa}$. For $\phi=0.8$, the critical flame radius could not be obtained for $\Omega_{\mathrm{C}_{2} \mathrm{H}_{4}}<$ 
0.1 at $P_{0}=0.6 \mathrm{MPa}$, but it was observed in all cases for $P_{0}=0.8 \mathrm{MPa}$. Both measured and theoretical critical flame radii decreased slightly (rather rapidly) with an increase in $\Omega_{\mathrm{C}_{2} \mathrm{H}_{4}}$ for $\phi=0.8$ (1.2), implying that increasing $\Omega_{\mathrm{C}_{2} \mathrm{H}_{4}}$ promotes cell formation. The calculated critical flame radii were in reasonably good agreement with the measured ones, while being slightly better than predicted when the temperature-dependent Zel'dovich numbers were used. For $\phi=1.2$, both predicted critical radii somewhat under-predicted the measured ones, whereas the prediction was close to the measured values for $\phi=0.8$, with good retracement.
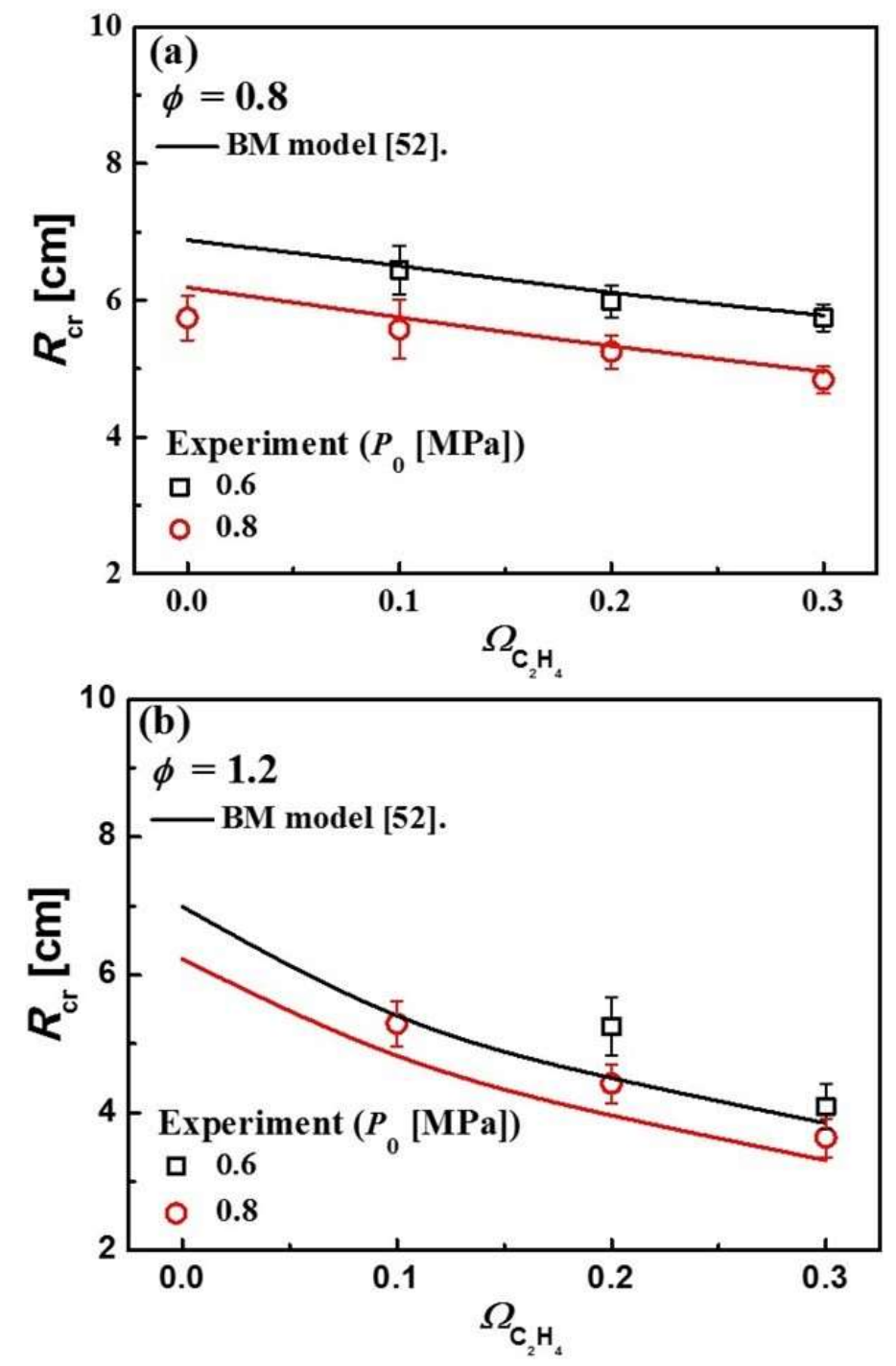

Fig. 11. Measured and theoretical critical radii against $\Omega_{\mathrm{C}_{2} \mathrm{H}_{4}}$ at $\phi=0.8$ (a) and 1.2 (b) for $P_{0}=0.6$ and $0.8 \mathrm{MPa}$. 


\section{Conclusions}

An experimental study was conducted to investigate unstretched laminar burning velocity, Markstein length, and cellular instability by varying the ethylene mixing ratio and the chamber pressure up to $0.8 \mathrm{MPa}$ in outwardly propagating spherical $\mathrm{CH}_{4} / \mathrm{C}_{2} \mathrm{H}_{4}$-air premixed flames. The following conclusions can be made.

1) The range of flame radius monitored was determined to be $13.0 \leq R_{\mathrm{f}} \leq 31.0 \mathrm{~mm}$ in the present experiment in measuring unstretched laminar burning velocities. The extrapolation model of NM II yielded the best results. Unstretched laminar burning velocities of $\mathrm{CH}_{4} / \mathrm{C}_{2} \mathrm{H}_{4}$ mixtures were in satisfactory agreement with the numerical results when adopting Aramco Mech 2.0, up to a pressure of 0.6 $\mathrm{MPa}$. Measured laminar flame speeds with respect to the burnt mixture against flame stretch were in reasonable agreement with NM II in both $\mathrm{CH}_{4}$-air and $\mathrm{CH}_{4} / \mathrm{C}_{2} \mathrm{H}_{4}$-air premixed flames at normal and elevated pressures.

2) For the $\mathrm{CH}_{4}$-air premixed flame, the theoretical Markstein lengths evaluated from the composite model with an iso-temperature of $600 \mathrm{~K}, \lambda(x)=x$, and $\delta_{\mathrm{f}}^{0}=\left(T_{\mathrm{b}}-T_{\mathrm{u}}\right) /(\partial T / \partial x)_{\max }$ were in good agreement with the present measured data. The measured Markstein number decreases appreciably (slightly) when the ambient pressure varies from 0.1 to 0.2 (0.2 to 0.6$) \mathrm{MPa}$, while the theoretical Markstein number remains nearly the same with ambient pressure. For $\mathrm{CH}_{4} / \mathrm{C}_{2} \mathrm{H}_{4}$-air premixed flame at $P_{0}=0.1 \mathrm{MPa}$, the theoretical Markstein lengths slightly underpredict the measured data for $\Omega_{\mathrm{C}_{2} \mathrm{H}_{4}}=0.1$, while they slightly over-predict (under-predict) the measured data for lean (rich) mixtures for $\Omega_{\mathrm{C}_{2} \mathrm{H}_{4}}=0.3$. With the increase of ambient pressure, theoretical Markstein length becomes less sensitive to the choice of iso-temperature surface while both theoretical and measured Markstein lengths decrease. The theoretical (measured) Markstein numbers vary little (appreciably) with ambient pressure.

3) For the $\mathrm{CH}_{4}$-air premixed flame, cellular instability was not observed at elevated pressures up to 0.6 (0.8) $\mathrm{MPa}$ for $\phi=0.8$ (1.2). For the $\mathrm{CH}_{4} / \mathrm{C}_{2} \mathrm{H}_{4}$-air premixed flame, cellular instability was enhanced with an increases in the chamber pressure and ethylene/methane mixing ratio, such that 
the critical flame radius for the onset of cellular instability could be reduced. These findings were mainly attributed to hydrodynamic instability, whereas the effect of diffusive-thermal instability was minor. The theoretical critical flame radii for cellular instability against ethylene mixing ratio were in good agreement with measured values for both lean and rich flame conditions, based on the theoretical model developed by Matalon's group.

\section{Acknowledgements}

This work was conducted under the framework of the Research and Development Program of the Korea Institute of Energy Research (B9-2431). CSY was supported by Basic Science Research Program through the National Research Foundation of Korea (NRF) funded by the Ministry of Science and ICT (NRF-2018R1A2A2A05018901). SHC was supported by the King Abdullah University of Science and Technology (KAUST).

\section{References}

[1] Market Report Series: Gas 2018, IEA, 2018, available at http://www.iea.org/topics/naturalgas.

[2] W. Xiao, Y. Huang, Lean blowout limit of a gas turbine combustor operated with aviation fuel and methane, Heat Mass Transfer 52(5) (2016) 1015-1024.

[3] Y. Lafay, B. Renou, G. Cabot, A. Boukhalfa, Effects of $\mathrm{H}_{2}$ or $\mathrm{CO}_{2}$ addition, equivalence ratio, and turbulent straining on turbulent burning velocities for lean premixed methane combustion, Combust. Flame 153 (2008) 510-524.

[4] J.S. Ha, C. W. Moon, J. Park, J. S. Kim, J. H. Yun, S. I. Keel, A study on flame interaction between methane/air and nitrogen-diluted hydrogen-air premixed flames, Int. J. Hydrog. Energy 35 (2010) 6992-7001.

[5] J.S. Kim, J. Park, O.B. Kwon, D.S. Bae, J.H. Yun, S.I. Keel, A study on flame structure and extinction in downstream interaction between lean premixed $\mathrm{CH}_{4}$-air and $\left(50 \% \mathrm{H}_{2}+50 \% \mathrm{CO}\right)$ syngas-air flames, Int. J. Hydrog. Energy 36 (2011) 5717-5728.

[6] F.H.V. Coppens, D. J. Ruyck, A. A. Konnov, The effects of composition on burning velocity and nitric oxide formation in laminar premixed flames of $\mathrm{CH}_{4}+\mathrm{H}_{2}+\mathrm{O}_{2}+\mathrm{N}_{2}$, Combust. Flame 149 (2007) 409-417.

[7] H.S. Guo, G.J. Smallwood, O.L. Gulder, The effect of reformate gas enrichment on extinction limits and $\mathrm{NO}_{\mathrm{X}}$ formation in counterflow $\mathrm{CH}_{4} /$ air premixed flames, Proc. Combust. Inst. 31 (2007) 1197-1204.

[8] G. Jomaas, X.L. Zheng, D.L. Zhu, C.K. Law, Experimental determination of counterflow 
ignition temperatures and laminar flame speeds of $\mathrm{C}_{2}-\mathrm{C}_{3}$ hydrocarbons at atmospheric and elevated pressures, Proc. Combust. Inst. 30 (2005) 193-200.

[9] J.L. Delfau, J. Biet, M. Idir, L. Pillier, C. Vocelle, Experimental and numerical study of premixed, lean ethylene flames, Proc. Combust. Inst. 31 (2007) 357-365.

[10] W. Liu, A. P. Kelly, C. K. Law, Flame propagation and counterflow nonpremixed ignition of mixtures of methane and ethylene, Combust. Flame 157 (2010) 1027-1036.

[11] H.J. Kim, K.H. Van, K.M. Lee, D.G. Lee, Y.T. Kwak, J. Park, Effects of additional diluents on flame propagation speed and Markstein length in outwardly propagating $\mathrm{CH}_{4} / \mathrm{C}_{2} \mathrm{H}_{4}$ flames, $\mathrm{J}$. Mech. Sci. Technol. 32(11) (2018) 5537-5544.

[12] Z. Chen, On the accuracy of laminar flame speeds measured from outwardly propagating spherical flames: Methane/air at normal temperature and pressure, Combust. Flame 162 (2015) 2442-2453.

[13] S.C. Taylor, Burning velocity and the influence of flame stretch, $\mathrm{PhD}$ Thesis, University of Leeds. (1991).

[14] F. Halter, T. Tahtouh, C. Mounaïm-Rousselle, Nonlinear effects of stretch on the flame front propagation, Combust. Flame 157 (2010) 1825-1832.

[15] S. Wang, H. Zhang, J. Jarosinski, A. Gorczakowski, J. Podfilipski, Laminar burning velocities and Markstein lengths of premixed methane/air flames near the lean flammability limit in microgravity, Combust. Flame 157 (2010) 667-675.

[16] K.T. Aung, L.K. Tseng, M.A. Ismail, G.M. Faeth, Laminar burning velocities and Markstein numbers of hydrocarbon-air flames, Combust. Flame 102 (1995) 526-530.

[17] M.I. Hassan, K.T. Aung, G.M. Faeth, Measured and predicted properties of laminar premixed methane/air flames at various pressures, Combust. Flame 115 (1998) 539-550.

[18] X.J. Gu, M.Z. Haq, M. Lawes, R. Woolley, Laminar burning velocity and Markstein lengths of methane-air mixtures, Combust. Flame 121 (2000) 41-58.

[19] X. Qin, Y. Ju, Measurements of laminar burning velocities of dimethyl ether and air premixed flames at elevated pressures, Proc. Combust. Inst. 30 (2005) 233-240.

[20] T. Tahtouh, F. Halter, C. Mounaim-Rousselle, Measurement of laminar burning speeds and Markstein lengths using a novel methodology, Combust. Flame 156 (2009) 1735-1743.

[21] W. Lowry, J. de Vries, M. Krejci, E. Petersen, Laminar flame speed measurements and modeling of pure alkanes and alkane blends at elevated pressures, J. Eng. Gas Turb. Power 133 (2011) 091501.

[22] E. Varea, V. Modica, A. Vandel, B. Renou, Measurement of laminar burning velocity and Markstein length relative to fresh gases using a new postprocessing procedure: Application to laminar spherical flames for methane, ethanol and isooctane/air mixtures, Combust. Flame 159 
(2012) 577-590.

[23] J. Beeckman, L. Cai, H. Pirch, Experimental investigation of the laminar burning velocities of methanol, ethanol, n-propanol, and n-butanol at high pressure, Fuel 117 (214) 340-350.

[24] G.P. Smith, D.M. Golden, M. Frenklach, N.W. Moriarty, B. Eiteneer, M. Goldenberg, C.T. Bowman, R.K. Hanson, S. Song, W.C. Gardiner Jr., V.V. Lissianki, Z. Qin, GRI-MECH 3.0, 1999, available at http://www.me.berkeley.edu/gri mech.

[25] H. Wang, X. You, A. V. Joshi, S. G. Davis, A. Salkin, F. Egolfopoukos, C. K. Law, USC MECH II, 2007, <http://ignis.use.edu/USC_II.htm>.

[26] C.J. Sung, B. Li, C. K. Law, H. Wang, Structure and sooting limits in counterflow methane/air and propane/air diffusion flames from 1 to 5 atmospheres, Proc. Combust. Inst. 27 (1998) 15231530.

[27] C-W. Zhou, Y. Li, E. O’Connor, K.P. Somers, S. Thion, C. Keesee, O. Mathieu, E.L. Petersen, T.A. DeVerter, M.A. Oehlschlaeger, G. Kukkadapu, C-J. Sung, M. Alrefae, F. Khaled, A. Farooq, P. Dirrenberger, P-A. Glaude, F. Battin-Leclerc, J. Santner, Y. Ju, T. Held, F.M. Haas, F.L. Dryer, H.J. Curran, A comprehensive experimental and modeling study of isobutene oxidation, Combust. Flame 167 (2016) 353-379.

[28] D. Bradley, R. A. Hicks, M. Lawes, C. G. W. Sheppard, R. Wooley, The measurement of laminar burning velocities and Markstein Numbers for iso-octane-air and iso-octane-n-heptane-air mixtures at elevated temperatures and pressures in an explosion bomb, Combust. Flame 115 (1998) 126-144.

[29] G. Rozenchan, D. L. Zhu, C. K. Law, S. D. Tse, Outward propagation, burning velocities, and chemical effects of methane flames up to 60 ATM, Proc. Combust. Inst. 29 (2003) 1461-1470.

[30] F. Halter, C. Chauveau, N. Djebaili-Chaumeix, I. Gokalp, Characterization of the effects of pressure and hydrogen concentration on laminar burning velocities of methane-hydrogen-air mixtures, Proc. Combust. Inst. 30 (2005) 201-208.

[31] G.H. Markstein, Experimental and theoretical studies of flame-front stability, Aeronaut. Sci. 18 (1951) 199-209.

[32] M.L. Frankel, G. I. Sivashinsky, On effects due to thermal expansion and Lewis number in spherical flame propagation, Combust. Sci. Tech 31 (1983) 131-138.

[33] P.D. Ronney, G.I. Sivashinsky, A theoretical study of propagation and extinction of nonsteady spherical flame fronts, SIAM J. Appl. Math. 49 (1989) 1029-1046.

[34] J.K. Bechtold, C. Cui, M. Matalon, The role of radiative losses in self-extinguishing and selfwrinkling flames, Proc. Combust. Inst. 30 (2005) 177-184.

[35] A.P. Kelley, C.K. Law, Nonlinear effects in the extraction of laminar flame speeds from expanding spherical flames, Combust. Flame. 156 (2009) 1844-1851. 
[36] D. Bradley, P. Gaskell, X. Gu, Burning velocities, Markstein lengths, and flame quenching for spherical methane-air flames: a computational study. Combust. Flame 104 (1) (1996) 176-198.

[37] M. Matalon, B.J. Matkowsky, Flames as gas dynamic discontinuities, J. Fluid Mech.124 (1982) 239-259.

[38] R. Addabbo, J.K. Bechtold, M. Matalon, Wrinkling of spherically expanding flames, Proc. Combust. Inst. 29 (2002) 1527-1535.

[39] M. Matalon, Intrinsic flame instabilities in premixed and nonpremixed combustion, Annu. Rev. Fluid Mech. 39 (2007) 163-191.

[40] S Kadowaki, H. Suzuki, H. Kobayashi, The unstable behavior of cellular premixed flames induced by intrinsic instability, Proc. Combust. Inst. 30 (2005) 169-176.

[41] O.C. Kwon, G. Rozenchan, C.K. Law, Cellular instabilities and self-acceleration of outwardly propagating spherical flames, Proc. Combust. Inst. 29 (2002) 1775-1783.

[42] G. I. Sivashinsky, Diffusional-thermal theory of cellular flames, Combust. Sci. Tech. 15 (1977) $137-146$.

[43] C.K. Law, G. Jomaas, J. K. Bechtold, Diffusional-thermal theory of cellular flames, Proc. Combust. Inst. 30 (2005) 159-167.

[44] T.M. Vu, W. S. Song, J. Park, Measurements of propagation speeds and flame instabilities in biomass derived gas-air premixed flames, Int. J. Hydrogen Energy 36 (2011) 12058-12067.

[45] T.M. Vu, J. Park, J.S. Kim, O.B. Kwon, Experimental study on cellular instabilities in hydrocarbon/hydrogen/carbon monoxide-air premixed flames, Int. J. Hydrog. Energy 36 (2011) 6914-6924.

[46] T.M. Vu, J. Park, O.B. Kwon, J.H. Yun, S.I. Keel, Effects of diluents on cellular instabilities in outwardly propagating spherical syngas-air premixed flames, Int. J. Hydrog. Energy 35 (2010) 3868-3880.

[47] E. Hu, Z. Huang, J. He, J. Zheng, H. Miao, Measurements of laminar burning velocities and onset of cellular instabilities of methane-hydrogen-air flames at elevated pressures and temperatures, Int. J. Hydrog. Energy 34 (2009) 5574-5584.

[48] Y. Xie, J. Wang, X. Cai, Z. Huang, Self-acceleration of cellular flames and laminar flame speed of syngas/air mixtures at elevated pressures, Int. J. Hydrog. Energy 41 (2016) 18250-18258.

[49] Z. Chen, C. Tang, J. Fu, X. Jiang, L. Wei, Z. Huang, Experimental and numerical investigation on diluted DME flames: thermal and chemical kinetic effects on laminar flame speeds, Fuel 102 (2012) 567-573.

[50] Q. Zhou, C.S. Cheng, C.W. Leung, X. Li, Z. Huang, Effects of diluents on laminar burning characteristics of bio-syngas at elevated pressures, Fuel 248 (2019) 8-15.

[51] Z. Chen, Y. Ju, Theoretical analysis of the evolution from ignition kernel to flame ball and planar 
flame, Combust. Theory Modelling 11 (2007) 427-453.

[52] Z. Chen, On the extraction of laminar flame speed and Markstein length from outwardly propagating spherical flames, Combust. Flame 158 (2011) 291-300.

[53] X. Cai, J. Wang, H. Zhao, Y. Xie, Z. Huang, Effects of initiation radius selection and Lewis number on extraction of laminar burning velocities from spherically expanding flames, Combust. Sci. Technol. 190(2) (2018) 286-311.

[54] J. Kee, K. Grcar, M.D. Smooke, J.A. Miller, Premix: Report No. SAND85-8240; Sandia National Laboratories: Livermore, CA, 1985.

[55] J.K. Bechtold, M. Matalon, The dependence of the Markstein length on stoichiometry, Combust. Flame 127 (2001) 1906-1913.

[56] G.K. Giannakopoulos, A. Gazoulis, C. Frouzakis, M. Matalon, A.G. Tomboulides, Consistent definitions of "flame displacement speed" and "Markstein length" for premixed flame propagation, Combust. Flame 162 (2015) 1249-1264.

[57] A.E. Dahoe, Laminar burning velocities of hydrogen-air mixtures from closed vessel gas explosions, J. Loss Prev. Process Ind. 18 (2005) 152-166. 


\title{
Supplementary Material
}

\section{Laminar flame speed, Markstein length, and cellular instability for spherically-propagating methane/ethylene-air premixed flames}

\author{
Hee June Kim ${ }^{1}$, Kyuho Van $^{1}$, Dae Keun Lee ${ }^{2}$, Chun Sang Yoo ${ }^{3 *}$, Jeong Park ${ }^{1 *}$, \\ Suk Ho Chung ${ }^{4}$ \\ ${ }^{1}$ Dept. of Mechanical Engineering, Pukyong National University, Busan, Korea \\ ${ }^{2}$ Advanced Combustion Lab, Korea Institute of Energy Research, Daejeon, Korea \\ ${ }^{3}$ Mechanical, Aerospace and Nuclear Engineering, Ulsan National Institute of Science and \\ Technology (UNIST), Ulsan, Korea \\ ${ }^{4}$ Clean Combustion Research Center (CCRC), King Abdullah University of Science and Technology \\ (KAUST), Thuwal, Saudi Arabia \\ Email: jeongpark@pknu.ac.kr, csyoo@unist.ac.kr
}

The flame radius range monitored must be optimized to minimize errors in measuring unstretched laminar burning velocities. The behavior of a spherically propagating flame with respect to burnt gas can be categorized into four propagation regimes: spark-assisted, unsteady transition, quasi-steady, and chamber-influencing, based on Refs. [12, 53], as demonstrated in Figs. S1 and S2 as a function of flame stretch for methane-air premixed flames. Quasi-steady flame propagation is achieved for $R_{\mathrm{f}} \geq 13 \mathrm{~mm}$. Note that the flame propagation may be independent of the ignition energies for radii exceeding $6 \mathrm{~mm}$, based on numerical simulations $[12,36]$.

The results also reveal that the effect of chamber confinement occurs for radii larger than say $58 \mathrm{~mm}$ (Figs. $\mathrm{S} 1$ and $\mathrm{S} 2$ ), whereas the reduction in $S_{\mathrm{u}}{ }^{\mathrm{o}}$ due to the effect of confinement with the equivalent chamber radius, $R_{w}=(3 V / 4 \pi)^{1 / 3}$ for a non-spherical chamber could be within $3 \%$ for $R_{\mathrm{f}} / R_{\mathrm{W}}<0.25$ [12], corresponding to $R_{\mathrm{f}}=31 \mathrm{~mm}$ in the present chamber. For the chamber pressure of $P_{0}=0.6 \mathrm{MPa}$ with $\phi=0.7$ in Fig. S1, a cellular instability occurs at $R_{\mathrm{f}}=34.6 \mathrm{~mm}$, accelerating the flame propagation. Thus, the available range of flame radius monitored can be taken reasonably to be in the range of $13.0 \leq R_{\mathrm{f}} \leq 31.0 \mathrm{~mm}$ in the present experiment.

The extrapolation models including LM, NM I and NM II were tested by measuring burnt flame speeds over the range of $13.0 \leq R_{\mathrm{f}} \leq 31.0 \mathrm{~mm}$ for $\mathrm{CH}_{4}$-air premixed flames at several equivalence ratios at $P_{0}=0.1$ (Fig. S3) and 0.6 (Fig. S4) MPa. The present results demonstrate that NM II traces the measured burnt flame speed as a function of flame stretch satisfactorily, as compared with those of LM and NM I. 

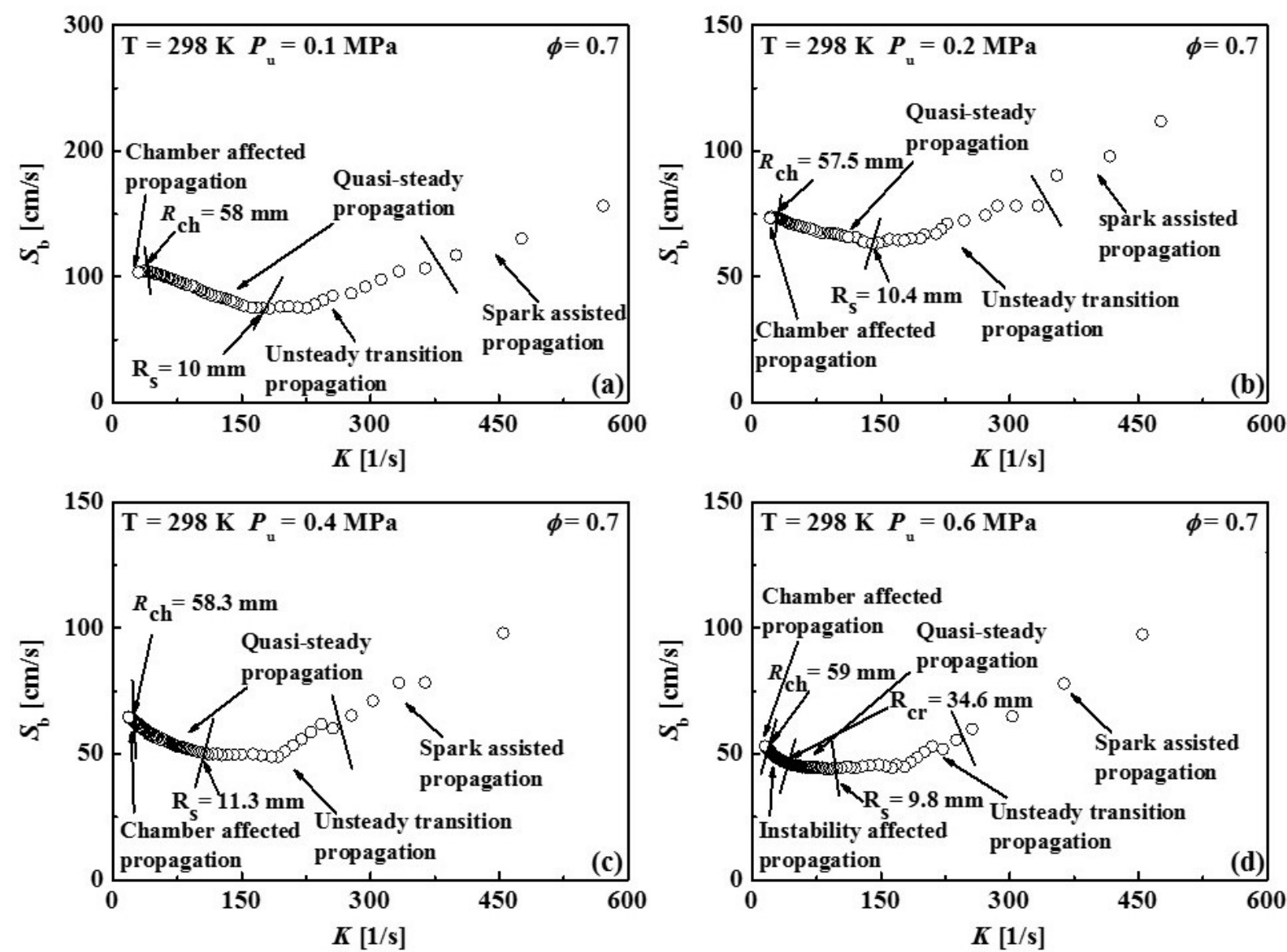

Fig. S1. Flame speed with respect to burnt gas against flame stretch at several chamber pressures for $\phi=0.7$ in methaneair premixed flames at normal temperature. To minimize the buoyancy effects, burnt flame speeds were measured based on the rate of change in horizontal flame front position with time. 

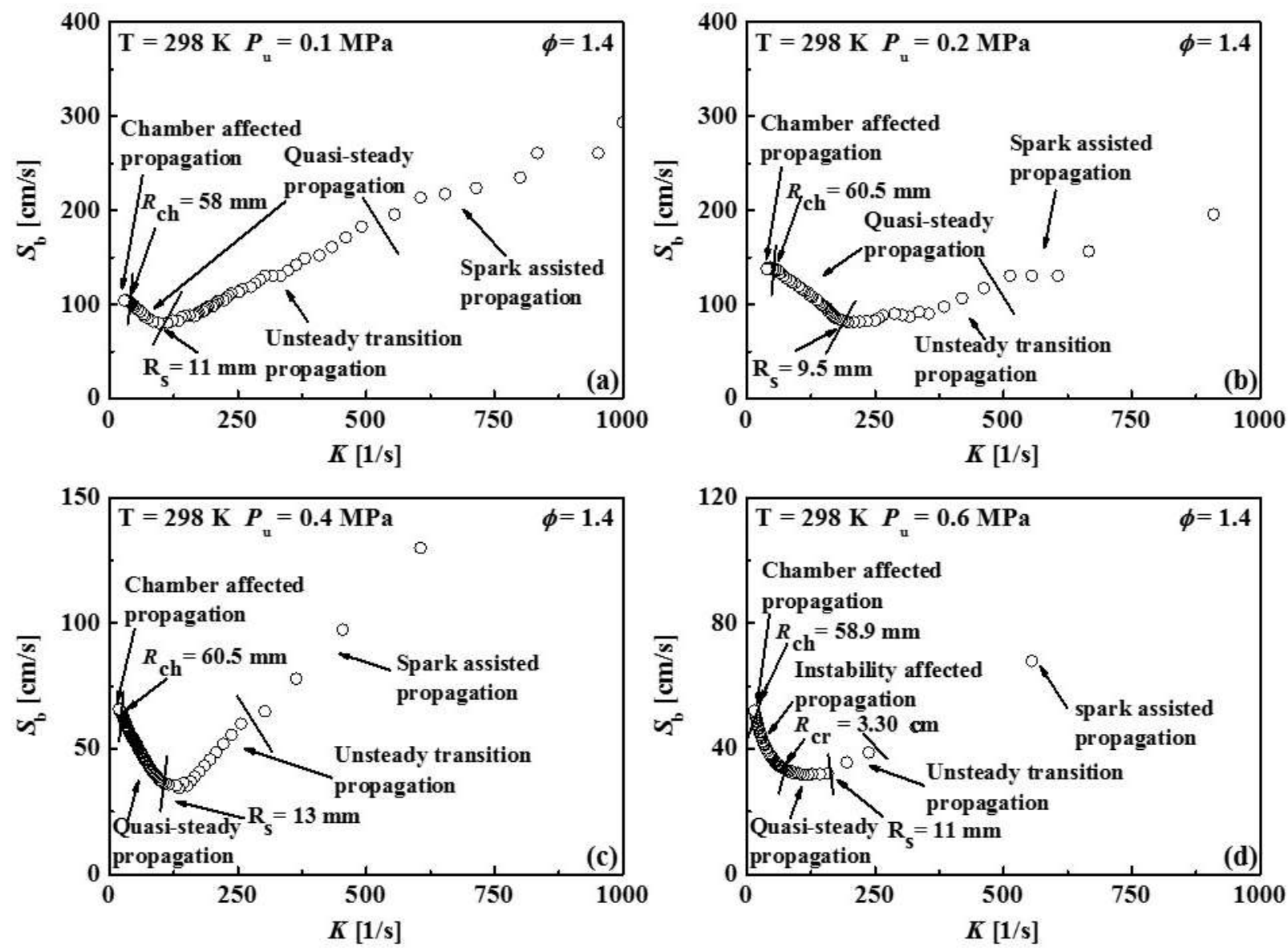

Fig. S2. Flame speed with respect to burnt gas against flame stretch at several chamber pressures for $\phi=1.4$ in methaneair premixed flames at normal temperature. To minimize the buoyancy effects, burnt flame speeds were measured based on the rate of change in horizontal flame front position with time. 

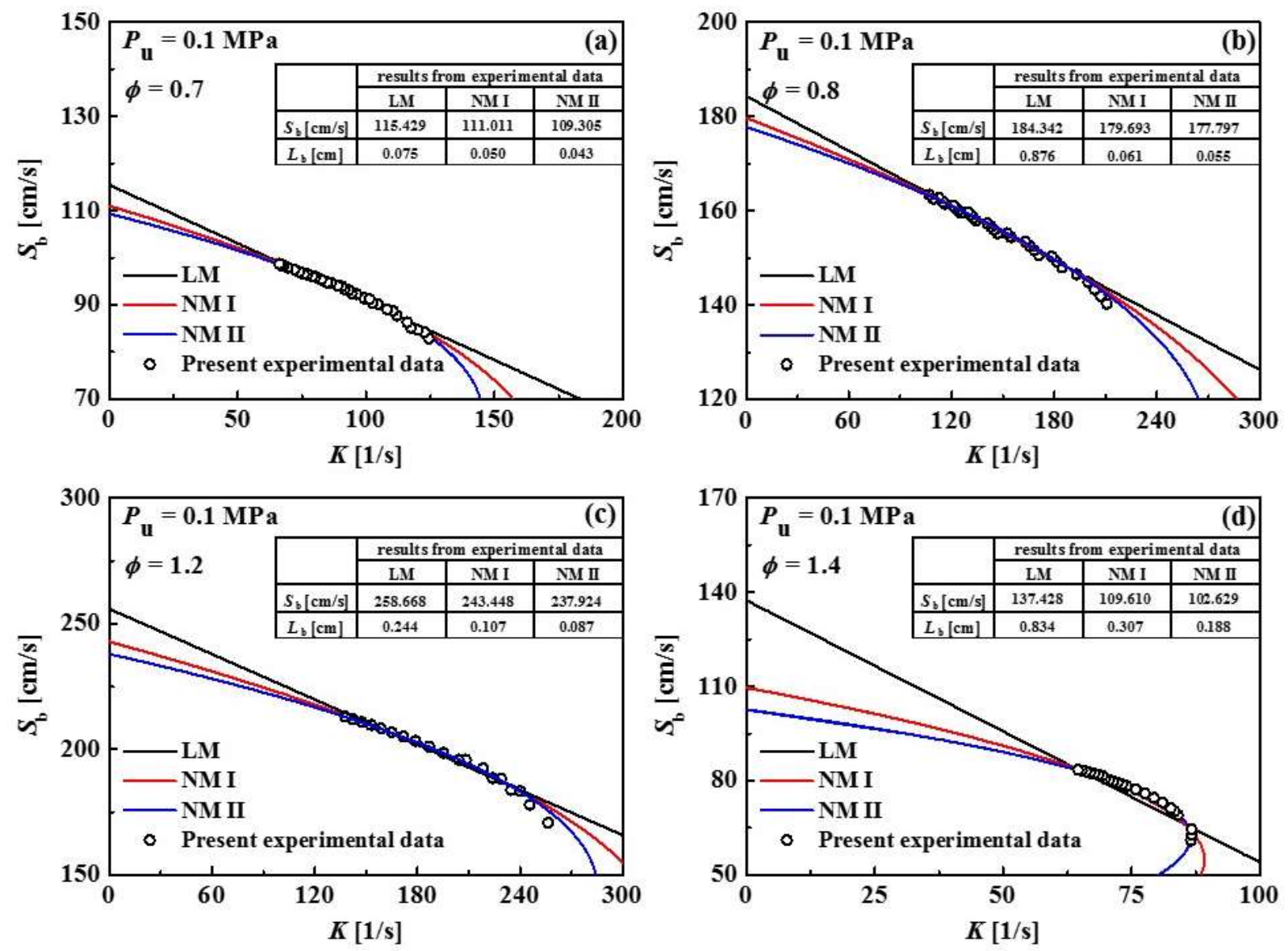

Fig. S3. Flame speed versus flame stretch for (a) $\phi=0.7$, (b) 0.8 , (c) 1.2 , and (d) 1.4 in methane-air premixed flames at normal temperature and pressure. Data was acquired in range of $13.0 \leq R_{\mathrm{f}} \leq 31.0 \mathrm{~mm}$.
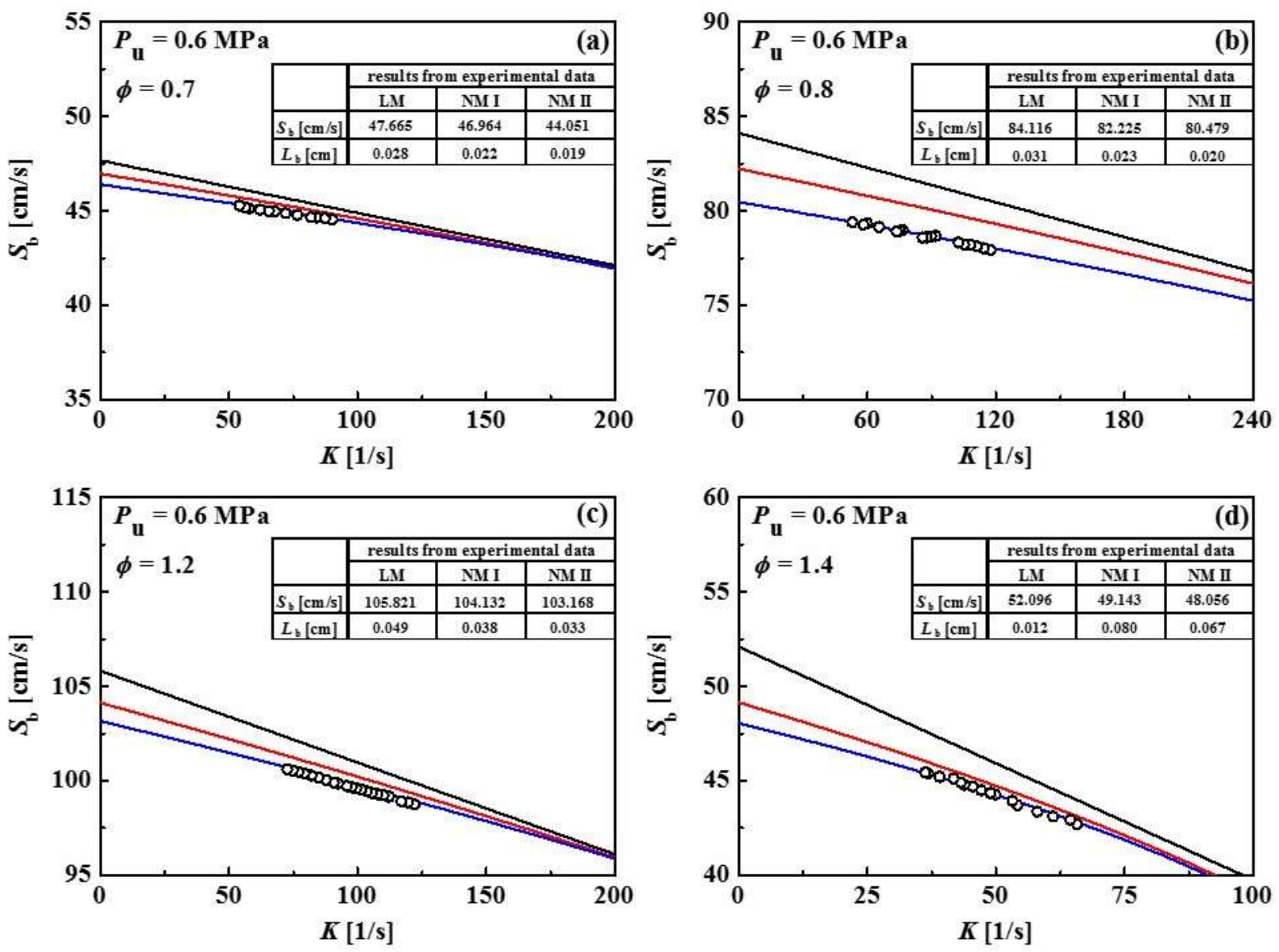
Fig. S4. Flame speed versus flame stretch for (a) $\phi=0.7$, (b) 0.8 , (c) 1.2 , and (d) 1.4 in methane-air premixed flames at $P_{0}=0.6 \mathrm{MPa}$ for normal temperature. Data was acquired in the range of $13.0 \leq R_{\mathrm{f}} \leq 31.0 \mathrm{~mm}$.

Extrapolated unstretched laminar burning velocity data were compared with numerical results using PREMIX code [54] by adopting several detailed kinetic mechanisms: GRI v-3.0 [24], USC Mech II [25], Sung Mech [26], and Aramco Mech 2.0 [27]. In Table S1, the deviation is defined as $\left|S_{\mathrm{u}, \text { meas }}^{\mathrm{o}}-S_{\mathrm{u}, \mathrm{c} \text { alc }}^{\mathrm{o}}\right| / S_{\mathrm{u}, \text { meas }}^{\mathrm{o}}$, where $S_{\mathrm{u}, \text { meas }}^{\mathrm{o}}$ and $S_{\mathrm{u}, \mathrm{c} a l c}^{\mathrm{o}}$ are the measured and calculated unstretched laminar burning velocities, respectively. Generally, Aramco Mech 2.0 best fits to the measured laminar burning velocity with equivalence ratios at all ambient pressures.

Table S1. Deviation between measured and predicted unstretched laminar burning velocities in $\mathrm{CH}_{4}$-air premixed flames for $P_{0}=0.1,0.4$, and $0.6 \mathrm{MPa}$. (Numbers denote the deviation (\%) of numerical result from the experimental result).

\begin{tabular}{|c|c|c|c|c|c|c|c|c|c|c|c|c|}
\hline \multirow{2}{*}{$\phi$} & \multicolumn{3}{|c|}{ Aramco 2.0} & \multicolumn{3}{|c|}{ GRI 3.0} & \multicolumn{3}{|c|}{ Sung Mech } & \multicolumn{3}{|c|}{ USC II } \\
\hline & $\begin{array}{c}0.1 \\
\mathrm{MPa}\end{array}$ & $\begin{array}{c}0.4 \\
\mathrm{MPa}\end{array}$ & $\begin{array}{c}0.6 \\
\mathrm{MPa}\end{array}$ & $\begin{array}{c}0.1 \\
\mathrm{MPa}\end{array}$ & $\begin{array}{c}0.4 \\
\mathrm{MPa}\end{array}$ & $\begin{array}{c}0.6 \\
\mathrm{MPa}\end{array}$ & $\begin{array}{c}0.1 \\
\mathrm{MPa}\end{array}$ & $\begin{array}{c}0.4 \\
\mathrm{MPa}\end{array}$ & $\begin{array}{c}0.6 \\
\mathrm{MPa}\end{array}$ & $\begin{array}{c}0.1 \\
\mathrm{MPa}\end{array}$ & $\begin{array}{c}0.4 \\
\mathrm{MPa}\end{array}$ & $\begin{array}{c}0.6 \\
\mathrm{MPa}\end{array}$ \\
\hline 0.7 & 3.09 & 2.71 & 5.51 & 11.26 & 5.36 & 4.61 & 2.11 & 18.09 & 21.62 & 17.41 & 23.09 & 24.63 \\
\hline 0.8 & 0.17 & 2.35 & 3.69 & 5.89 & 4.25 & 1.99 & 4.15 & 7.64 & 15.40 & 7.66 & 12.99 & 10.60 \\
\hline 0.9 & 3.65 & 0.87 & 3.96 & 7.93 & 1.00 & 5.22 & 2.34 & 4.89 & 11.45 & 5.94 & 5.00 & 0.46 \\
\hline 1.0 & 1.01 & 2.18 & 1.19 & 8.03 & 0.19 & 0.92 & 4.19 & 2.95 & 3.42 & 2.85 & 1.84 & 1.53 \\
\hline 1.1 & 0.24 & 3.98 & 0.66 & 4.26 & 5.83 & 1.02 & 2.54 & 6.83 & 1.91 & 1.68 & 10.11 & 7.66 \\
\hline 1.2 & 0.38 & 6.98 & 2.08 & 2.75 & 1.70 & 5.46 & 3.64 & 2.30 & 7.77 & 3.26 & 5.29 & 12.32 \\
\hline 1.3 & 5.98 & 0.03 & 6.69 & 2.11 & 3.22 & 4.31 & 4.20 & 8.17 & 8.96 & 1.28 & 8.15 & 11.70 \\
\hline 1.4 & 1.51 & 4.55 & 7.19 & 0.75 & 9.07 & 7.75 & 0.82 & 1.92 & 0.76 & 1.73 & 2.51 & 3.84 \\
\hline
\end{tabular}

Based on the optimal range of flame radius $\left(13.0 \leq R_{\mathrm{f}} \leq 31.0 \mathrm{~mm}\right)$ and NM II for the extrapolation model, the measured unstretched laminar burning velocities as a function of equivalence ratio are compared along with several existing datasets [12-23]. In Fig. S5 the error is defined as the deviation from the predicted result using Aramco Mech 2.0. Overall, the present measured unstretched laminar burning velocities yielded satisfactory results. 


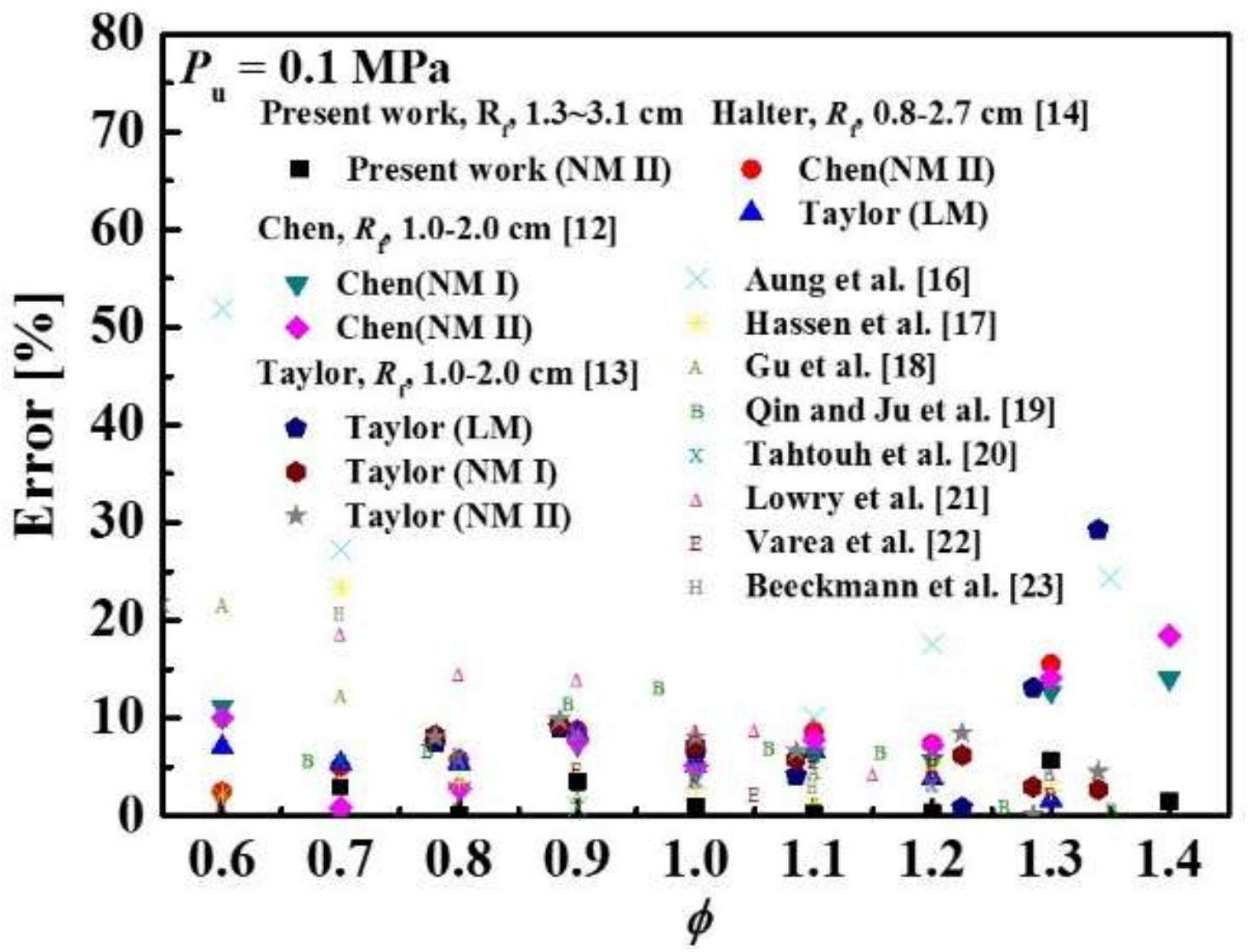

Fig. S5. Comparison of errors for the measured unstretched laminar burning velocities with several previous datasets. Here, the error is defined as the deviation from predicted results using Aramco 2.0.

The measured unstretched laminar burning velocities by varying equivalence ratio and pressure are shown in Fig. S6 for $\mathrm{CH}_{4}$-air premixed flames, exhibiting satisfactory agreement.

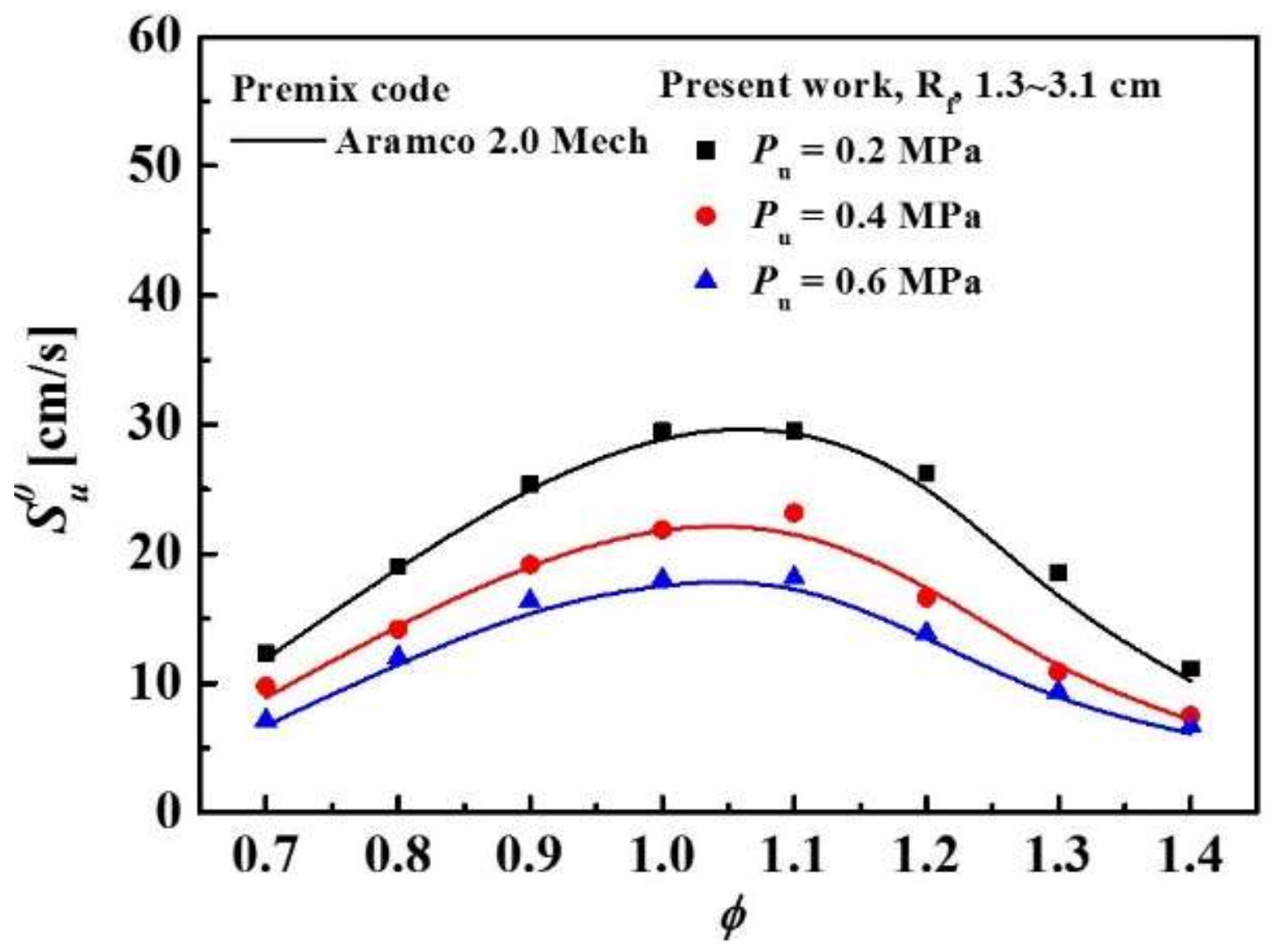


Fig. S6. Measured and predicted unstretched laminar burning velocities with equivalence ratio at several elevated pressures for $\mathrm{CH}_{4}$-air flame.

The extrapolation models, including LM, NM I and NM II, were also tested by measuring burnt flame speeds over the range of $13.0 \leq R_{\mathrm{f}} \leq 31.0 \mathrm{~mm}$ for a $\mathrm{CH}_{4} / \mathrm{C}_{2} \mathrm{H}_{4}$-air premixed flame $\left(\Omega_{\mathrm{C}_{2} \mathrm{H}_{4}}=0.3\right)$ at several equivalence ratios in Fig. S7 at 0.1 MPa and in Fig. S8 at 0.6 MPa for normal temperature. The results show that NM II traces the measured burnt flame speed as a function of flame stretch satisfactorily, as compared with those of LM and NM I, similarly to those for methane-air premixed flames shown in Figs. S3 and S4.

Extrapolated unstretched laminar burning velocity data for a $\mathrm{CH}_{4} / \mathrm{C}_{2} \mathrm{H}_{4}$-air premixed flame $\left(\Omega_{\mathrm{C}_{2} \mathrm{H}_{4}}=0.3\right)$ at several ambient pressures for normal temperature were compared with numerical results using PREMIX code [50] by adopting several detailed kinetic mechanisms: GRI v-3.0 [24], USC Mech II [25], Sung Mech [26], and Aramco Mech 2.0 [27]. In Table S2, the same definition (Table S1) for the deviation was here used. Generally, Aramco Mech 2.0 best fits to the measured laminar burning velocity with equivalence ratios at all ambient pressures. The data used in predicting Markstein lengths for $\mathrm{CH}_{4} / \mathrm{C}_{2} \mathrm{H}_{4}$-air premixed flames were list in Table S3.


Fig. S7. Flame speed versus flame stretch for (a) $\phi=0.7$, (b) 0.8 , (c) 1.2, and (d) 1.4 in methane/ethylene-air premixed flames for normal temperature and pressure. Data was acquired in the range of $13.0 \leq R_{\mathrm{f}} \leq 31.0 \mathrm{~mm}$. 

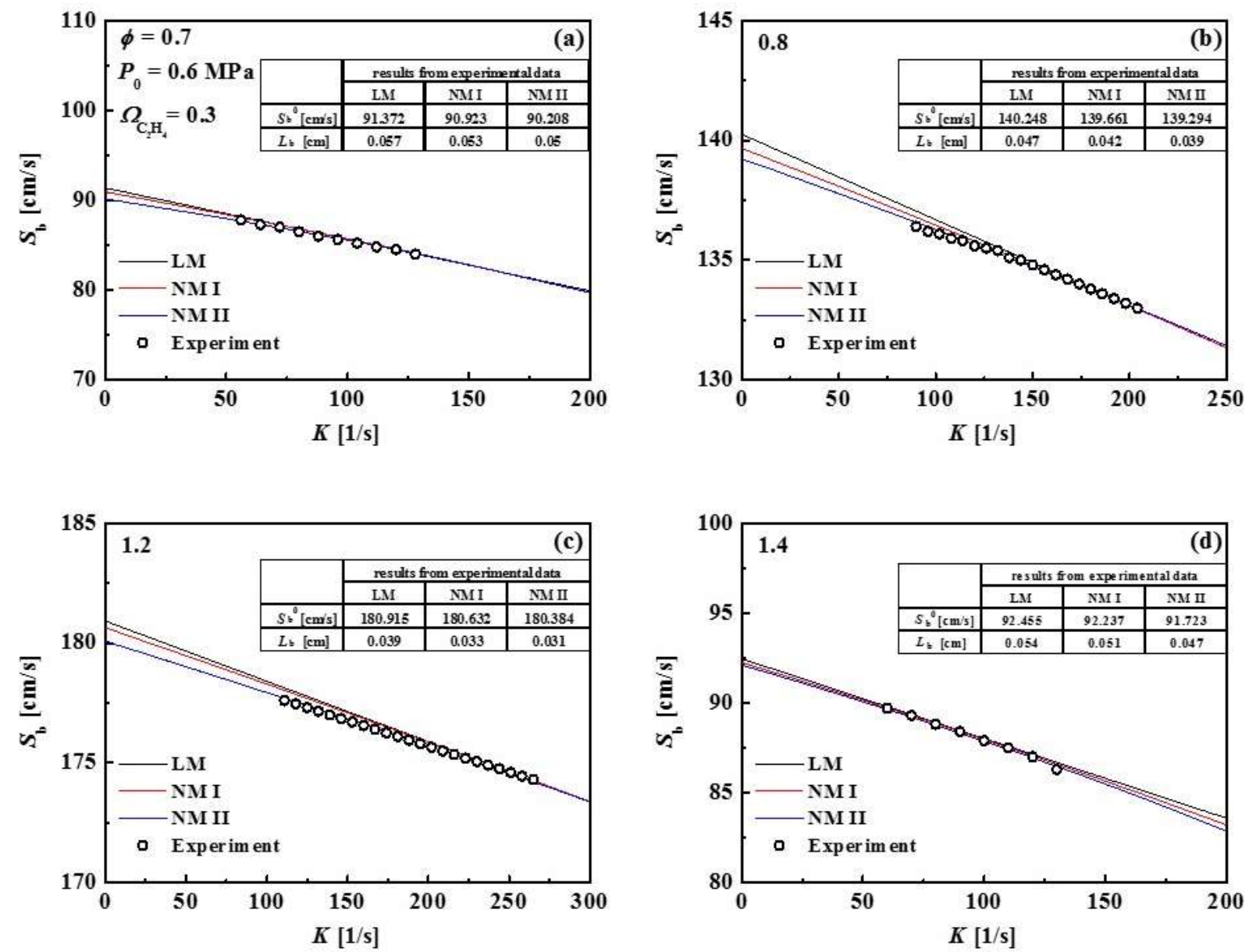

Fig. S8. Flame speed versus flame stretch for (a) $\phi=0.7$, (b) 0.8 , (c) 1.2 , and (d) 1.4 in methane/ethylene-air premixed flames at $0.6 \mathrm{MPa}$ for normal temperature. Data was acquired in the range of $13.0 \leq R_{\mathrm{f}} \leq 31.0 \mathrm{~mm}$.

Table S2. Deviation between measured and predicted unstretched laminar burning velocities in $\mathrm{CH}_{4} / \mathrm{C}_{2} \mathrm{H}_{4}-$ air premixed flames $\Omega_{\mathrm{C}_{2} \mathrm{H}_{4}}=0.3$ ) for $P_{0}=0.1,0.4$, and $0.6 \mathrm{MPa}$. (Numbers denote the deviation (\%) of numerical result from the experimental result).

Table S2. Deviation between measured and predicted unstretched laminar burning velocities in $\mathrm{CH}_{4} / \mathrm{C}_{2} \mathrm{H}_{4}-$ air premixed flames for $P_{0}=0.1,0.4$, and $0.6 \mathrm{MPa}$. (Numbers denote the deviation (\%) of numerical result from the experimental result).

\begin{tabular}{|c|c|c|c|c|c|c|c|c|c|c|c|c|}
\hline \multirow{2}{*}{$\phi$} & \multicolumn{3}{|c|}{ Aramco 2.0} & \multicolumn{3}{|c|}{ GRI 3.0} & \multicolumn{3}{|c|}{ Sung Mech } & \multicolumn{3}{|c|}{ USC II } \\
\hline & $\begin{array}{c}0.1 \\
\mathrm{MPa}\end{array}$ & $\begin{array}{c}0.4 \\
\mathrm{MPa}\end{array}$ & $\begin{array}{c}0.6 \\
\mathrm{MPa} \\
\end{array}$ & $\begin{array}{c}0.1 \\
\mathrm{MPa}\end{array}$ & $\begin{array}{c}0.4 \\
\mathrm{MPa}\end{array}$ & $\begin{array}{c}0.6 \\
\mathrm{MPa}\end{array}$ & $\begin{array}{c}0.1 \\
\mathrm{MPa} \\
\end{array}$ & $\begin{array}{c}0.4 \\
\mathrm{MPa}\end{array}$ & $\begin{array}{c}0.6 \\
\mathrm{MPa} \\
\end{array}$ & $\begin{array}{c}0.1 \\
\mathrm{MPa} \\
\end{array}$ & $\begin{array}{c}0.4 \\
\mathrm{MPa} \\
\end{array}$ & $\begin{array}{c}0.6 \\
\mathrm{MPa} \\
\end{array}$ \\
\hline 0.7 & 2.98 & 0.35 & 2.76 & 15.51 & 7.76 & 5.03 & 3.99 & 15.43 & 22.90 & 7.62 & 9.28 & 9.50 \\
\hline 0.8 & 3.20 & 5.35 & 1.48 & 15.96 & 13.30 & 9.62 & 2.70 & 2.32 & 7.75 & 0.12 & 7.38 & 7.22 \\
\hline 0.9 & 3.76 & 2.34 & 1.19 & 16.56 & 11.21 & 6.99 & 5.27 & 0.53 & 5.07 & 3.07 & 1.83 & 0.06 \\
\hline 1 & 2.67 & 0.73 & 0.14 & 16.43 & 11.77 & 9.83 & 6.34 & 2.86 & 0.84 & 0.42 & 2.88 & 3.42 \\
\hline 1.1 & 3.35 & 3.87 & 3.18 & 17.44 & 9.07 & 15.06 & 8.25 & 0.52 & 5.67 & 1.84 & 10.18 & 2.99 \\
\hline 1.2 & 2.81 & 2.67 & 3.09 & 18.19 & 15.62 & 11.15 & 8.83 & 6.60 & 0.44 & 2.77 & 6.49 & 11.43 \\
\hline 1.3 & 0.20 & 0.39 & 4.84 & 16.51 & 11.90 & 6.67 & 8.70 & 2.58 & 5.23 & 5.75 & 10.14 & 16.22 \\
\hline 1.4 & 4.38 & 8.04 & 5.74 & 13.86 & 9.84 & 16.62 & 3.82 & 3.49 & 1.83 & 8.64 & 12.71 & 5.84 \\
\hline
\end{tabular}

Table S3. Heat-release-rate- and volume-weighted effective Lewis numbers $\left(\mathrm{Le}_{\mathrm{q}}\right.$, Le $\left.\mathrm{V}\right)$, constant and temperaturedependent Zel'dovich numbers $\left(\beta_{\text {const }}, \beta_{\mathrm{T}}\right)$, thermal expansion ratio $(\sigma)$ used in predicting Markstein lengths in $\mathrm{CH}_{4} / \mathrm{C}_{2} \mathrm{H}_{4}-$ air premixed flames at various equivalence ratios.

\begin{tabular}{|c|c|c|c|c|c|c|c|c|c|c|}
\hline \multirow{2}{*}{$\phi$} & \multicolumn{9}{|c|}{$\Omega_{\mathrm{C}_{2} \mathrm{H}_{4}}=0$} & \multicolumn{5}{c|}{0.1} \\
\cline { 2 - 23 } & $\mathrm{Le}_{\mathrm{q}}$ & $\mathrm{Le}_{\mathrm{V}}$ & $\beta_{\mathrm{T}}$ & $\beta_{\text {const }}$ & $\sigma$ & Le $_{\mathrm{q}}$ & Le $_{\mathrm{V}}$ & $\beta_{\mathrm{T}}$ & $\beta_{\text {const }}$ & $\sigma .26$ \\
\hline 0.7 & 1.007 & 1.008 & 11.55 & 14.64 & 6.17 & 1.056 & 1.057 & 11.41 & 13.94 & 6.80 \\
\hline 0.8 & 1.013 & 1.014 & 10.79 & 13.67 & 6.71 & 1.057 & 1.058 & 10.66 & 13.03 & 6 \\
\hline
\end{tabular}




\begin{tabular}{|c|c|c|c|c|c|c|c|c|c|c|}
\hline 0.9 & 1.022 & 1.023 & 10.20 & 12.93 & 7.20 & 1.059 & 1.059 & 10.09 & 12.33 & 7.29 \\
\hline 1.0 & 1.037 & 1.037 & 9.84 & 12.47 & 7.54 & 1.061 & 1.061 & 9.76 & 11.93 & 7.61 \\
\hline 1.1 & 1.050 & 1.049 & 9.88 & 12.53 & 7.61 & 1.063 & 1.062 & 9.77 & 11.94 & 7.71 \\
\hline 1.2 & 1.057 & 1.057 & 10.19 & 12.92 & 7.45 & 1.063 & 1.063 & 10.07 & 12.31 & 7.57 \\
\hline 1.3 & 1.063 & 1.062 & 10.53 & 13.35 & 7.30 & 1,064 & 1.064 & 10.37 & 12.67 & 7.43 \\
\hline 1.4 & 1.066 & 1.065 & 10.91 & 13.83 & 7.13 & 1.064 & 1.064 & 10.71 & 13.09 & 7.30 \\
\hline \multirow{9}{*}{$\phi$} & \multicolumn{9}{|c|}{0.2} & \multicolumn{7}{|c|}{0.3} \\
\cline { 2 - 12 } & $\mathrm{Le}_{\mathrm{q}}$ & $\mathrm{Le}_{\mathrm{V}}$ & $\beta_{\mathrm{T}}$ & $\beta_{\text {const }}$ & $\sigma$ & $\mathrm{Le}_{\mathrm{q}}$ & $\mathrm{Le}_{\mathrm{V}}$ & $\beta_{\mathrm{T}}$ & $\beta_{\text {const }}$ & $\sigma$ \\
\hline 0.7 & 1.099 & 1.098 & 11.12 & 13.27 & 6.34 & 1.135 & 1.133 & 11.16 & 12.60 & 6.42 \\
\hline 0.8 & 1.094 & 1.094 & 10.41 & 12.42 & 6.88 & 1.126 & 1.124 & 10.47 & 11.82 & 6.69 \\
\hline 0.9 & 1.089 & 1.088 & 9.83 & 11.74 & 7.38 & 1.116 & 1.113 & 9.89 & 11.18 & 7.46 \\
\hline 1.0 & 1.081 & 1.081 & 9.54 & 11.38 & 7.69 & 1.098 & 1.098 & 9.61 & 10.86 & 7.75 \\
\hline 1.1 & 1.073 & 1.074 & 9.53 & 11.37 & 7.80 & 1.081 & 1.081 & 9.59 & 10.83 & 7.88 \\
\hline 1.2 & 1.068 & 1.069 & 9.80 & 11.70 & 7.67 & 1.071 & 1.071 & 9.84 & 11.12 & 7.77 \\
\hline 1.3 & 1.065 & 1.066 & 10.09 & 12.04 & 7.55 & 1.065 & 1.065 & 10.11 & 11.42 & 7.67 \\
\hline 1.4 & 1.064 & 1.064 & 10.40 & 12.41 & 7.43 & 1.061 & 1.061 & 10.41 & 11.76 & 7.55 \\
\hline
\end{tabular}

The theoretical Markstein lengths were first compared with measured ones for $\mathrm{CH}_{4}$-air premixed flames in Figs. S9-S13 (SM) at normal pressure. For better understanding, the raw data of Markstein length used in Figs. S9-S13 for 0.1 MPa were and those of Markstein number in Fig. S14 for 0.1, 0.2, 0.4 and 0.6 MPa were presented in Table S4. The non-dimensional thermal conductivity was tested for $\lambda(x)=1$ and $x$, and the two different definitions for flame thickness, $\delta_{\mathrm{f}}^{0}=\left(\lambda / c_{\mathrm{p}}\right) /\left(\rho_{u} S_{u}^{0}\right)$ and $\delta_{\mathrm{f}}^{0}=\left(T_{\mathrm{b}}-T_{\mathrm{u}}\right) /(\partial T / \partial x)_{\max }$ were tested, respectively. Four iso-temperatures was taken as the flame front to compare the theoretical Markstein lengths with the measured ones. Because the present study adopt the Schlieren imaging, $600 \mathrm{~K}$ was taken approximately as the Schlieren boundary [36]. Here, the heat-release-rate weighted effective Lewis number and the Zel'dovich number with the temperature-dependent activation energy were used to obtain theoretical Markstein lengths. The results show that the theoretical Markstein lengths vary from negative to positive values in terms of the iostemperature surface taken, similarly to previous results [56], emphasizing the strong dependence of selected flame front on Markstein length. As the selected iso-temperature surface approaches to the burnt zone, the Markstein length increases. The theoretical Markstein lengths better trace measured data for $\lambda(x)=x$ (Figs. $\mathrm{S} 10$ and S12), while these underpredict the present measured data for $\lambda(x)=1$ (Figs. S9 and S11). In Figs. S10 and S12, the theoretic Markstein lengths with $\delta_{\mathrm{f}}^{0}=\left(\lambda / c_{\mathrm{p}}\right) /\left(\rho_{u} S_{u}^{0}\right)$ are slightly larger than those with $\delta_{\mathrm{f}}^{0}=$ $\left(T_{\mathrm{b}}-T_{\mathrm{u}}\right) /(\partial T / \partial x)_{\max }$, while the theoretic Markstein lengths with $\delta_{\mathrm{f}}^{0}=\left(T_{\mathrm{b}}-T_{\mathrm{u}}\right) /(\partial T / \partial x)_{\max }$ better traces the measured data at high pressures. For $\lambda(x)=x$, when the iso-temperature is larger than $1100 \mathrm{~K}$, the Markstein length changes little. With $600 \mathrm{~K}$ (estimated to be the temperature of Schlieren boundary [36]) in Figs. S10 and S12, the theoretical Markstein lengths with $\delta_{\mathrm{f}}^{0}=\left(\lambda / c_{\mathrm{p}}\right) /\left(\rho_{u} S_{u}^{\mathrm{o}}\right)$ better traces in comparison with those with $\left(T_{\mathrm{b}}-T_{\mathrm{u}}\right) /(\partial T / \partial x)_{\max }$ while the theoretical Markstein lengths with $\delta_{\mathrm{f}}^{0}=\left(T_{\mathrm{b}}-T_{\mathrm{u}}\right) /(\partial T / \partial x)_{\max }$ are less sensitive to the choice of the iso-temperature of flame front $(\geq 600 \mathrm{~K})$ and overall better trace the measured data at high pressures.

Table S4. Measured Markstein length and number against equivalence ratio in a CH4-air premixed flame for $P_{0}=0.1,0.2$, 0.4 and $0.6 \mathrm{MPa}$. Here, the Markstein numbers using different definitions of flame thicknesses $\delta_{\mathrm{f}}^{0}=\left(\lambda / c_{\mathrm{p}}\right) /\left(\rho_{u} S_{u}^{0}\right)$ and $\left(T_{\mathrm{b}}-T_{\mathrm{u}}\right) /(\partial T / \partial x)_{\max }$ were presented. The latter was expressed as numbers in the parenthesis. 


\begin{tabular}{|c|c|c|c|c|c|c|c|c|}
\hline \multirow{2}{*}{$\phi$} & \multicolumn{2}{|c|}{$0.1 \mathrm{MPa}$} & \multicolumn{2}{c|}{$0.2 \mathrm{MPa}$} & \multicolumn{2}{c|}{$0.4 \mathrm{MPa}$} & \multicolumn{2}{c|}{$0.6 \mathrm{MPa}$} \\
\cline { 2 - 9 } & $\begin{array}{c}\text { Markstein } \\
\text { length (cm) }\end{array}$ & $\begin{array}{c}\text { Markstein } \\
\text { number }\end{array}$ & $\begin{array}{c}\text { Markstein } \\
\text { length (cm) }\end{array}$ & $\begin{array}{c}\text { Markstein } \\
\text { number }\end{array}$ & $\begin{array}{c}\text { Markstein } \\
\text { length } \\
(\mathrm{cm})\end{array}$ & $\begin{array}{c}\text { Markstein } \\
\text { number }\end{array}$ & $\begin{array}{c}\text { Markstein } \\
\text { length (cm) }\end{array}$ & $\begin{array}{c}\text { Markstein } \\
\text { number }\end{array}$ \\
\hline 0.7 & 0.043 & $\begin{array}{c}3.543 \\
(6.471)\end{array}$ & 0.025 & $\begin{array}{c}2.052 \\
(3.748)\end{array}$ & 0.023 & $\begin{array}{c}1.905 \\
(3.479)\end{array}$ & 0.019 & $\begin{array}{c}1.567 \\
(2.863)\end{array}$ \\
\hline 0.8 & 0.055 & $\begin{array}{c}6.506 \\
(10.665)\end{array}$ & 0.029 & $\begin{array}{c}3.468 \\
(5.684)\end{array}$ & 0.025 & $\begin{array}{c}2.917 \\
(4.781)\end{array}$ & 0.020 & $\begin{array}{c}2.342 \\
(3.840)\end{array}$ \\
\hline 0.9 & 0.064 & $\begin{array}{c}9.520 \\
(14.551)\end{array}$ & 0.033 & $\begin{array}{c}4.852 \\
(7.416)\end{array}$ & 0.027 & $\begin{array}{c}3.964 \\
(6.060)\end{array}$ & 0.022 & $\begin{array}{c}3.230 \\
(4.937)\end{array}$ \\
\hline 1 & 0.065 & $\begin{array}{c}10.775 \\
(15.499)\end{array}$ & 0.034 & $\begin{array}{c}5.703 \\
(8.202)\end{array}$ & 0.029 & $\begin{array}{c}4.854 \\
(6.982)\end{array}$ & 0.024 & $\begin{array}{c}3.932 \\
(5.656)\end{array}$ \\
\hline 1.1 & 0.071 & $\begin{array}{c}12.331 \\
(17.927)\end{array}$ & 0.040 & $\begin{array}{c}6.876 \\
(9.997)\end{array}$ & 0.034 & $\begin{array}{c}5.935 \\
(8.629)\end{array}$ & 0.028 & $\begin{array}{c}4.771 \\
(6.937)\end{array}$ \\
\hline 1.2 & 0.087 & $\begin{array}{c}13.196 \\
(20.575)\end{array}$ & 0.051 & $\begin{array}{c}7.797 \\
(12.156)\end{array}$ & 0.042 & $\begin{array}{c}6.406 \\
(9.988)\end{array}$ & $\begin{array}{c}0.033 \\
(7.707)\end{array}$ \\
\hline 1.3 & 0.118 & $\begin{array}{c}13.359 \\
(20.526)\end{array}$ & 0.067 & $\begin{array}{c}7.646 \\
(11.748)\end{array}$ & 0.057 & $\begin{array}{c}6.484 \\
(9.963)\end{array}$ & $\begin{array}{c}4.943 \\
(7.049\end{array}$ \\
\hline 1.4 & 0.188 & $\begin{array}{c}12.243 \\
(20.968)\end{array}$ & 0.113 & $\begin{array}{c}7.400 \\
(12.673)\end{array}$ & 0.086 & $\begin{array}{c}5.584 \\
(9.562)\end{array}$ & $\begin{array}{c}5.522 \\
(8.484)\end{array}$ \\
\hline
\end{tabular}

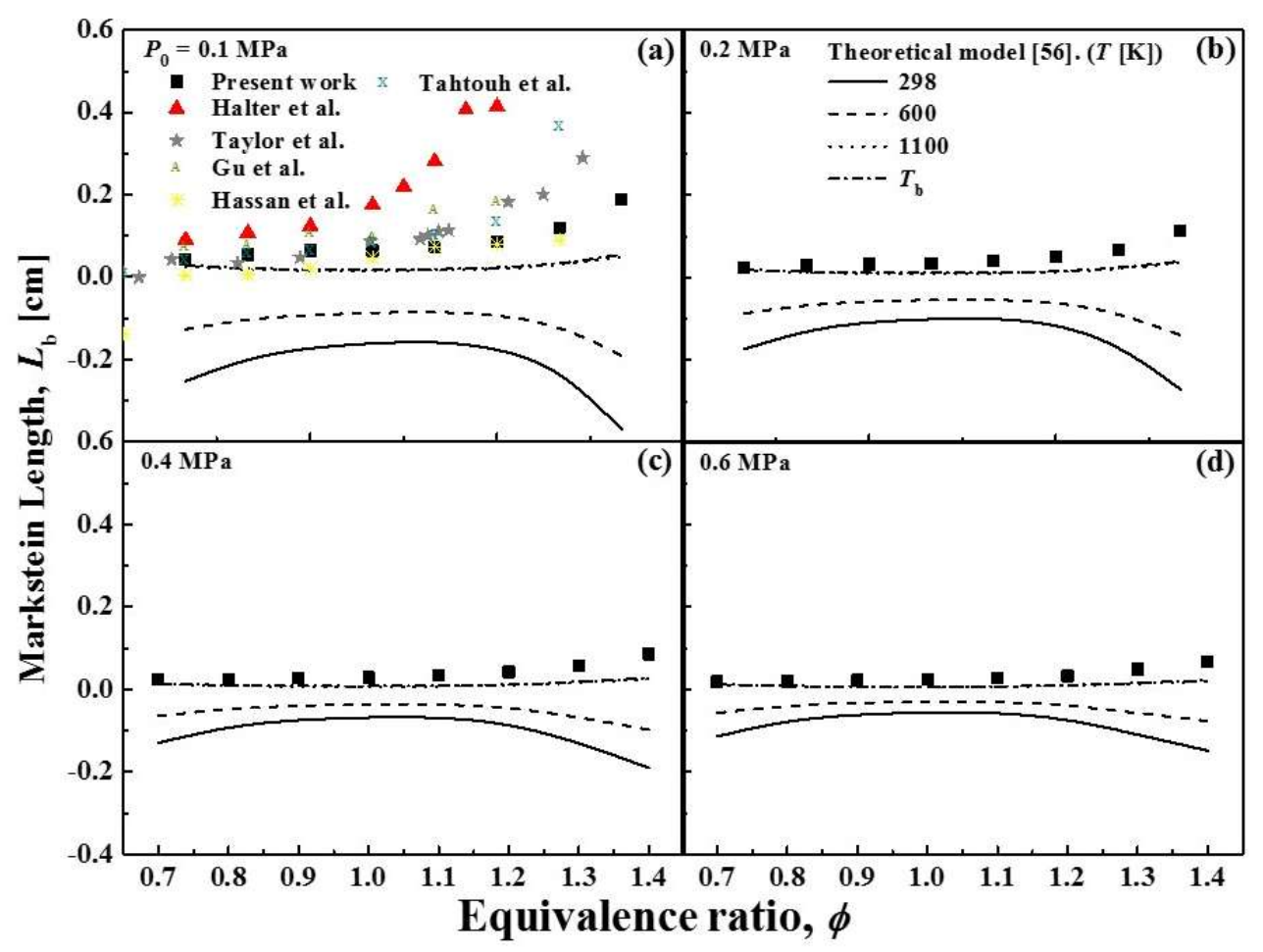

Fig. S9. Measured and predicted Markstein lengths against equivalence ratio in a $\mathrm{CH}_{4}$-air premixed flame. Here $\lambda(x)=$ 1 and the flame thickness was calculated by $\delta_{\mathrm{f}}^{0}=\left(\lambda / c_{\mathrm{p}}\right) /\left(\rho_{u} S_{u}^{0}\right)$. 


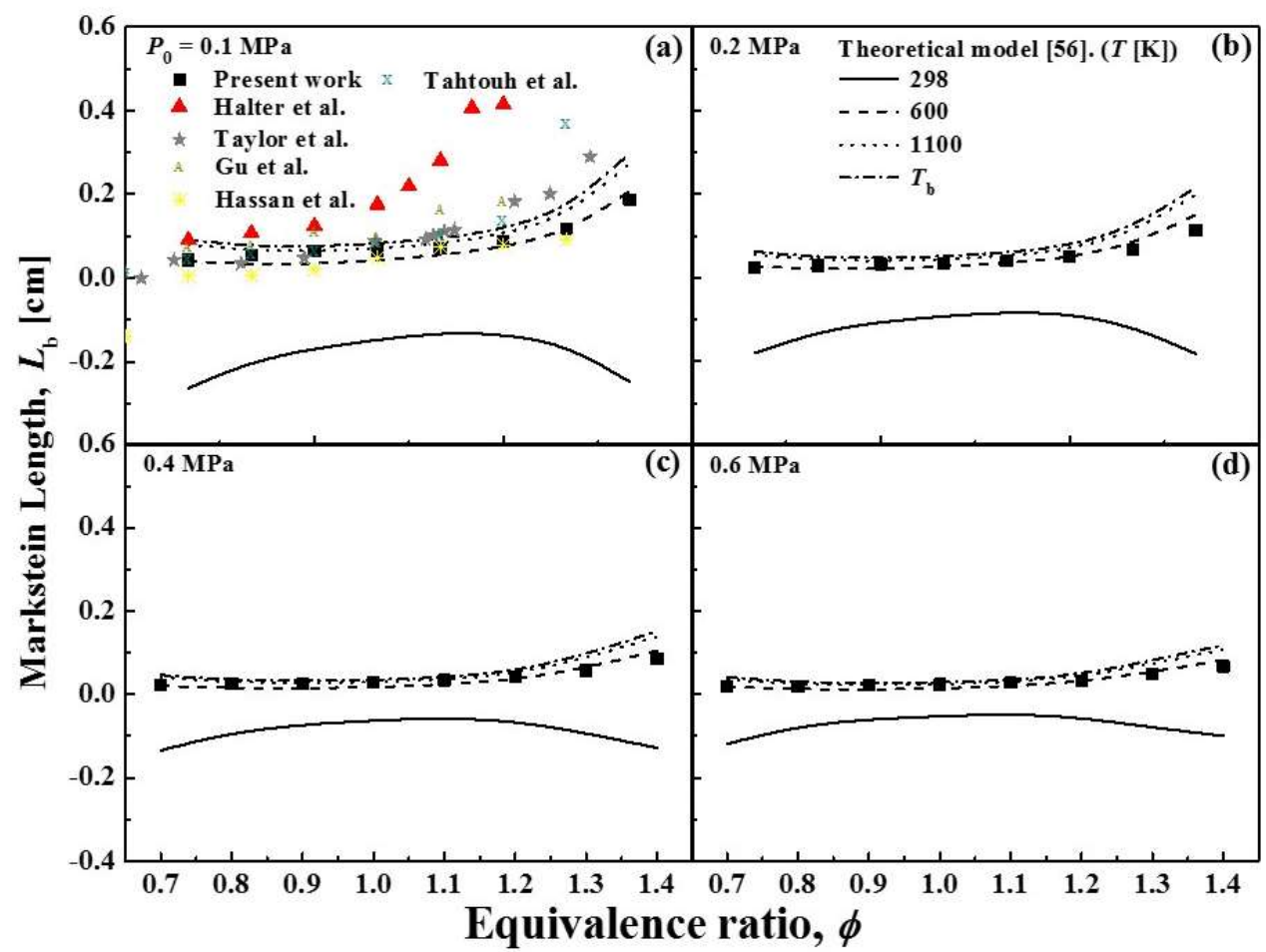

Fig. S10. Measured and predicted Markstein lengths against equivalence ratio in a $\mathrm{CH}_{4}$-air premixed flame. Here $\lambda(x)=$ $x$ and the flame thickness was calculated by $\delta_{\mathrm{f}}^{0}=\left(\lambda / c_{\mathrm{p}}\right) /\left(\rho_{u} S_{u}^{o}\right)$.

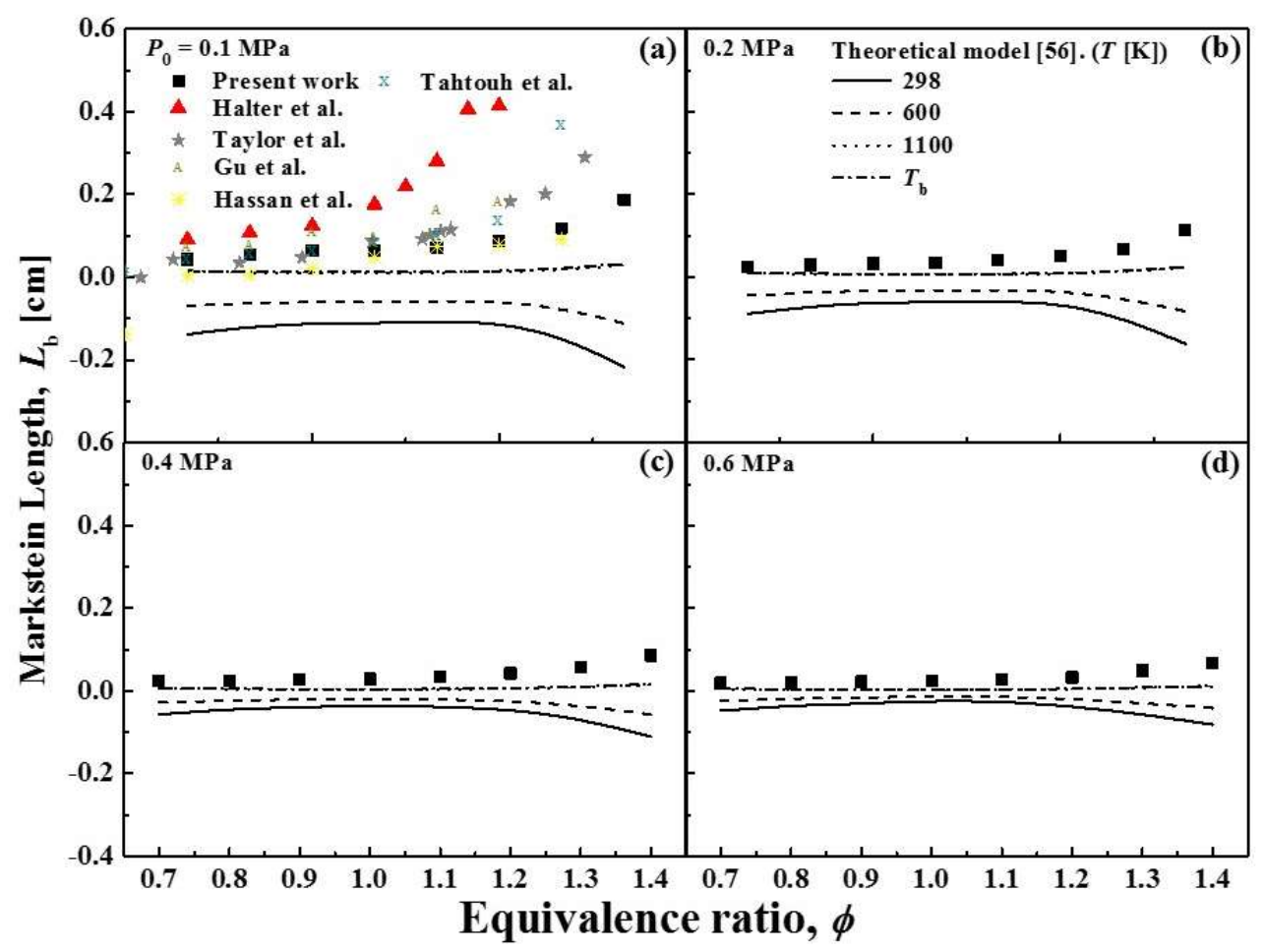

Fig. S11. Measured and predicted Markstein lengths against equivalence ratio in a $\mathrm{CH}_{4}$-air premixed flame. Here $\lambda(x)=$ 1 and the flame thickness was calculated by $\delta_{\mathrm{f}}^{0}=\left(T_{\mathrm{b}}-T_{\mathrm{u}}\right) /(\partial T / \partial x)_{\max }$. 


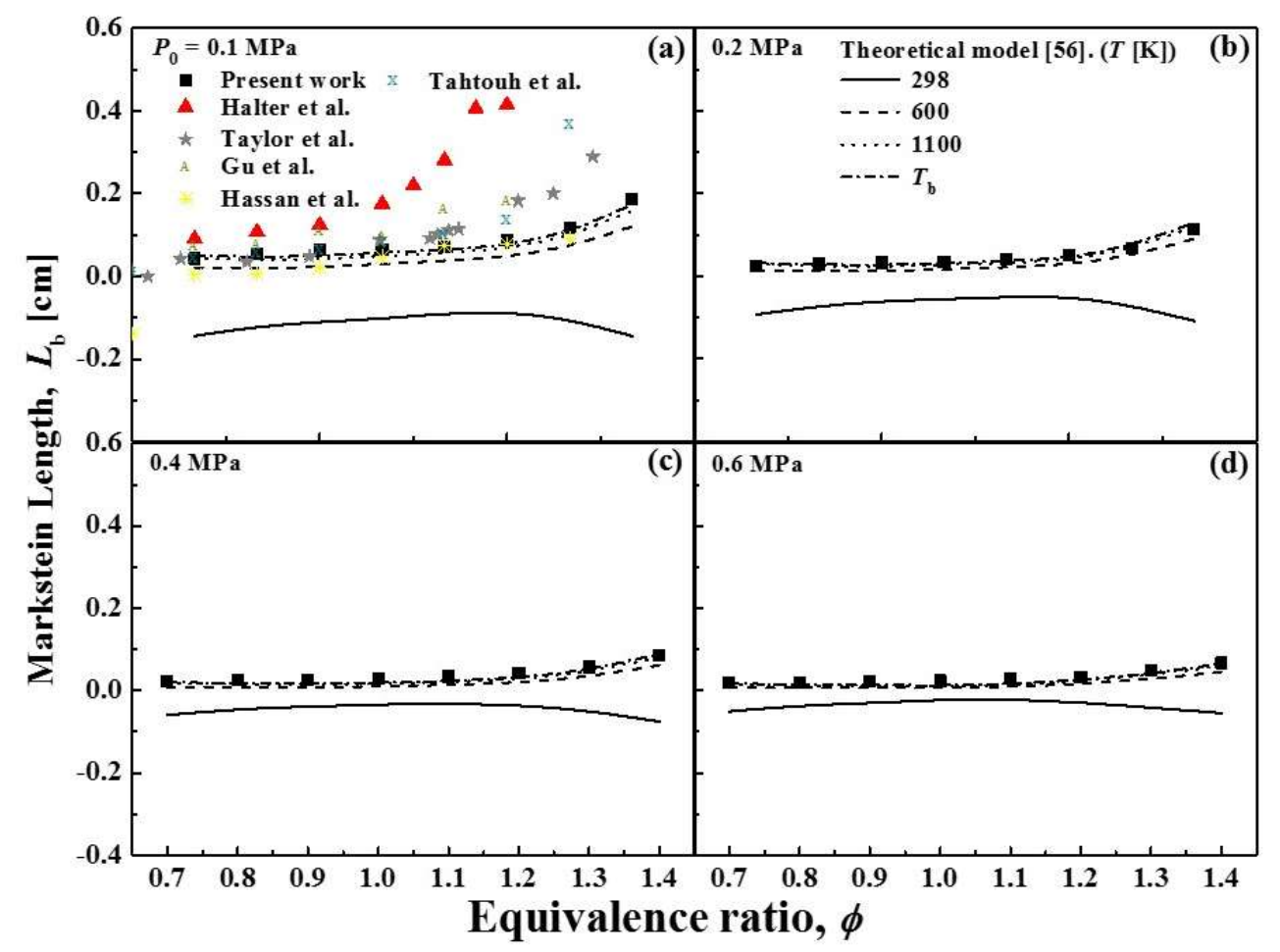

Fig. S12. Measured and predicted Markstein lengths against equivalence ratio in a $\mathrm{CH}_{4}$-air premixed flame. Here $\lambda(x)=$ $x$ and the flame thickness was calculated by $\delta_{\mathrm{f}}^{0}=\left(T_{\mathrm{b}}-T_{\mathrm{u}}\right) /(\partial T / \partial x)_{\max }$.

The effect of using different effective Lewis numbers $\left(\mathrm{Le}_{\mathrm{q}}, \mathrm{Le}_{\mathrm{v}}\right)$ on Markstein length is tested in terms of ambient pressures in Fig. $\mathrm{S} 13$ for $\mathrm{CH}_{4}$-air premixed flame. The results show that the effects are minor at normal and elevated pressures (up to $0.6 \mathrm{MPa}$ ).

Measured and predicted Markstein numbers against equivalence ratio were compared in terms of ambient pressure in Fig. S14 for $\mathrm{CH}_{4}$-air premixed flames with $\lambda(x)=x$ for $\delta_{\mathrm{f}}^{0}=\left(\lambda / c_{\mathrm{p}}\right) /\left(\rho_{u} S_{u}^{\mathrm{o}}\right) \quad$ (a) and $\left(T_{\mathrm{b}}-\right.$ $\left.T_{\mathrm{u}}\right) /(\partial T / \partial x)_{\max }(\mathrm{b})$. Here, the flame thicknesses are given later in Figs. S15 and S16. For the theoretical Markstein lengths, the temperature-dependent Zel'dovich number and the heat-release-weighted Lewis number are used. Overall, the tendency of theoretical Markstein length versus equivalence ratio better traces the measured ones when the definition of flame thickness is used as $\left(T_{\mathrm{b}}-T_{\mathrm{u}}\right) /(\partial T / \partial x)_{\max }$. The measured Markstein number decreases appreciably (slightly) when the ambient pressure varies from 0.1(0.2) to $0.2(0.6) \mathrm{MPa}$. While the theoretical Markstein numbers are not influenced by ambient pressure. When the isotemperature is larger than $1100 \mathrm{~K}$, the Markstein length varies only a little. 


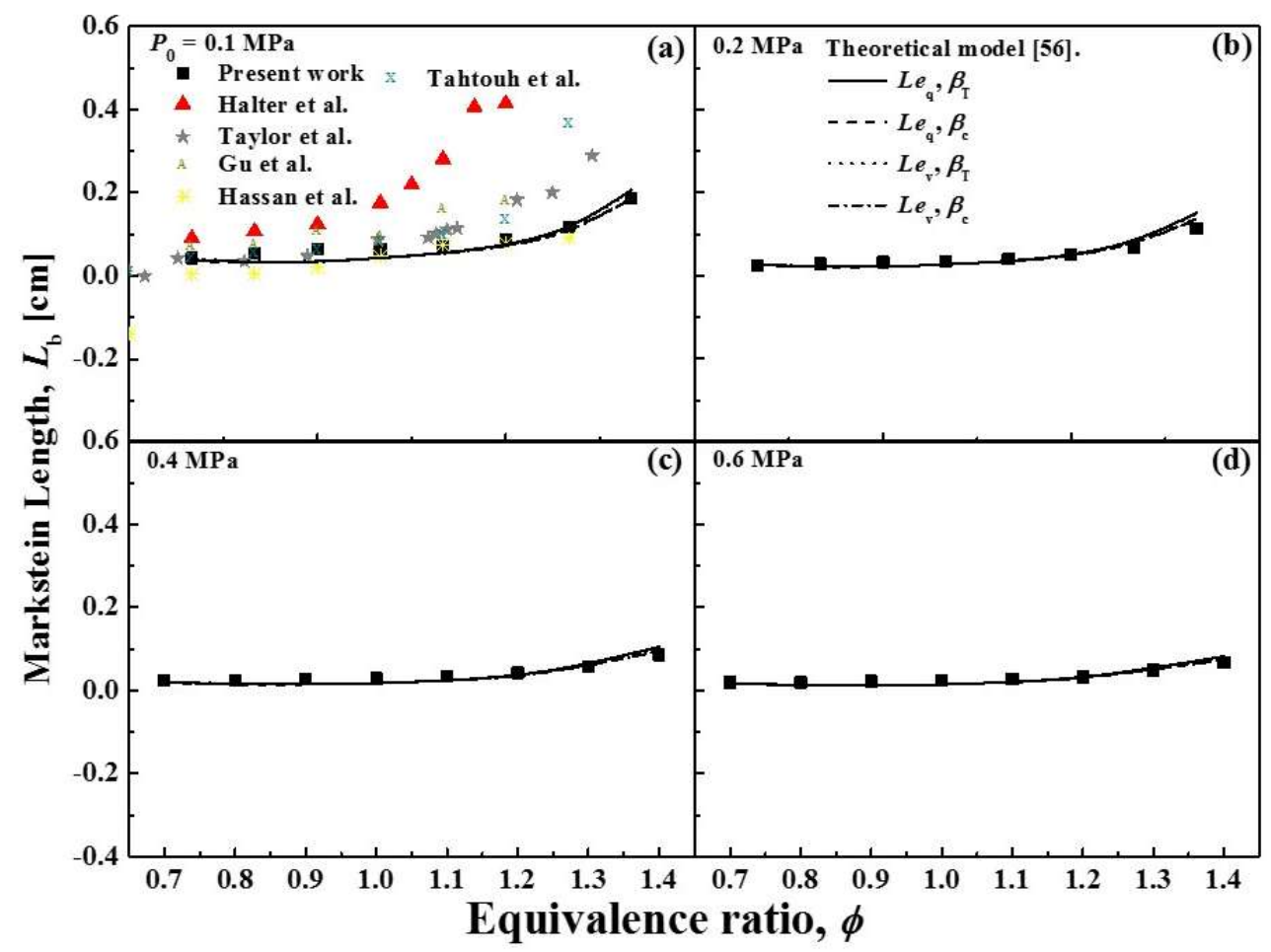

Fig. S13. Measured and predicted Markstein lengths against equivalence ratio in a $\mathrm{CH}_{4}$-air premixed flame. Here $\lambda(x)=$ $x$ and the flame thickness was calculated by $\delta_{\mathrm{f}}^{0}=\left(\lambda / c_{\mathrm{p}}\right) /\left(\rho_{u} S_{u}^{\mathrm{o}}\right)$.

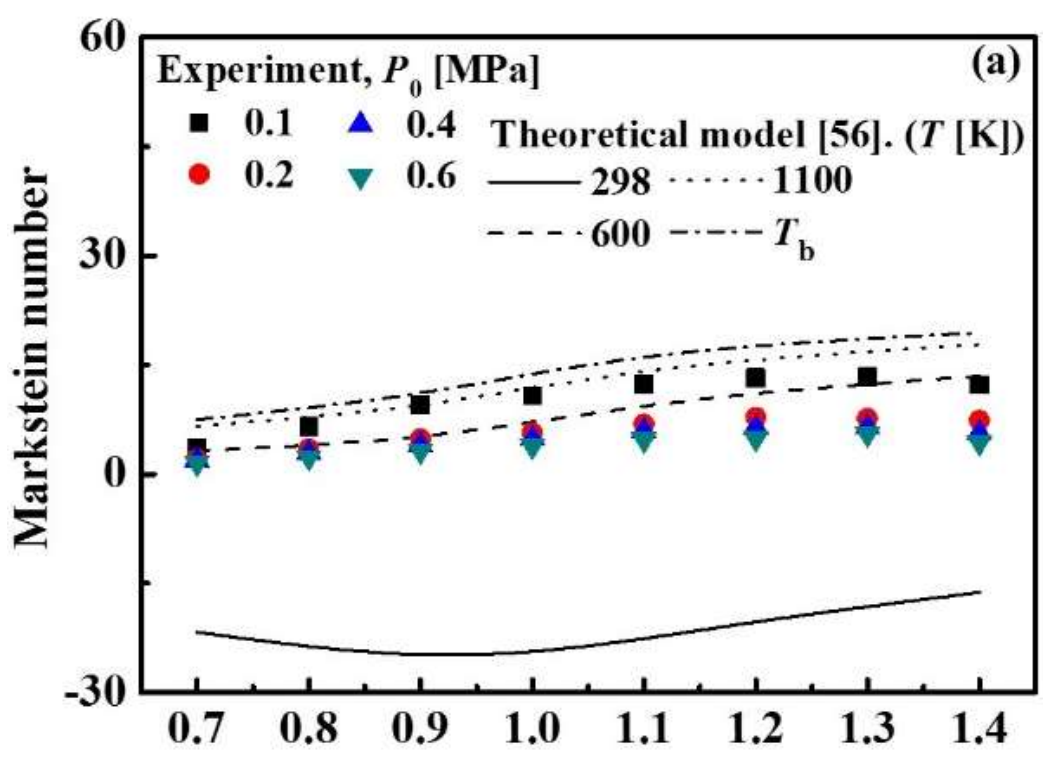




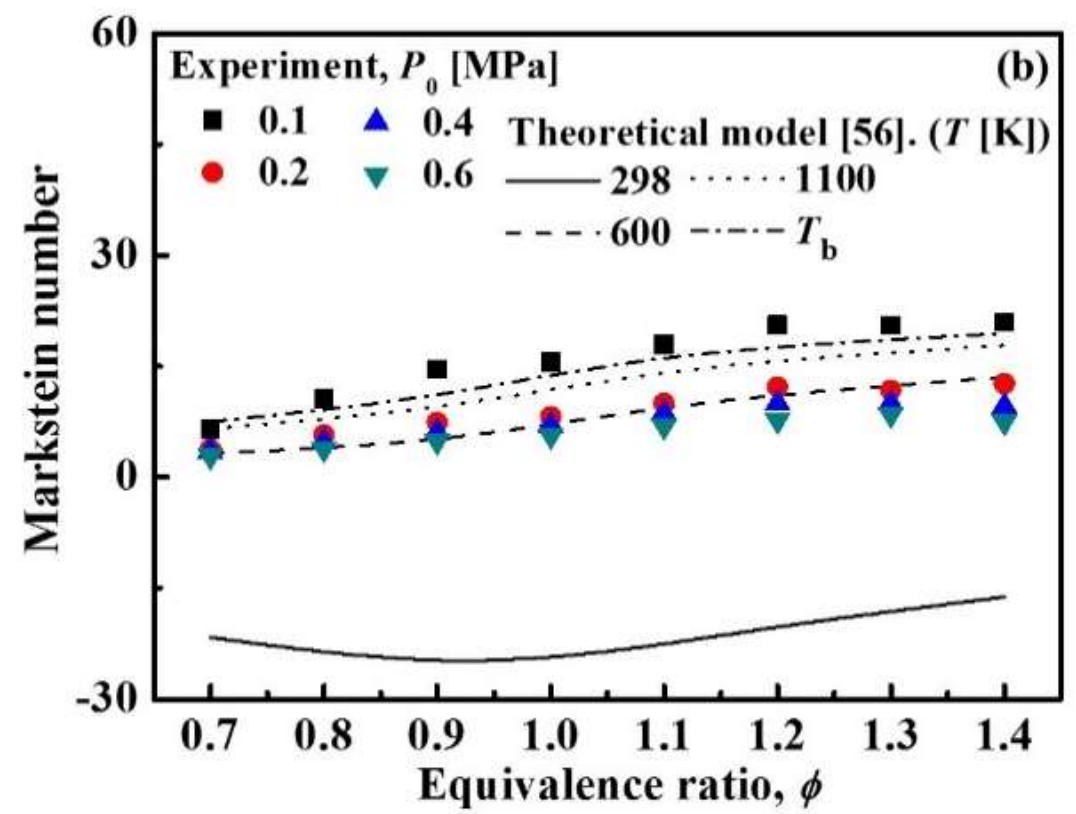

Fig. S14. Measured and predicted Markstein numbers against equivalence ratio in terms of ambient pressure in a $\mathrm{CH}_{4}-$ air premixed flame with $\lambda(x)=x$ for $(\mathrm{a}) \delta_{\mathrm{f}}^{0}=\left(\lambda / c_{\mathrm{p}}\right) /\left(\rho_{u} S_{u}^{\mathrm{o}}\right)$ and $(\mathrm{b})\left(T_{\mathrm{b}}-T_{\mathrm{u}}\right) /(\partial T / \partial x)_{\max }$.

As shown in Figs. S15 and S16, both flame thicknesses, $\delta_{\mathrm{f}}^{0}=\left(\lambda / c_{\mathrm{p}}\right) /\left(\rho_{u} S_{u}^{\mathrm{o}}\right)$ and $\left(T_{\mathrm{b}}-T_{\mathrm{u}}\right) /(\partial T / \partial x)_{\max }$ decreased and then increased with the equivalence ratio for all chamber pressures, whereas it decreased with an increase in pressure. While the values with $\delta_{\mathrm{f}}^{0}=\left(T_{\mathrm{b}}-T_{\mathrm{u}}\right) /(\partial T / \partial x)_{\max }$ are somehow smaller than $\delta_{\mathrm{f}}^{0}=$ $\left(\lambda / c_{\mathrm{p}}\right) /\left(\rho_{u} S_{u}^{o}\right)$. Note that the flame thicknesses for $\mathrm{CH}_{4} / \mathrm{C}_{2} \mathrm{H}_{4}$-air premixed flames with an ethylene ratio of $\Omega_{\mathrm{C}_{2} \mathrm{H}_{4}}$ were thinner than those for $\mathrm{CH}_{4}$-air premixed flames, due to the increases in laminar burning velocity, as discussed in Section 3.2.

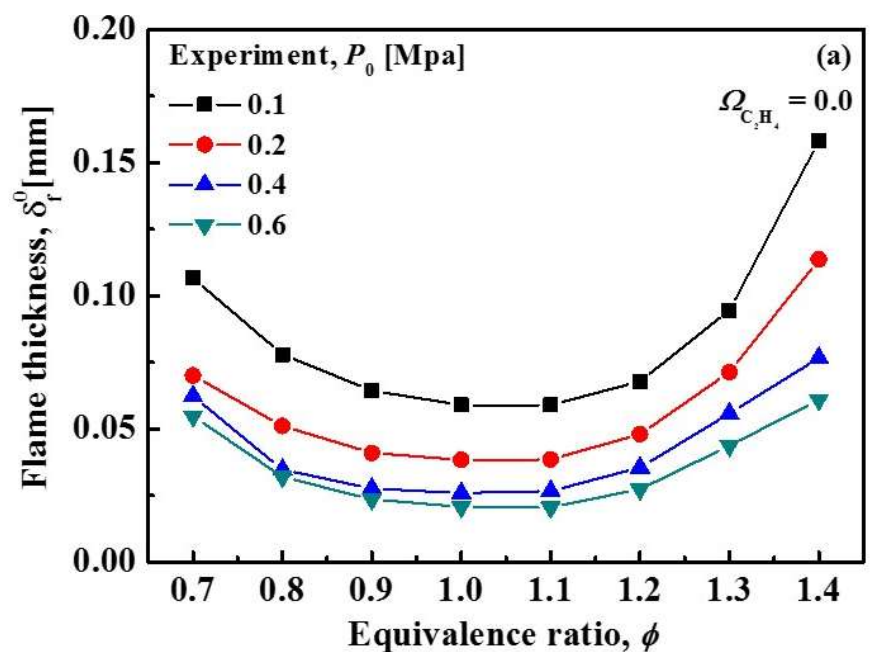



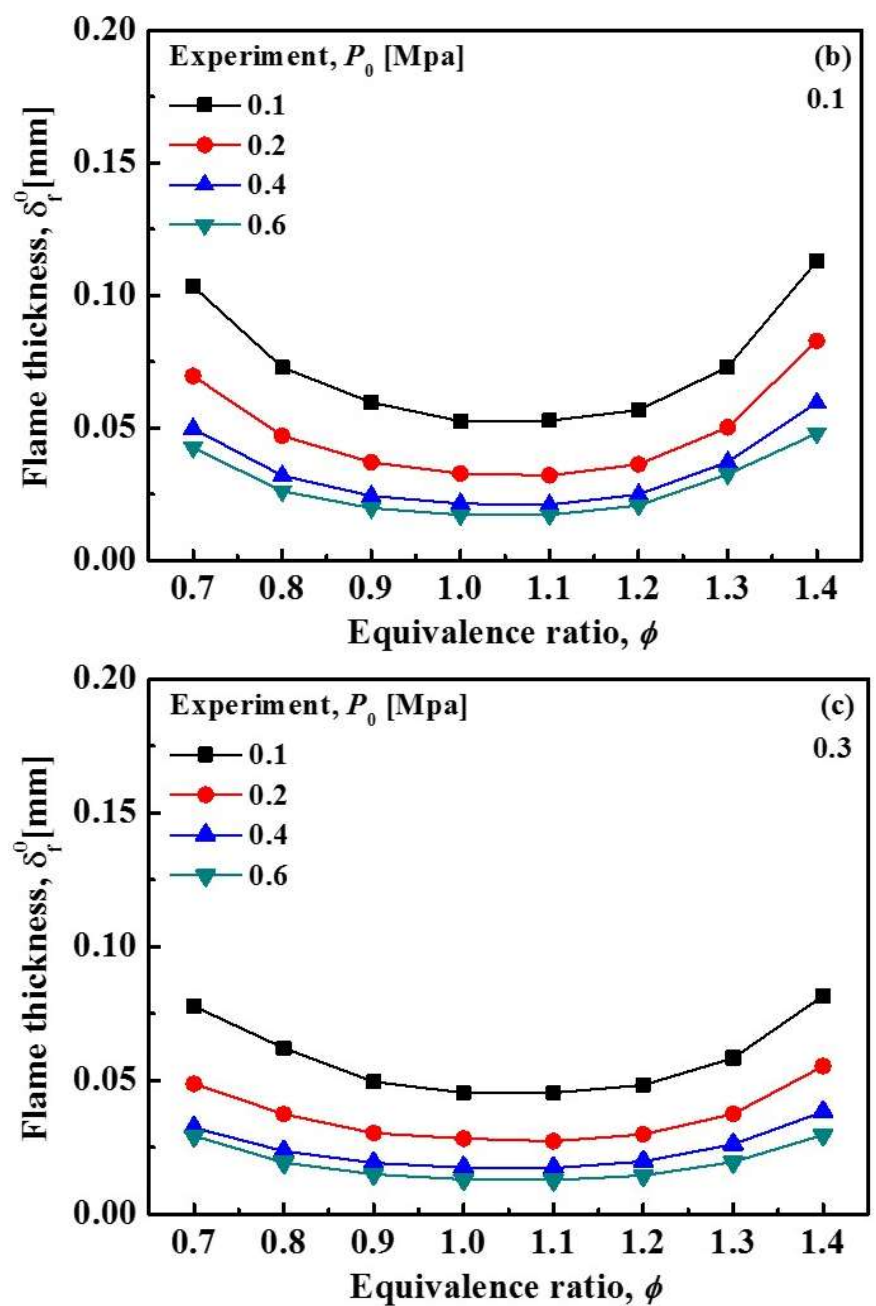

Fig. S15. Calculated flame thickness against equivalence ratio in $\mathrm{CH}_{4} / \mathrm{C}_{2} \mathrm{H}_{4}$-air premixed flames with (a) $\Omega_{\mathrm{C}_{2} \mathrm{H}_{4}}=0$, (b) 0.1 , and (c) 0.3 at several chamber pressures. Here the flame thickness was used with $\delta_{\mathrm{f}}^{0}=\left(\lambda / c_{\mathrm{p}}\right) /\left(\rho_{u} S_{u}^{o}\right)$.

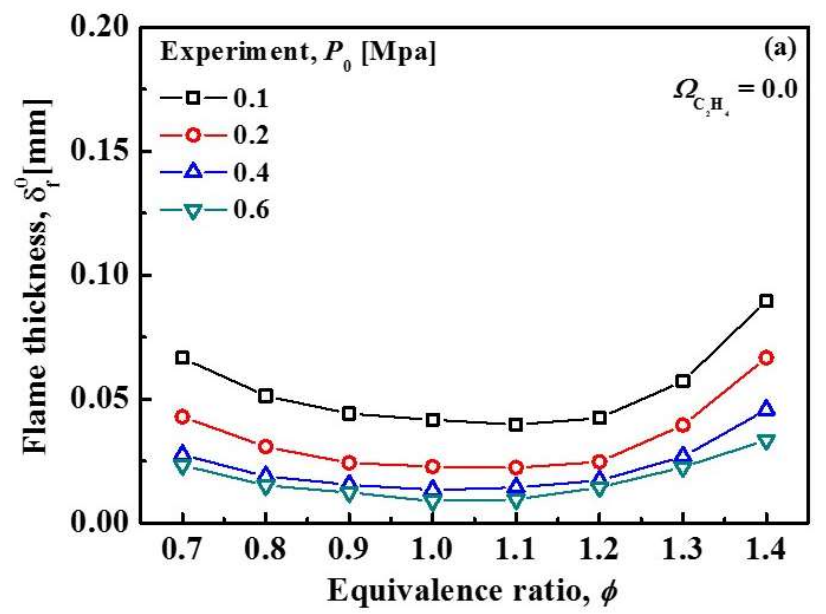



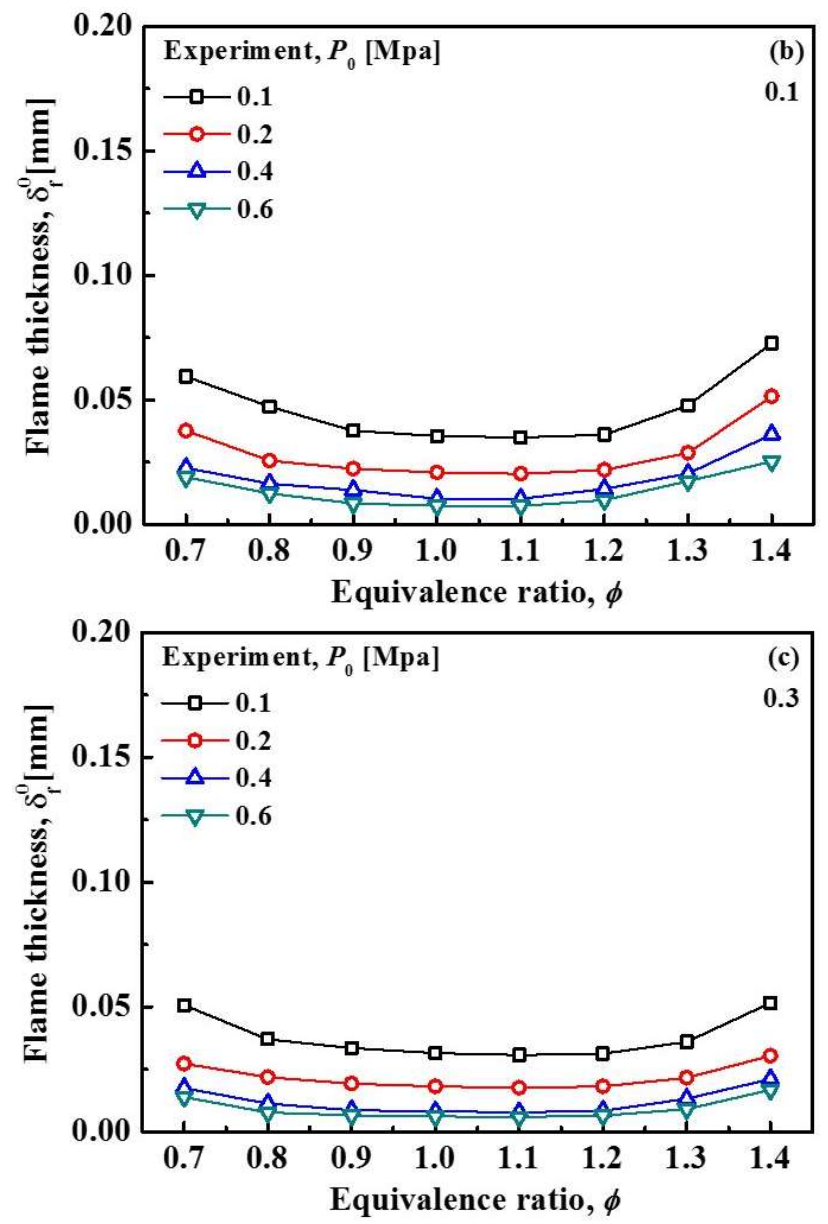

Figure S16. Calculated flame thickness against equivalence ratio in $\mathrm{CH}_{4} / \mathrm{C}_{2} \mathrm{H}_{4}$-air premixed flames with (a) $\Omega_{\mathrm{C}_{2} \mathrm{H}_{4}}=0$, (b) 0.1 , and (c) 0.3 at several chamber pressures. Here the flame thickness was used with $\delta_{\mathrm{f}}^{0}=\left(T_{\mathrm{b}}-T_{\mathrm{u}}\right) /(\partial T / \partial x)_{\max }$. 
The critical flame radius $\left(R_{\mathrm{cr}}\right)$ for the onset of cellular instability is defined as the flame radius at which cells start to grow in Schlieren images $[41,43]$. In the present measurement, we first observed the instant of transition to fine cells on flame surface via high-speed Schlieren images. As shown on a $S_{\mathrm{b}}-K$ plot in Fig. S9, the critical flame radius for the onset of cellular instability exhibited appreciable increases in $S_{\mathrm{b}}$ as $K$ decreased ( $R_{\mathrm{f}}$ increased) due to the onset of cellular instability.
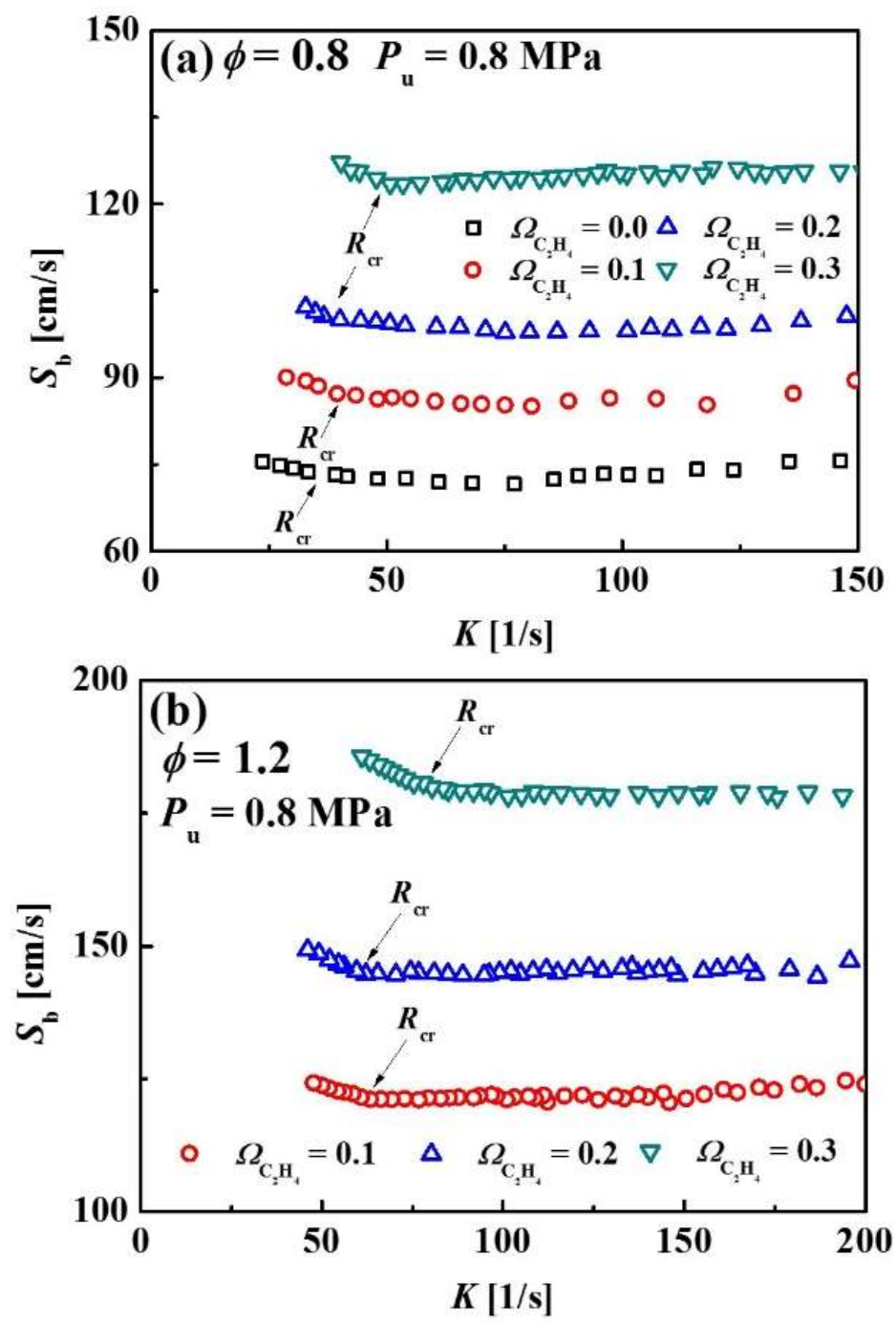

Figure S17. Burnt flame speed against flame stretch at $\phi=0.8$ (a) and 1.2 (b) for $P_{0}=0.8 \mathrm{MPa}$ in $\mathrm{CH}_{4} / \mathrm{C}_{2} \mathrm{H}_{4}$-air premixed flames. 